\title{
Duct Injection Technology Prototype Development
} Nozzle Development Subtask 4.1: Atomizer Specifications for Duct Injection Technology Topical Report 8

PREPARED FOR:

UNITED ENGINEERS \& CONSTRUCTORS STEARNS-ROGER DIVISION PO BOX 5888, DENVER, COLORADO 80217

SUBMITTED BY:

Babcock \& Wilcox CONTRACT RESEARCH DNISION 1562 BEESON STREET, ALLLANCE, OHIO 44601

PREPARED BY:

Babcock \& Wilcox RESEARCH AND DEVELOPMENT DIVISION 1562 BEESON STREET, ALLLIANCE, OHIO 44601

DOE CONIRACT: DE-AC22-88PC-88852; UE\&C CONTRACT: $70009330.001:$ B\&W CONTRACT: CRD 1230

PRINCIPAL INVESTIGATORS:

R. ILAN AND R. T. BAILEY 


\section{CUSTOMER FEEDBACK QUESTIONNAIRE}

Please help us do a better job for you.

Report Tile: $\frac{\text { Duct Injection Technology Nozzle Development Final Report - }}{\text { Atomizer Specifications for Duct Injection Technology }}$
Report No.: $\quad$ RDD:92:4572-57-01:01

Customer feedback on our work is important to us. We would like to have your comments conceming this report. Your cooperation in completing this form and returning it to the address shown will assist us in improving our service to you.

Do the contents of this report meet your needs? $\square$ Yes

Not Entirely, because

Did you receive this report when we promised it? $\square$ Yes $\square$ No

Comment:

How could we have made this report more useful to you?

Thank you.

Name:

Date:

Organization:

Please fold and return this form to address shown on the reverse side. 
E. A. Wornack, Jr., Vice President The Babcock \& Wilcox Company Research and Development Division Alliance Research Center 1562 Beeson Street Alliance, Ohio 44601-2196 
This report documents the results of the Nozzle Development subtask 4.1 of the DOE Duct Injection Prototype Development (DOE Contract DE..RP22-88PC-88852). As a subcontractor to United Engineers and Constructors (UE\&C), Babcock and Wilcox has conducted a program to identify atomizers appropriate for successful in-duct injection of humidification water and lime slurries.

Duct Injection Technology is designed to be a retrofit $\mathrm{SO}_{2}$ removal process that is suitable for installation in the flue work of older coal-burning power generation facilities. The basis of this technology is the in-duct injection of calcium-based sorbents. Because the temperature in the post-furnace flue is low (less than $350^{\circ} \mathrm{F}$ ), the reaction of the calcium-based sorbent with the $\mathrm{SO}_{2}$ in the flue gas must be enhanced by the presence of water. The water needed is introduced by slurrying the sorbents, or by humidifying the flue stream separately.

The most serious problem affecting the reliability and successful commercialization of the duct injection process is material deposition, especially as wet solids. The operational performance and spray characteristics of slurry or humidification atomizers are critical to eliminating material deposition. poor atomization leads to wall wetting, wet solids deposition, and frequent and costly maintenance. The key to controlling deposition and optimizing $\mathrm{SO}_{2}$ removal for the in-duct injection process is through good design of the atomizers and atomizer arrays selected for slurry and water injection.

As part of the Nozzle Development Program, B\&W developed atomizer performance criteria that met the constraints of an in-duct retrofit application. The atomizer requirements that were identified fall into two categories: spray and functional performance requirements. Spray performance criteria address atomizer characteristics which include atomizer flow type, droplet size, spray angle/droplet trajectory, and operating air consumption. Functional performance requirements include atomizer capacity, sensitivity to controlled process variables, turndown, alignment, atomizer deposition, corrosion and wear characteristics, and vendor quality control.

\section{SPRAY AND FUNCTIONAT PERFORMANCE REQUIREMENTS FOR IN-DUCT HUMID IFICATION AND SLURRY INJECTION ATOMIZERS}

The spray and functional performance requirements developed as part of Nozzle Developinent Subtask 4.1 include the following:

\section{Atomizer Type}

- Dual-fluid type atomizers should be used for duct injection applications.

\section{Drop Size}

- The droplet size distribution produced by the atomizer is the key parameter determi.ling its success in a duct injection application. The largest acceptable droplet size is determined by evaporation requirements and will depend on the available 
drying time in the flue. Based on the Burns and Roe Duct Survey, a majority of utility-scale flues have residence times of 1 second or less. Retrofit systems that are designed to operate at approach-to-saturation temperatures of $20^{\circ} \mathrm{F}$ and have residence times of 1 second or less will require atomizers with sprays that include less than 18 of the mass in droplets over 100 microns, and the mass percent of droplets over 80 microns should be limited to less than 58 . The sauter Mean diameter of a spray that meets the above large droplet crituria will generally be less than 25 microns.

\section{Spray Angle}

- Atomizer spray angles should be less than $30^{\circ}$.

\section{Compressed Air Consumption}

- The compressed air requirements must be considered when choosing among candidate atomizers. For duct injection technologies, it has been estimated that the compressed air power cost may be second only to sorbent costs. Based on the amount of power required, a conservative estimate of maximum acceptable air-to-liquid mass flow ratio for atomizers with operating air pressures that range from 60 to 120 psig is $0.5 \mathrm{lb} / \mathrm{lb}$.

\section{Atomizer Capacity and spacing}

- The exact number of atomizers to provide total liquid flow is not well understood at this time. Results of pilot-scale tests indicate that multiple small atomizers perform better than a single large atomizer.

- Atomizer-to-atomizer spacing and wall clearance requirements are a function of atomizer capacity. For atomizers on the orde: of 0.8 to $2 \mathrm{gpm}$, and with co-axial injection, minimum atomizer :0atomizer spacings of $1 \mathrm{ft}$. and atomizer-to-wall spacings of 2 ft. are required.

- The optimum atomizer configuration for a given duct geometry cannot be determined without detailed numerical or physical modeling.

\section{Hydraulic Characteristics}

- The atomizer hydraulic characteristics are important for controlling the droplet size and water flow distribution across the flue cross-section. A poor distribution of liquid can cause localized regions of saturated gas that can lead to wall wetting and wet solids deposition. For large arrays of atomizers, an estimate of maximum acceptable atomizer hydraulic sensitivity (change in liquid flow caused by change in liquid pressure) is on the order of 58 of liquid flow per psi liquid pressure at full load.

- Arrays of atomizers must have good atomizer-to-atomizex uniformity. 
- Atomizers that are at different elevations and are supplied by a common liquid source are subject to flow maldistributions caused by variations in the liquid static pressure. This elevational flow maldistribution must be corrected through a control scheme.

Atomizer Alianment

- Atomizer alignment can have a significant effect on humidification and slurry injection performance.

Wear, Deposition, Pluggage, and Corrosion

- To prevent wear, which can lead to variations in the partto-part performance characteristics of the individual atomizers in an array, critical wear points in the atomizer should be fabricated with ceramic inserts.

- Atomizer tip deposition should be reduced, eliminated, or removed by periodic cleaning. One method to reduce deposition is through the use of shielding devices. Air lances may also be installed to control deposition on the atomizer and manifold surfaces. Mechanical devices such as rappers may be used to dislodge material and prevent buildup of solids.

- Atomizer headers should be aerodynamic to avoid material deposition on the upstream side.

- Pluggage of the internal air and liquid passages must be avoided. Atomizers with narrow internal passages should not be used for spraying unfiltered humidification water or unstrained slurry. If the water quality is questionable, a filtering systern should be used. Slurry should be strained upstream of the atomizers to remove large particles. The compressed air used for atomization should be filtered near the atomizer inlet to eliminate tramp materials in the air lines.

- scale from either the lime in the slurry or hardness in the water may cause pluggage. Scale pluggage may be, in part, related to shutdown and downtime procedures. Protocols should be developed to account for scheduled or unscheduled downtime. Periodic maintenance through dilute acid cleaning may be required.

- Atomizers and headers must be resistant to cold-end corrosion. The materials of construction should be at least as corrosionresistant as $316 \mathrm{ss}$.

\section{Turndown}

- Atomizer turndown should be based on preserving spray quality. It is recommended to follow load swings by turning down to 508 load at a constant air-to-liquid ratio. Below 50 load, the liquid flow rate to all atomizers should be reduced while the air pressure is maintained at a constant value. 


\section{Quality control}

- The importance of vendor quaiity control must be stressed. Vendor formation about droplet size and hydraulic performance should - carefully monitored. Atomizer part-to-part uniformity should we checked by an independent source.

\section{A COMPARISON OF COMOEERCIALLY AVAILABLE ATOMIZERS TO DEVELOPED CRITERIA}

Several of the standards and criteria discussed above apply specifically to the selection of atomizers for commercial duct injection applications. These guidelines were used to compare 22 commercially available atomizers. The atomizers that were considered come from a list of those used or considered for use at the ongoing and past pilot duct injection and related test facilities. The specific guidelines for comparing and ranking commercially available atomizers are listed below. These guidelines should be used for both slurry injection and

humidification atomizers.

\section{Atomizer Selection Requirements}

1. Sufficiently few large droplets and a Sauter Mean diameter less than $25 \mu$ at reasonable air-to-liquid mass ratios

2. Low susceptibility to internal passage pluggage

\section{Practical Concerns for Atomizer Selection}

1. Atomizer tip deposition

2. Spray angle

3. Hydraulic sensitivity

4. Materials of construction

of the atomizers considered as part of this program, the only commercially available atomizer which meets the constraints and requirements imposed by in-duct retrofit technologies with 1 second or less residence times and an approach-to-saturation temperature of $20^{\circ} \mathrm{F}$ is the B\&W MK12 DuraJet. If the residence time'is relaxed, or the approach-to-saturation temperature is increased, then it is possible that the Lechler (Model 170.961.17) atomizex and larger capacities of the Durajet atomizer may be appropriate. 


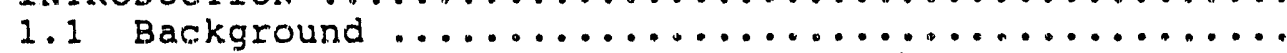

1.2 Purpose of Nozzle Development Task 4.1 .........

1.3 A Review of Duct Injection Technology Humidifica-

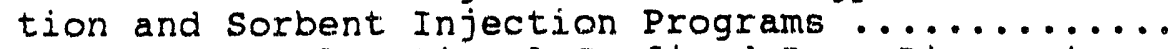
1.3.1 Bechtel National Confined Zone Dispersion.

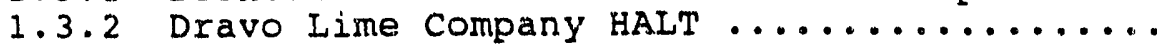
1.3.3 Consolidation Coal Company Multi-Nozzle

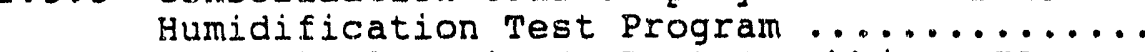

1.3.4 General Electric In-Duct Scrubbing (IDS) ..

1.3 .5 Babcock \& Wilcox E-SO $\ldots \ldots \ldots \ldots \ldots \ldots \ldots$

1.3.6 Babcock \& Wilcox Iime Injection Multistage Burners Humidification Extension (IIMB) Humidification) and Consolidation coal

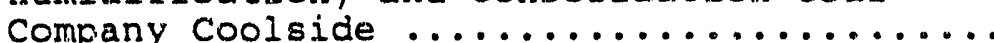

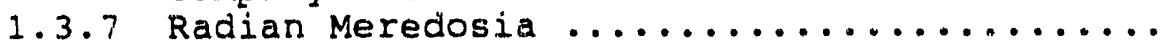
1.3.8 Gilbert/Comnonwealth and SRI Scale-up Tests and supporting Research for the Development

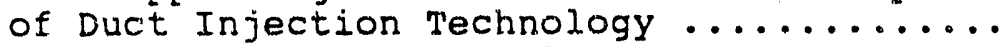

1.4 Babcock and Wilcox Nozzle Development Test.

Programs

SPRAY AND FUNCTIONAL PERFORMANCE REQUIREMENTS FOR INDUCT HUMIDIFICATION AND SLURRY INJECTION ATOMIZERS ...

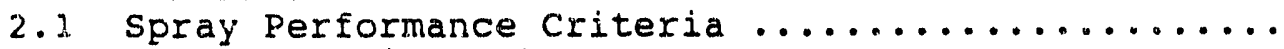

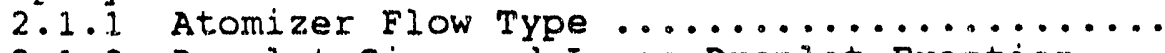
2.1.2 Droplet Size and Large Droplet Fraction ....

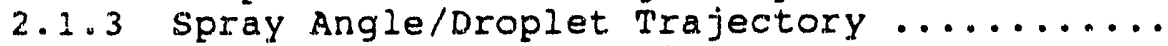

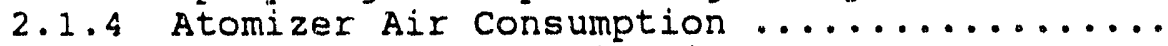

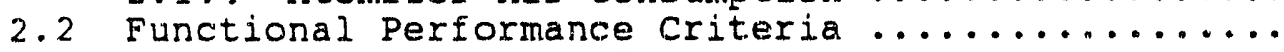

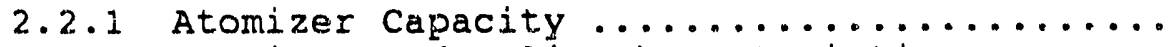
2.2.2 Atomizer Hydraulic Characteristics .......

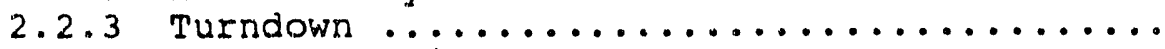

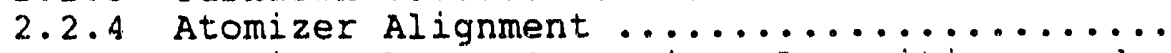
2.2.5 Atomizer Wear, Corrosion, Deposition, and

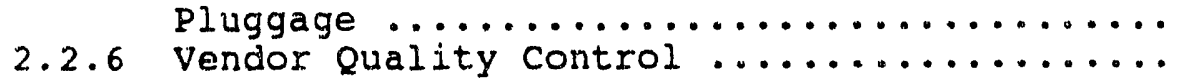
2.3 Summary of spray and Functional Performance Criteria for Duct. Injection Technology Atomizers.

3.0 A COMPARISON OF COMMERCIALIY AVAILABLE ATOMIZERS TO

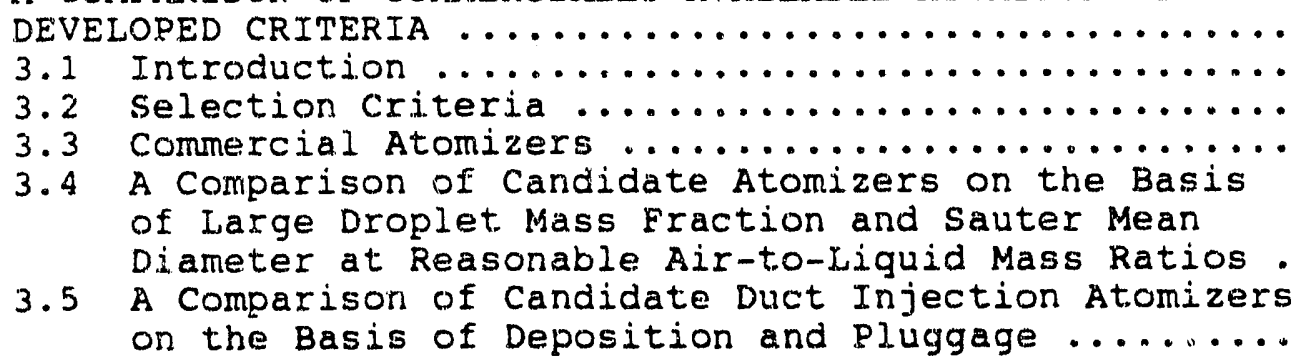




\section{TABLE OF CONTENTS (CONTINUED)}

Section

Page

3.0

3.6 A Comparison of the Lechler and B\&W DuraJet Atomizers on the Basis of Spray Angle and Droplet

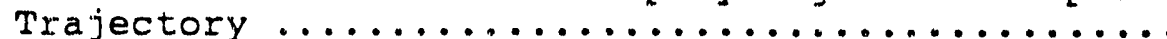

3.7 A Comparison of the Lechler and B\&W DuraJet Atomizers on the Basis of Hydraulic Sensitivity ..

3.8 Materials of Construction for the Lechler and B\&W

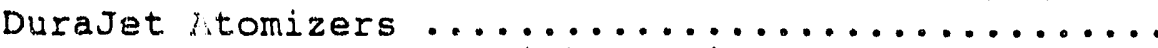

3.9 Summary of the Commercial Atomizer Comparison to Selection criteria ...................... 56

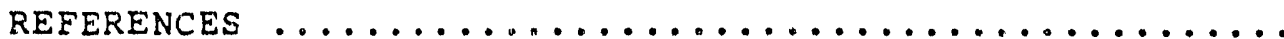

APPENDICES

$\begin{aligned} \text { APPENDIX A - } & \text { Droplet Size Data for Lechler and B\&W } \\ & \text { I-Jet Atomizers for the Beverly, Ohio, } \\ & \text { Pilot Facility } \\ \text { APPENDIX B - } & \text { Thrust Data for Lechler, Parker Hannifin, } \\ & \text { and B\&W I-Jet Atomizers } \\ \text { APPENDIX C - } & \begin{array}{l}\text { B\&W's Alliance Research Center Atomiza- } \\ \text { tion Facility }\end{array}\end{aligned}$




\section{LIST OF FIGURES}

Fiqure

Page

2.1

Power Consumption vs. A/W Ratio for a $100 \mathrm{MW}$

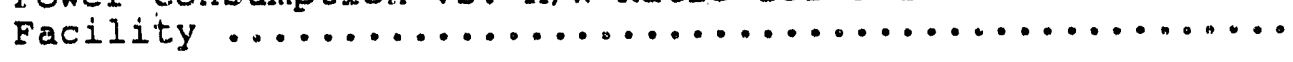

3.1

Sauter Mean Diameter vs. A/W Mass Ratio for High

3.2

Capacity Candidate Duct Injection Atomizers ............

Large Droplet Mass Fraction vs. A/W Mass Ratio for $\mathrm{High}$

3.3

Capacity Candidate. Duct Injection Atomizers .........

Sauter Mean Diameter vs. A/W Mass Ratio for Medium

3.4

Capacity Candidate Duct Injection Atomizers ..........

Large Droplet Mass Fraction vs. A/W Mass Ratio for

3.5 Sauter Mean Diameter vs. A/W Mass Ratio for Low

3.6

3.7

Capacity Candidate Duct Injection Atomizers .......... Large Droplet Mass Fraction vs. A/W Mass Ratio for Low Capacity Candidate Duct Injection Atomizers .......... Sauter Mean Diameter vs. A/W Mass Ratio for Meredosia

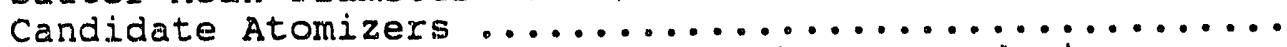
Large Droplet Mass Fraction for Three Meredosia

3.8

3.9

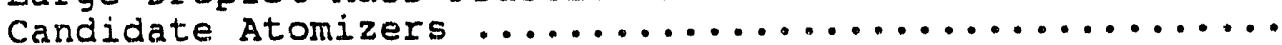

Atomizer Sensitivity - For Lechler and B\&W DuraJet

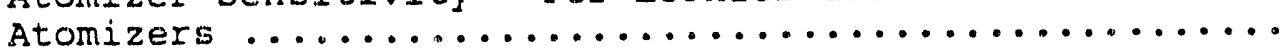

\section{LIST OF TABLES}

Table

Paqe

2.1

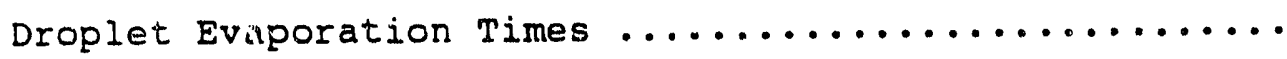

3.1 A List of Commercial Atomizers That were Compared to

Developed Selection Guidelines $\ldots \ldots \ldots \ldots \ldots \ldots \ldots \ldots \ldots$

3.2 Droplet Size Distribution Data for 22 Candidate Duct

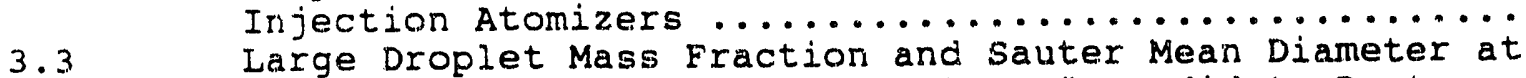
Large Droplet Mass Fraction and Sauter Mean Diameter
an $A / W$ Ratio of $0.5 \mathrm{lb} / \mathrm{lb}$ for "Best" Candidate Duct

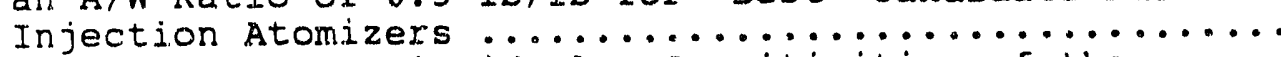

3.4 Liquid Pressure-Liquid Flow Sensitivities of the Lechler and B\&W Mini Durajet Atomizers at Full and

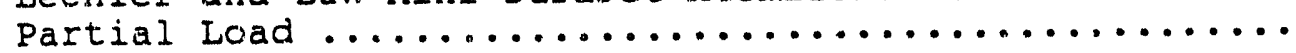




\subsection{INTRODUCTION}

The U.S. Department of Energy, Pittsburgh Energy Technology Center, is currentiy sponsoring a Duct Injection Technology Development Program. The purpose of the program is to support the development of a retrofit $\mathrm{SO}_{2}$ removal process that is suitable for installation in existing power plants. The basis of this technology is the in-duct injection of calcium-based sorbents into the flue that exists between the air heater and the particulate removal system of older power plants. These older facilities do not fall uncer the guidelines of the New Source Performance standards of 1971; however, they are affected by the clean Air Act Amendments of 1990.

Criteria developed to meet the goals of the program include providing an $\mathrm{SO}_{2}$ removal efficiency of 508 or greater with at least 358
sorbent utilization. The retrofit changes should be minimal and simple to install, and the capital expendicures for a typical retrofit should not exceed $\$ 50$ or $\$ 60 / \mathrm{KW}$ ( 1990 dollars). Two of the most important goals of the duct injection development program are to provide a technology that is reliable and easily operated.

The most serious operation problem affecting the reliability and successful commercialization of the duct injection process is solids deposition. The operational performance and spray characteristics of slurry or humidification atomizers are critical to eliminating solids deposition. Poor atomization performance leads to wall wetting, wet solid; depoition, and frequent and costly majntenance.

This report documents the results of the Nozzle Development Subtask 4.1 of the DOE Duct Injection Technology Prototype Development (DOE Contract DE-RP22-88PC-88852). As a subcontractor to United Engineers and Constructors (UE\&C), Babcock wilcox has conducted a program to j.dentify atomizers appropriate for successful in-duct injection of humidification water and lime slurries. The purpose of this program was to identify and guantify atomizer spray and performance criteria that affect the operations and reliability of the in-duct $\mathrm{SO}_{2}$ removal process, and compare commercially available atomizers to these criteria.

\subsection{Background}

Duct Injection Technology is designed to be a retrofit process that is suitable for installation in the flue gas flue work of older coalhurning power generation facilities. Because the temperature in the post-furnace flue is low (generally less than $350^{\circ} \mathrm{F}$ ), the reaction of the calcium-based sorbent with the $\mathrm{SO}_{2}$ in the flue gas must be enhanced by the presence of water.

For an in-duct process, the calcium-based sorbents and water are introduced in one of two ways. With in-duct dry scrubbing (DDS), water and sorbent are mixed together and injected as a slurry through an atomizer or array of atomizers. With in-duct dry sorbent injection (DSI), a dry sorbent material, usually hydrated lime, is injected into the flue gas stream and humidification occurs by the separate injection of atomized water. The flue gas is cooled to temperatures approaching the saturation temperature by evaporation of the water. Tests have indicated that the approach to the adiabatic saturation temperature is one of the most important parameters affecting $\mathrm{SO}_{2}$ removal. 
The need to operate at a close approach temperature and enhance the sorbent/ $/ \mathrm{SO}_{2}$ reaction $\mathrm{w}^{*}$ th water has led to the problem of material deposition on flue wa. $\therefore$ and flue internals in every pilot-scale duct injection project to aute. ${ }^{2}$ Deposition is the single most important factor affecting duct injection process performance reliability and operability. Deposition is caused by incomplete evaporation of droplets which contact flue walls and internals and by direct impingement of slurry or humidification water. Material deposition is a concern for utilities because it can lead to down time and increased maintenance costs. Controlling deposition is more of a challenge for retrofit duct injection than it is for conventional spray drying and humidification systems. This challenge is due to the configuration constraints of the available flue work between the air heater and the particulate removal device, and the lack of available residence time for droplet drying.

The key to controlling material deposition and optimizing $\mathrm{SO}_{2}$ removal for the in-duct injection process is through good design of the atomizers and atomizer arrays selected for slurry and water injection. Inadequate atomizer performance led to material deposition problems in most of the pilot-scale test programs to date. In addition, the compressed air required for atomization is the second most expensive operating cost of durt processes; sorbent costs are the most expensive.

\subsection{Purpose of Nozzle Development Task ik.1}

The purpose of the Nozzle Development Task was to categorize optimal in-duct injection atomization parameters. There are three main objectives of the task. The first objective was to develop atomizer performance criteria that meet the constraints of an in-duct retrofit application. The second objective was to determine if commercially available atomizers meet the above criteria. The final objective was to improve existing atomizers or develop a new atomizer if no existing atomizer met the specified criteria.

The atomizer requirements that were identified to meet the constraints of in-duct humidification or dry sorbent injection fall into two categories. The first set of criteria and guidelines govern spray performance requirements. Spray performance criteria address atomizer characteristics which include atomizer flow type, droplet size, spray angle/droplet trajectory, and operating air consumption. The second set of criteria and guidelines govern functional performance reguirements. These functional characteristics include atomizer capacity, sensitivity to controlled process variables, turndowr, atomizer alignment, atomizer deposition, corrosion and wear characteristics, and vendor quality control.

he standards and criteria developed were used to judge candidate comme-cial atomizers under consideration for use in commercial duct injection applications. In order to develop the above criteria and to compare commercial nozzles, the experiences obtained from various recent laboratory and pilot-scale studies were reviewed. What follows is brief description of the various test programs that were reviewed during the course of this task.

\subsection{A Review of Duct Injection Technology Bumidification and sorbent Injection Programs}

The following section contains a description of several pilot-scale duct injection test facilities whose operations were reviawed to provide 
data for the body of this report. The reviews provided in the following section are intunded to be brief introductions to each of the test programs. A majority of these pxograms were conducted under the United States Department of Erergy's eponsorship.

\section{3 .1 Bechtel National Confined Zone Dispersion.}

Bechtel National, Ine. studied Confined zone Dispersion (CrD). The principal behind the CzD process if to form a wet zone of atomized slurry in the center of flue and confine this zone with an envelope of hot gas. Bechtel conducted a $7 \mathrm{MW}$ "proof of concept test" at Consumers power Company West olive Michigan Camoell station. Full-size flue testing was performed at Pennsylvania Electric Company's $140 \mathrm{MW}$ Seward station.

The Cambeli station facility was designed to be on acale equivalent to 7 MWe power plant and treated an approximately 25,400 acfm slipstres.h of flue gas from cambeli Unit \#l which was witharawn downstream of one of the air heaters. The flue configuration was 130 ft. straight length of circular flue with a $3 \mathrm{ft}$. diameter. slurry atomization was through two dual-fiuid atomizers in a staged spray. The atomizers were centered in the flue and were separated by an axial distance of 40 feet. Approach-to-saturation temperature was varied by changing the slurry injection rate of the upstream atomizer. Flow to the downstream atomizer was kept constant, s it had a greater tendency to deposit wet solids on the flue wall.

To achieve program goals of continuous operation at a removal. rate of 508 , Bechtel had to limit the amount of slurry sprayed and, hence, flue gas treated. To control deposition, flue gas velocity was limited to $20 \mathrm{ft} / \mathrm{s}$. This velocity corresponds to flue gas flow rate of about 8600 ACFM (2.4 MW), which is only 338 of the design flow. At $20 \mathrm{ft} / \mathrm{s}$, the flue gas resicience time for the $130 \mathrm{ft}$. Ilue was 6.5 seconds. This residence time is relatively long compared to most utility scale in-duct available drying times. The spraydown temperature was $160^{\circ} \mathrm{F}$, which corresponds to $35^{\circ} \mathrm{F}$ approach to saturation temperature.

At the seward station. Bechtel retrofitted the CzD system to one of two parallel $70 \mathrm{MW}$ flue gas flues. The flue was a $35 \mathrm{ft}$. long and $8 \mathrm{ft}$. wide by $11 \mathrm{ft}$. high section of straight flue work between two sets of turning vanes, In-duet tests with multiple atomizers led to a final configuration of nine dual-Eluid atomizers in $3 \times 3$ configuration.

At the seward station, a nominal flue gas velocity of $64 \mathrm{ft} / \mathrm{s}$ (3r0,000 ACFM) limited the gas residence time to 0.5 meconds. This short residence time limited the injection rate of the slurxy, which was used to control spraydown temperature. Wet solids deposition on the flue walls was controlled by limiting the spraydown temperature to $45^{\circ} \mathrm{F}$ approach-to-saturation temperature or greater. Limiting the injection rate limited $\mathrm{SO}_{2}$ removal, and the seward station program was not able to meet DOE gOals of 508 removal. The $\mathrm{SO}_{2}$ removal ranged between 68 and $30 \%$, depending on the type of slurry and the solids content of the slurry.

\section{3 .2 Dravo Lime Company HALT"}

The Dravo Iimu Company and ohio Edison studied dry hydrate addition with downstream humidification at the "Hydrate Addition at Low Temperature" (HALT) facili.ty. In this test, "low temperature" refers to 
the post-preheater sorbent injection site, where the temperatures are usually around $300^{\circ} \mathrm{F}$. The HALT facility treated a 21,000 ACFM (5 MW) slipotream of flue gas from either of two pulverized coal-fired boilers at Ohio Edison's Toronto facility. The unit flue was a 31 "x31" square flue that had about 61 feet of straight length past the humidification atomizer array. The dry sorbent injection location was at the bottom of a vertical inlet flue section from the boiler. The humidification atomizer array was $34 \mathrm{ft}$. downstream of the dry sorbent injection location.

Dravo concluded that humidification performance is the single most important factor governing operability. Dravo went through several trial-andmerror experiments to solve the problem of wall wetting and wet solids deposition. HALT facility humidification problems were aggravated because of the small flue size and the unexpectedly high inlet flue gas temperatures $\left(350-370^{\circ} \mathrm{F}\right)$. Stable operations were achieved with an array of eight dual-fluid humidification atomizers; the atomizers were arranged in three rows containing three, two, and three atomizers in each. Auxiliary cooling water was sprayed from a second array of five atomizers located about $10 \mathrm{ft}$. downstram of the lime injection location. Without the initial auxiliary cooling water, the closest approach-to-saturation temperature that could be maintained without severe wall wetting was $80^{\circ} \mathrm{F}$.

With staged cooling, approach-to-saturation temperatures of between 20-30\% were obtained. Dravo was able to mest DoE program goals of $50 \%$ $\mathrm{SO}_{2}$ removal at these approach to saturation temperatures and with $\mathrm{Ca} / \mathrm{s}$ ratios of between 1.74 and 2.5 . These tests were conducted a flue gas flow rate of about $15,000 \mathrm{ACFM}(3.5 \mathrm{MW}),{ }^{5}$ which corresponds to flue gas velocity of $37 \mathrm{ft} / \mathrm{s}$. Based on this velocity and the available straight length of flue, the residence time during these tests was 1.6 seconds. No removal efficiency tests were conducted at full load conditions, although there is no documentation describing why this is the case.

\subsubsection{Consolidation Coal Company Multi-Nozzle Humidification Test Program ${ }^{6}$}

As a subcontractor to the Dravo Lime company, the Consolidation coal Company (Consol) conducted Multi-Nozzle Humidification field test program using the HALT Toronto facility flue work. This program evaluated a humidifier scale-up method in which each atomizer in a humidification array operates at the same fixed conditions used in single-atomizer tests in a cylinarical humidifier. According to the scale-up method, the approach-to-saturation temperature and the amount of flue gas that can be treated in the large-scale facility is varied by changing the number of atomizers in the humidification arrayn

Consol began testing by spraying a single, mall capacity atomizer in an $8.3^{\prime \prime}$ diameter vertical downflow humidifier. This humidifier treated 175 SCFM of $300^{\circ} \mathrm{F}$ flue gas by cooling it to a $20-30^{\circ} \mathrm{F}$ approachto-saturation temperature. From this initial test, consol identified optimum atomizer operating conditions that allowed for drying times of less than 1 second and avoided wall wetting. These conditions ineluded an air-to-liquid mass flow ratio ( $/ \mathrm{W}$ ratio) of 0.43 and an atomizing air pressure of 95-110 psig. Optimum water throughput was 4 gph per atomizer. 
After the tests, Consol tested arrays ranging from 9 to 46 atomizers in the 31 "x31" HALT flue work. The available 1 -ue length was 56 feet. Testing included base tests at $14 \mathrm{ft} / \mathrm{s}(5,600 \mathrm{ACFM})$ and high velocity tests at $23 \mathrm{ft} / \mathrm{s}$ and $35 \mathrm{ft} / \mathrm{s}$. Consol used an upstream pre-cooler atomizer array to control the inlet flue gas temperature at $280^{\circ} \mathrm{F}$. Arrays with 9,13 , and 16 atomizers sprayed 4 gph per atomizer during the base teste. The 9,13 , and 16 atomizer base tests allowed humidification of the flue gas to $70^{\circ} \mathrm{F}, 45^{\circ} \mathrm{F}$, and $25^{\circ} \mathrm{F}$ approach-tosatuiation temperatures, respectively. Based on the flue gas velocity and available flue length, the gas residence time was 4 seconds. Consol injected ary, hydrated lime during the base tests, but was unable to obtain reliable $\mathrm{SO}_{2}$ removal data. Wall wetting was minimal and there was no serious wet solids deposition problems during these tests.

The base tests demonstrated the humidifier scale-up method. These tests confirmed that approach-to-saturation temperature can be controlled by varying the number of atomizers in an array, rather than the water throughput to each atomizer. From the results of the base tests, Consol conciuded that for successful humidifier operation, a uniform inlet flue gas velocity distribution is critical.

The purpose of the high velocity rests was to determine the effect of atomizer spray plume overlap on humidifier operability. For these tests, flue gas velocities were $23 \mathrm{ft} / \mathrm{s}(9,200 \mathrm{ACFM})$ and $35 \mathrm{ft} / \mathrm{s}(14,000$ ACFM) and used arrays of 25 and 46 atomizers, respectively. The gas residence times were 2.4 seconds for the 25 -atomizer test and 1.6 seconds for the 46 -atomizer test. These tests demonstrated that at higher velocities, significant spray plume overlap was acceptable. Droplet drying times were estimated from flue gas temperature profiles. Even with significant spray plume overlap, droplet drying times were comparable to the $8.3^{\prime \prime}$ tests. An approach-to-saturation temperature of $20^{\circ} \mathrm{F}$ was obtained with minimal wall wetting. One problem that was discovered with the multi-nozzle scale-up method was an inability to quickly respond to load swings because the method for responding to load swings included taking atomizers out of service. During testing, a bojler load swing caused the approach-to-saturation temperature to drop to $5^{\circ} \mathrm{F}$, causing severe wall wetting.

\subsubsection{General Electric In-Duct Scrubbing (IDS)?}

General Electric Environmental systems, Inc. (GEESI) sprayed slaked lime slurry with a rotary disk atomizer in their In-Duct scrubbing (IDS) process. The IDS process was tested at a DOE $12 \mathrm{MW}(50,000$ ACFM) facility at Ohio Edison's Muskingum River station unit 5. The IDS facility treated a slipstream of flue gas downstream of the air preheater from the Unit 5 boiler. GEESI evaluated both a 50 " diameter vertical downcomer flue configuration and a horizontal 50 "x40" rectangular horizontal flue. The horizontal flue was designed for residence times of either 0.5 or 1 second, depending on the injection location.

GEESI reports $\mathrm{SO}_{2}$ removals of 50 at $\mathrm{Ca} / \mathrm{S}$ ratio of 1.5 and approach temperatures of 40 to $55^{\circ} \mathrm{F}$. However, GEESI was only able to reach flue gas flows of about 25,000 ACFM ( 6 MW), which is half the design flow, before wall wetting and wet solids deposition problems became severe. This flue gas flow rate corresponds to a flue gas velocity of $30 \mathrm{ft} / \mathrm{s}$, and a residence time of 2 seconds. Tests were limited to 2 to 3 hours duration. Poor gas flow distribution, small flue size, and the high radial slurry velocities exiting the rotary 
atomizer were cited as the major causes of material deposition. ${ }^{2}$

feels that the wall wetting and wet solids deposition problems encountered during their test program are peculiar to small flues. However, the rotary atomizer used during this test program had an included spray angle of $180^{\circ}$; better performance has been achieved in tests of a similar scale with dual-fluid atomizers that had a smaller spray angle. $3.4,8$

\subsubsection{Babcock and Wilcox E-SO,9,10}

E-SO is a variation of duct dry scrubbing that uses a modified inlet field of an electrostatic precipitator (ESP) as a lime slurry injection system. The added moisture content of the lime slurry reduces the flue gas volume and flyash resistivity and enhances ESP performance.

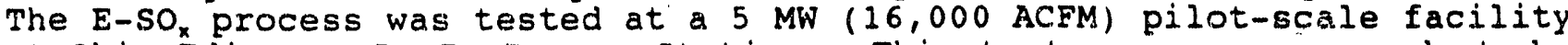
at Ohio Edison's R. E. Burger Station. This test program was conducted under joint sponsorship by the EPA, the Ohio Coal Development office, $B \& W$, and Ohio Edison.

The E-SO, test flue at the R. E. Burger Station was 6 feet by 14 feet. The available flue straight length was 14.5 feet. Flue gas entered the flue at $275^{\circ} \mathrm{F}$ and was cooled to a $40^{\circ} \mathrm{F}$ approach-to-saturation temperature with a $2 \times 1$ array of dual-fluid slurry atomizers. Flue gas velocities in the flue ranged from 3 to $8 \mathrm{ft} / \mathrm{s}$. These velocities correspond to flue residence times from 1.5 to 3.0 seconds, which is generally longer than those available for in-duct retrofits of duct injection technologies. However, it was necessary to install a droplet impingement device (DID) between the exit of the E-SO ${ }_{x}$ flue work and the ESP. The DID trapped any unevaporated slurry droplets before they entered the ESP. After these droplets dried, mechanical rappers knocked the dried deposits off of the DID and into a hopper located on the floor of the flue. The program goal of $508 \mathrm{SO}_{2}$ removal was obtained at $\mathrm{Ca} / \mathrm{S}$ ratios from 1.3 to 1.6 and approach-to-saturation temperatures from $35-45^{\circ} \mathrm{F}$.

The E-SO has provided useful experience regarding control of in-duct material deposition. During shakedown, a 3x:2 array of dual-fluid atomizers was used for slurxy atomization. A large recirculation zone caused material deposition on the bottom row of atomizers. This buildup degraded atomization performance and led to severe wet solids deposition on the flue walls; this deposition limited test runs to 4 or 5 hours. When the atomizer array was changed to the $2 \times 1$ array discussed above, deposition was no longer a concern. After modification, the E-SO operated for 400 hours with no significant material deposition.

1.3.6 Babcock and Wilcox Lime Injection Multistage Burners Humidification Extension (LIMB/Humidification) and Consolidation coal Company Coolside

Limestone Injection Multistage Burner (LIMB) technology is based on the injection of dry sorbent into the boiler combined with the use of low-NO $\mathrm{N}_{\mathrm{x}}$ burners for the reduction of both $\mathrm{SO}_{2}$ and $\mathrm{NO}_{x}$ in the flue gas. Babcock and Wilcox (B\&W), Consol, the Envirormental Protection Agency (EPA), the Ohio Coal Development office (OCDO), and Ohio Edison conducted a utility-scale demonstration of LIMB technology at Ohio Edison's 105 MW Edgewater Station in Lorain, Ohio. Two similarities exist between IIMB and duct injection processes. First, IIMB is desigried to be a low-capital, retrofit control technology. More 
importantly, LIMB uses flue gas humidification downstream of the air heater. Humidification is necessary to condition the flue gas when sorbent is injected in the boiler because the increased particle loading and resistivity degrades ESP performance. Humidification also increases $\mathrm{SO}_{2}$ removal by utilizing unreacted free lime in the IIMB ash.

At Edgewater, the humidification flue measures $14^{\prime} 7^{\prime \prime}$ square and is $57 \mathrm{ft}$. long. Water is sprayed with an array of 100 dual-fluid atomizers. The flue gas velocity of $23 \mathrm{ft} / \mathrm{s}(293,500 \mathrm{ACFM})$ corresponds to a residence time on the order of 2.5 seconds. Results indicate that only minimal humidification (a $150^{\circ} \mathrm{F}$ approach-to-saturation temperature) is required to enable continuous ESP operation. In addition, humidification to a $20^{\circ} \mathrm{F}$ approach-to-saturation temperature increases $\mathrm{SO}_{2}$ removal by 108 . System removal efficiencies ranging from 65 to 728 have been achieved at $\mathrm{Ca} / \mathrm{S}$ ratios of 2 when operating at an approach-tosaturation temperature of $20^{\circ} \mathrm{F}$. This humidification level has been achieved with no significant material deposition problems.

Developrnent of the IIMB humidifier design included pilot-scale humidification tests and extensive atomizer characterization at B\&W's Alliance Research Center (ARC) in Alliance, Ohio. Pilot-scale humidification tests in a $3 \times 3$ by $40 \mathrm{ft}$. long flue and then in $a 6 \times 6$ by $80 \mathrm{ft}$. long flue provided insight into the effect of various parameters on humidification operability. The objectives of these tests included evaluating candidate atomizers and developing an arrangement of atomizers that could provide sufficient humidification under varying inlet conditions without gross wall wetting. Results of these tests showed the importance of a good inlet flow distribution, the need to avoid material deposition on the atomizer tips, the importance of good atomization quality, and the importance of mixing.

The Consolidation Coal Company used the LIMB Edgewater humidification chamber for a full-scale ( $70 \mathrm{MW})$ demonstration of the Coolside process. Coolside involves the in-duct injection of dry hydrated lime with flue gas humidification using dual-fluid atomizers. Coolside sponsors include the DOE, Consolidation Coal Company, Ohio Coal Development office, and Babcock and Wilcox. Coolside has been the only completed utility.uscale demonstration of a duct injection retrofit technology.

With the coolside process at Edgewater, dry, hydrated lime is injected into the flue gas stream at $300^{\circ} \mathrm{F}$ through five $2^{\prime \prime}$ diameter pipes and the flue gas is cooled by water injection to a $20^{\circ} \mathrm{F}$ approach-tosaturation temperature. Coolside uses the IIMB humidifier, with the bottom row of ten atomizers removed from the array. The flue gas velocity in the chamber was about $27 \mathrm{ft} / \mathrm{s}(340,000 \mathrm{ACFM})$. This velocity corresponded to a flue residence time of about 2 seconds.

Initially, dry, hydrated lime was injected $6 \mathrm{ft}$ upstream of the humidification lances. ${ }^{13}$ This upstream injection caused severe deposition on the lances, which eventualiy caused a shutdown due to the increased pressure drop across the deposition-caked lances. The system was modified to include coplanar injection of dry sorbent and humidification water. After this modification, material deposition was not a problem at approach temperatures of $20^{\circ} \mathrm{F}$ and above. coolside was able to maintain continuous operation for as long as 11 days. The Coolside process achieved $\mathrm{SO}_{2}$ removals of 508 at a $\mathrm{Ca} / \mathrm{S}$ ratio of 1.4 and 708 at a $\mathrm{Ca} / \mathrm{S}$ ratio of 2.0 . This removal was achieved with sodium 
hydroxide (NaOH) addition to the humidif_cation water, and at approachto-saturation temperature of $20^{\circ} \mathrm{F}$.

\subsubsection{Radian Meredosia ${ }^{14}$}

The Radian Corporation conducted a $1.7 \mathrm{MW}$ duct injection pilotscale test program at central Illinois Public service Company's Meredosia station. Radian studied dry sorbent injection with both upstream and downstream humidification. The facility treated a 6300 ACFM slipetream from Meredosia's Unit 5. This flow rate corresponds to a $63 \mathrm{ft} / \mathrm{s}$ flue gas velocity. The test section flue was horizontal and had a 17.5 " diameter. The available straight length of flue was 90 feet. Multiple ports were located along the flue so that the humidification and lime injection locations could be varied. The $90 \mathrm{ft}$. flue provided a maximum residence time of 1.5 seconds at design flow.

Radian initiated testing with a single 1.5 gpm humidification atomizer. When lime injection occurred either upstream or $4 \mathrm{ft}$. downstream of the atomizer, severe wet solids deposition near the atomizer ( 6 to $14 \mathrm{ft.}$ ) caused complete pluggage and limited testing to a few hours. Sorbent injection $24 \mathrm{ft}$. downstream of the atomizer limited the wet solids deposition; however, it also severely limited the removal efficiency. Several attempts were made $t$ s limit deposition with upstream sorbent injection by varying such parameters as approach-tosaturation temperature and flue gas flow rate. However, Radian found it impossible to avoid plugging the flue while spraying a single atomizer. Eventually, Radian used staged spray with two humidification atomizers spaced between 12 and $16 \mathrm{ft}$. apart. With staged spray, tests lasted between 4 and 22 hours, but Radian was unable to meet program goals of $50 \& \mathrm{SO}_{2}$ removal. The most successful test runs showed remolis of 408 at a Ca/s ratio of $2.0 \mathrm{with}$ lime injected upstream of humidification. The severe deposition problems which limited the success of this test program can be attributed entirely to the narrow flue diameter.

\subsubsection{Gilbert/Commonwealth and SRI Scale-up Tests and Supporting} Research for the Development of Duct Injection Technology

Gilbert/Commonwealth $(G / C)$ and its testing subcontractor, southern Research Institute (SRI), modified the DOE's existing 12 MW Duct Injection Test Facility (DITF) at Ohio Edison's Muskingum River station Unit 5 to conduct Scale-up Tests and Supporting Research for Development of Duct Injection Technology. This program is currently underway. Atomizers to be used for both slurry injection and humidification water have been installed in the 40" 550 " horizontal flue section. The atomizer array consists of two rows with three atomizers per row. There are plans to investigate two types of dual-fluid atomizers, with internal and external air and water mix. The test section is designed for flue gas velocities from $20-60 \mathrm{ft} / \mathrm{s}(16,700-50,000 \mathrm{ACFM})$. These flows correspond to flue residence times of $0.5-3.0$ seconds. Inlet flue gas temperatures range from $275-320^{\circ} \mathrm{F}$. Spraydown temperature is controlled by the addition of dilution water to the slurxy stream.

Program goals include optimizing boch slurry and dry injection process configurations. Testing to optimize atomizer orientation in the flue has been completed. To minimize wall wetting, the nozzles have been angled away from the flue walls and ceilings by $5^{\circ}$.

Results to date indicate a higher degree of success with slurry atomization than with dry sorbent injection. $\mathrm{SO}_{2}$ removal experiments are 
currently underway. Preliminary data analysis show an $\mathrm{SO}_{2}$ removal efficiency of 428 across the flue with dry sorbent injection at a Ca/s of 2.5 and a $26^{\circ} \mathrm{F}$ appreach-to-saturation temperature. In comparison, with slurry injection, $\mathrm{G} / \mathrm{C}$ has obtained $508 \mathrm{SO}_{2}$ removal across the flue at a Ca/s ratio of 1.5 and a $43^{\circ} \mathrm{F}$ approach temperature. Preliminary results also indicate that it is much essier to minimize wall deposition with slurry injection rather than dry sorbent injection with either upstream or downstream humidification. There are plans to attempt dry sorbent injection with coplanar humidification. This approach has achieved success at the consolidation coal Company's coolside Demonstration at Edgewater, Ohio.12

\subsection{Babcock and Wilcox Nozzle Development Test Proqrams}

In addition to developing criteria for commercial atomizers, $B \& W$ has conducted two test programs as part of the Nozzle Development subtask 4.1. The purpose of the first test program was to compare drop size data for three styles of atonizers with capacities similar to those required for the Beverly, ohio, facility. The purpose of the second test program was to provide atomizer velocity and momentum data for input to the second Generation Duct Injection Model. Babcock and Wilcox is developing this model for United Engineers and Constructors as part. of the U.S. Department of Energy's Duct Injection Technology Development program. The results of these two test programs are presented in Appendices $A$ and $B$. 


\subsection{SPRAY AND FUNCTIONAL PERFORMANCE REQUIREMENTS FOR IN-DUCT BUMIDIFICATION AND SLURRY INJECTION ATOMIZERS}

To meet the constraints of in-duct retrofit sulfur removal technologies, criteria governing various atomizer characteristics and performance parameters have been established. All of the design specifications that apply to humidification atomizers used with duct sorbent injection (DSI) will likewise apply to atomizers used for duct spray drying (DSD). The DSD atomizers will have additional specifications that address problems particular to slurry inject on. These problems include atomizer wear and pluggage of the atomize orifices with dried slurry and agglomerates.

The atomizer requirements that were identified to meet the constraints of in-duct humidification or dry sorbent injection fall into two categories. The first set of criteria and guidelines govern spray ferformance requirements. Spray performance criteria address atomizer characteristics which include atomizer flow type, droplet size, spray angle/droplet trajectory, and operating air consumption. The second set of criteria and guidelines govern functional performance requirements. These functional. requirements address atomizer capacity, sensitivity to controlled process variables, turndown, atomizer alignment, atomizer wear, corrosion, deposition and pluggage characteristics, and vendor quality control.

\subsection{Spray Performance Criteria}

The spray performance criteria developed during this nrogram address atomizer characteristics which include atomizer fluw type, droplet size, spray angle/droplet trajectory, and operating air consumption. The foliowing section is a discussion of these criteria.

\section{1 .1 Atomizer Flow Type 26.17}

Atomization occurs in part by the breakup of thin, liquid sheets into droplets by the shear forces between the liquid and surrounding gas. This shear force is highly dependent on the relative velocity of the liquid and the surrounding medium. There are three basic types of atomizers that are commonly used for industrial applications. These types are the dual-fluid atomizers, mechanical or pressure atomizers, and rotary atomizers. Mechanical or pressure atomizers convert the potential energy of a high pressure liquid to kinetic energy of thin, liquid sheets. These sheets break up due to frictional effects with the relatively slow-moving gas in the surrounding environment. With dual-fluid atomization, the high velocity fluid is air or steam which impinges on the liquid, creating the high frictional forces that lead to breakup. With rotary atomizers, the liquid is fed to a rotating surface and centrifugally accelerated to a high relative velocity prior to being thrown out to the surroundings. With respect to in-duct atomization, each category of atomizer has its associated advantages and disadvantages.

Although mechanical or pressure atomizers rend to be simpler and less costly than dual-fluid or rotary atomizers, they have not been developed for use with in-duct processes for several reasons. These atomizers are very susceptible to erosion because of the high velocities of the liquids, and are not recommended for use with slurries. These atomizers also have poor turndown characteristics, and special designs 
would be required to accommodate duct injection appiications which have large load swings. All other parameters held constant, the mean droplet size produced by pressure atomizers will increase with the square of orifice diameter; orifices that are small enough to produce the small droplets required for in-duct processes may be susceptible to pluggage with slurry solids. Finally, for a given type of pressure atomizer, smaller spray angles tend to produce larger droplets because of the reduced tendency of the liquid sheets to thin. Small spray angles are required to maintain wall clearances for in-duct retrofits.

To date, dual-fluid atomizers have been used in all but one pilotscale duct injection or related test facility. Dual-fluid atomizers have several advantages over pressure atomizers for in-dyct applications:

- Dual-fluid atomizers can produce sprays with a relatively small mean droplet size.

- Droplet sizes can be controlled over a wide range by varying the air/liquid ratio.

- The high relative velocity required for liquid sheet breakup can be achieved at a lower liquid pressure, because the high velocity fluid is air.

- The liquid side passages can be relatively large, which decreases the chance of pluggage of the atomizer with slurry solids.

- Because the internal liquid velocities are not high, dual-fluid nozzles are less susceptible to erosion than pressure atomizers during duct dry scrubbing.

- Dual-fluid atomizers tend to have smaller spray angles than pressure or rotary atomizers.

Finally, there is some indication ${ }^{12}$ that with coplanar humidification and dry sorbent injection, the entrainment of flue gas by the nigh velocity atomization air aspirates the sorbent and aids in initial mixing.

Rotary atomizers are in common use for conventional spray drying and dry scrubbing applications. In full-scale dry scrubbers, the wide spray pattern caus ad by the radial momentum of the droplets has an increased vorticity which aids in mixing.? Rotary atomizers do not require a high compressed air consumption. However, the geometry of conventional dry scrubbers is designed to accommodate rotary atomizers and the large spray angles they produce. Atomizers which produce sprays with small angles are generally required for in-duct injection. At the IDS facility at Ohio Power Company's Muskingum River Unit 5, wall wetting and wet solids deposition were serious problems at flow rates that exceeded half the design flow. In contrast, Gilbert commonwealth has been successful in avoiding severe wet solids deposition in the same flue configuration at full load while spraying slurry with an array of dual-fluid atomizers with narrow spray angles. ${ }^{8,15}$

In summary, it is recommended that dual-fluid nozzles be used for duct dry scrubbing and duct sorbent injection retrofits. pressure atomizers are too susceptible to erosion and have poor turndown characteristics. The body of available data on successful dual-fluid 
atomizers for use with in-duct retrofit applications vastly exceeds that on rotary atomizers. Rotary atomizers were used for one duct injection program, and that facility was unsuccessful in meeting program goals. While rotary atomizers generally have a lower energy requirement than dual-fluid atomizers, the capital costs are higher. The $180^{\circ}$ spray angle of rotary atomizers will be too large for most retrofit applications. Dual-fluid atomizers can provide sprays with narrow spray angles and small droplet sizes.

\section{1 .2 Droplet Size and Large Droplet Fraction}

For successful atomization of water or slurry, the largest droplets produced by an atomizer must be small enough to allow for sufficient evaporation in the short residence times available in most flues. Close to the atomizers' discharge, the available drying time is dictated by spray angle, wall clearance, gas velocity, and droplet velocity. As the droplet velocity relaxes to the flue gas velocity and the jet exiting the atomizer collapses due to entrainment of surrounding flue gas, the flue residence time dictates available droplet drying time. The following discussion on maximum droplet size and evaporation assumes that wall clearance and spray angle, which will be discussed in detail in subsequent sections, have been optimized.

The iargest acceptable droplet size can be estimated based on the flue gas residence time in the flue and the inlet and spraydown cemperatures. The results of the Burns and Roe Duct Configuration Survey ${ }^{18}$ indicate that almost 608 of the units surveyed have available drying times of 1 second or less in their longest straight run flue lengths. For a single pure water droplet below $100 \mathrm{microns}$ in diameter traveling in a gas stream, the time to complete evaporation can be estimated by: ${ }^{16}$

$$
t=\frac{p * \lambda * D_{0}^{2}}{8 * k_{d} * \operatorname{LMTD}}
$$

where: $k_{d}$ = the average thermal conductivity of gaseous film surrounding an evaporating droplet

$\lambda \quad=$ latent heat of vaporization of water

$\rho \quad=$ density of water

LMTD = the log mean temperature difference between the gas stream and the droplet; this average is based on the inlet and spraydown temperatures

$D_{0} \quad$ initial droplet diameter

Applying the logarithmic mean temperature difference in the above equation includes the effect of a decreased driving force for evaporation as the gas stream is cooled to the spraydown temperature. The above equation assumes no relative velocity between the spherical water droplet and the gas stream. This assumption is appropriate for droplets under 100 microns. In general, droplets exit the atomizer at high velocities, but relax to the surrounding velocity relatively quickly. 
As an example, Table 2.1 contains estimated times for evaporation of a single water droplet in a flue gas stream which has an inlet temperature of $300^{\circ} \mathrm{F}$ and is cooled to a $20^{\circ} \mathrm{F}$ approach-to-saturation temperature.

\begin{tabular}{|c|c|}
\hline \multicolumn{2}{|c|}{ TABLE 2.1} \\
Droplet Evaporation Times \\
\hline $\begin{array}{c}\text { Droplet Diameter } \\
\text { (nicrons) }\end{array}$ & $\begin{array}{c}\text { Estimated Evaporation } \\
\text { Time (seconds) }\end{array}$ \\
\hline 100 & 1.95 \\
80 & 1.25 \\
70 & 0.96 \\
50 & 0.49 \\
30 & 0.18 \\
20 & 0.08 \\
\hline
\end{tabular}

The evaporation of multiple water droplets in a spray will differ from the evaporation of a single droplet in a flue stream. Dual-fluid atomizers generally will spray jets of droplets which have a cooler inner core. Temperature gradients in the flue will affect evaporation. However, the above analysis is a practical method t:o determine the maximum tolerable droplet diameter for a given in-duct process. The drying times given in Table 2.1 are in agreement with results of an independent analysis conducted by FERCo. ${ }^{19}$

Based on the above analysis and the Burns and Roe survey, for induct atomization the amount of spray mass over 100 microns should be limited to 18 or less. Also, there should be a minimum of droplets above 80 microns (58). These droplet size criteria are highly dependent on available flue residence time and the tolerable amount of unevaporated water for a given process.

The droplet size distribution of a spray represents a relationship between the various sizes of droplets in the spray and the frequency of their occurrence. There are a number of droplet size distribution functions which have been described in the open literature. ${ }^{20,21}$ These functions include both empirically-derived equations, such as the Nuki yama-Tanasawa, Rossin-Rammler, and Upper-Limit function equations, and probability-based equations such as normal, log-normal, and square-root normal formulations. In addition, the droplet size distribution can be represented graphically, assuming no specific distribution, with a histogram or a cumulative distribution curve. This last technique is tedious, and researchers generally use one of the droplet size distribution functions which best fits their experimental data. Each of these functions has its associated advantages and disadvantages.

Besides the maximum droplet sizes, there are representative mean diameters of a spray which help indicate an atomizer's usefulness for a given application. For processes which are dominated by mass transfer, evaporation, or reaction constraints, the Sauter Mean diameter is important. The Sauter Mean diameter is defined as the diameter of a droplet whose surface-to-volume ratio is the same as that of the entire spray. The Sauter Mean diameter is a good measure of the spray's fineness. Depending on the droplet size measurement technique, the 
Sauter Mean diameter can be calculated based on measured data, or from the droplet size distribution function which has been defined for the particular spray.

In general, no single parameter can completely define droplet size distribution. 21 Two sprays with the same sauter Mean diameter do not necessarily have the same drop size distribution or large droplet mass fraction. There is no universal correlation relating mean diameter and large droplet mass fraction.

Simons ${ }^{22}$ analyzed droplet size data from a large number of dual-fluid and pressure fuel atomizers. These atomizers were designed and manufactured to the high standards specified by aircraft gas turbine manufacturers. For these atomizers, simmons showed that a correlation between mean diameter and large droplet mass fraction could be established based on a square-root normal probability distribution when droplet diameter was normalized to the mass median diameter. From this correlation, simmons developed charts that may be used to predict required Sauter Mean diameter for a given required large droplet mass fraction. B\&W performed a similar analysis on several styles of duct injection atomizer and found that these data also were best fit to a square-root normal probability distribution, and that a correlation existed between the large droplet mass fraction and mean diameter.

Based on Simmons' correlation, for the type of atomizer manufactured to high tolerances, to limit the mass fraction of droplets over 100 microns to less than 18 , and the mass fraction of droplets over 80 microns to 58 , the required Sauter Mean diameter is predicted to be about 35 microns. However, based on the $B \& W$ analysis, to limit the mass fraction of droplets over 100 microns to less than 18 will require limiting the sauter Mean diameter to less than 25 microns. It is likely that the type of atomizer used in duct injection will be more similar to those studied by $B \& W$ than to those studied by simmons. It is recommended that for duct injection processes with residence times of less than one second the sauter Mean diameter produced by a candidate atomizer should be less than 25 microns. Also, it is recommended that the atomizer vendor be required to report both the sauter Mean diameter and large droplet mass fraction data.

The above Sauter Mean and large droplet mass fraction criteria will also apply to slurry atomization. Low viscosity slurries, such as lime or flyash, behave very much like water, producing Sauter Mean diameters that are less than 158 larger than those produced with water. ${ }^{23}$ There is a drying advantage to atomizing slurxy. The solids in the spray increase the surface area per volume of water. Both $B \& W^{10}$ and Gilbert/Commonweal.th ${ }^{15}$ found that at conditions that caused wall wetting with water spray, no wetting occurred with slurry atomization.

In summary, the droplet size distribution produced by an atomizer is a key parameter governing its usefulness in in-duct retrofit applications. Sauter Mean diameters under 25 microns are required to provide a spray of sufficient fineness for flues with residence times of under one second. This sauter Mean diameter requirement is based on the allowable large droplet mass fraction. There should be no more than 18 of the weight above 100 microns, and less than 58 above 80 microns. 


\subsubsection{Spray Angle/Droplet Trajectory}

Atomizers of different designs provide sprays with widely varying spray patterns and droplet trajectories. Droplet trajectory influences atomizer performance because the initial direction of the high velocity spray can result in direct impingement on flue walls and internals. In contrast, it is imperative that the spray adequately mix with the surrounding flue gas so that complete drying of the droplets can occur in the limited time available.

Spray angles for dual-fluid atomizers are generally smaller than those for rotary or pressure atomizers. Unlike droplet size distributions, spray angles for dual-fluid atomizers do not vary appreciably with air/liguid mass ratio. A lower limit on spray angle is on the order of $14^{\circ}$ and represents the expansion of a free jet.

The maximum tolerable spray angle for a given flue application will depend on the clearances between the atomizer and the walls. In the flue region close to the atomizer plane, droplet trajectory and spray angle may o'etermine the available residence time for evaporation. Narrow spray angles are important for humidification or slurry injection in small diameter flues or with arrays with close wall clearances. Spray angle is not a "stand alone" constraint: successful humidification or sorbent injection without deposition in the near field will depend on wall clearances as well as spray angle. Further downstream of the atomizer plane, wall deposition is more likely to be a function of turbulence rather than direct impingement. Correlations exist in the open litezature for relating droplet momentum and angle to droplet trajectory when injecting into co-flowing gas of a known velocity.

While there is no specific technique for specifying spray angle, the facilities which have used atomizers with a single discharge hole or with multiple holes oriented at a small included angle have had the highest operational success. Bechtel ${ }^{3}$ cited narrow spray angle as necessary for the $3 \mathrm{ft}$. diameter Cambell station tests. During atomizer testing at the Seward Station, Bechtel eliminated several atomizer designs because of wide spray angle. To avoid impingement of wet slurry or water, spray angles should be less than $15^{\circ}$ from the flow axis.

The extreme of spray trajectory is represented by the GEESI IDS process." This test program used a rotary mechanical atomizer in which the initial trajectory is a disk with an include spray angle of $180^{\circ}$. At the IDS facility at ohio Power Company's Muskingum River Unit 5, wall wetting and wet solids deposition were serious problems at flow rates exceeding half the design flow. GEESI attributed this problem to the small flue size. However, better performance has been achieved in tests of a similar scale with dual-fluid atomizers that had a smaller included spray angle. ${ }^{3,4,8}$ For example, Gilbert/Commonwealth has been successful in avoiding severe wet solids deposition in the same flue using dualfluid atomizers with a much smaller included angle.

\subsubsection{Atomizer Air Consumption}

Comparison of the droplet size performance of water or slurry atomizers on the basis of air consumption is a measure of the relative efficiency of the atomizers. Droplet size is the desired product of atomization, while the air-to-liquid mass ratio ( $A / W$ ratio) required to generate the drop size is a measure of the cost. For dual-fluid atomizers, the $\mathrm{A} / \mathrm{W}$ ratio is the most important parameter affecting 
droplet size. For a given type of dual-fluid atomizer, droplet size is in arsely proportional to $A / W$ ratio.

Given the prohibitive costs to produce quantities of compressed air and the large water or slurry flows required for full-scale duct injection applications, it is beneficial to operate at the lowest possible $A / W$ ratio. An atomizer-to-atomizer comparison based on the compressed air consumption, or $A / W$ ratio, does not account for differences in atomizing air pressure that ultimately affect the cost of the atomizing air. The operating pressure for each atomizer will also need to be considered.

Assuming two-stage adiabatic compression, the power required to compress a given flow rate of air to a specific pressure is given by the following equation: ${ }^{17}$

$$
P=0.0596 * W_{1} *\left(\left[P_{2} / P_{1}\right]^{0.143}-1\right)
$$

where: $P$ is the required power (KW)

$W_{a}$ is the mass flow rate of air ( $\left.1 \mathrm{~b} / \mathrm{hr}\right)$

$P_{1}$ is the absolute inlet pressure (psia)

$P_{2}$ is the absolute outlet pressure (psia)

The power needed to supply the compressed air will depend on the required air flow rate and the atomizers' operating pressure. The amount of compressed air consumed by the dual-fluid atomizers used to humidify the flue will depend on the specific $A / W$ ratio required to produce a spray with sufficient fineness for complete evaporation. In general, the air flow requirement for a given droplet size distribution will vary considerably among the available commercial atomizers and must be specified by the vendor.

As an example, consider a $100 \mathrm{MW}$ power plant. This plant will generate on the order of 1 million $1 \mathrm{~b} / \mathrm{hr}: \mathrm{f}$ flue gas. Assume that the available straight length of flue is $60 \mathrm{ft}$. long and $10 \mathrm{ft}$. by $10 \mathrm{ft}$. square. These dimensions correspond to a flue gas inlet velocity of 57 $\mathrm{ft} / \mathrm{s}$ with a residence time of about 1 second, which is typical of utility-scale flow rate and residence times. It is desired to humidify the flue gas to a $25^{\circ} \mathrm{F}$ approach-to-saturation temperature. To cool the flue gas from $300^{\circ} \mathrm{F}$ to $150^{\circ} \mathrm{F}$ will require about $34,100 \mathrm{lb} / \mathrm{hr}$ of humidification water.

The amount of compressed air will depend on the rated $A / W$ ratio for the specific atomizer chosen. Figure 2.1. shows the power required to supply compressed air to the plant in the above example as function of $A / W$ ratio for a range of atomizing air pressures from 60 to $120 \mathrm{psig}$. The power consumption is shown as a percentage of the total plant power. These values were calculated based on adiabatic two-stage compression, with aftercooling between the stages. These values are also based on a compressor discharge pressure which assumes a 30 psi overhead for line losses to the atomizers.

Referring to Figure 2.1 , if the atomizers chosen for installation require an $\mathrm{A} / \mathrm{W}$ ratio of $0.5 \mathrm{ib} / \mathrm{lb}$ to atomize to sufficient fineness and have a design load operating pressure of $120 \mathrm{psig}$, then it is estimated that it will require 0.428 of the plant power, or $420 \mathrm{KW}$, to supply the 


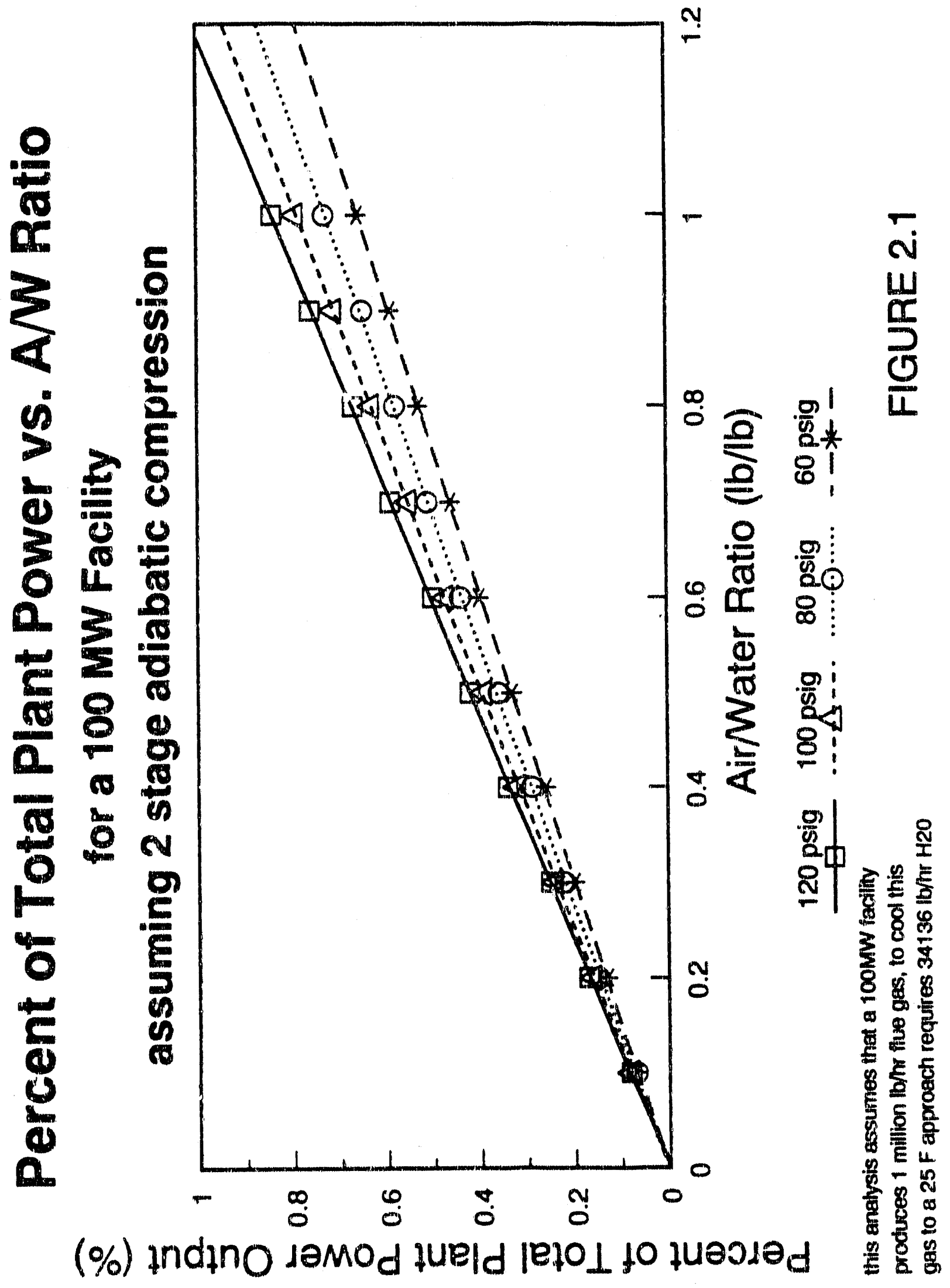


compressed air for atomization. As can be seen from the above aualysis, the compressed air power cost can become quickly prohibitive.

Commercially available atomizers have operating air pressures that range from 60 to 120 psig. The required $A / W$ ratio must be specified by the atomizer supplier, and should depend on generating sprays with a sauter Mean diameter and large droplet mass fraction consistent with available residence times. The candidate atomizers must be chosen based on a power consumption analysis similar to the one above. A conservative estimate of maximum acceptable $\mathrm{A} / \mathrm{W}$ ratio is $0.5 \mathrm{lb} / \mathrm{lb}$.

\subsection{Eunctional Performance Criteria}

Atomizer functional performance criteria have been developed to provide guidelines for the selection and operation of dual-flujd atomizers for duct injection applications. These criteria include flow specifications such as atomizer capacity, iydraulic characteristics, and turndown. Also, although the sorbent and water injection schemes will depend on the particular flue work and geometry, criteria have been developed which address alignment and spacing of atomizers in a flue, whether singly or in an array. Functional performance criteria also include material specifications regarding wear, erosion, and atomize: material deposition and pluggage. Finally, vendor quality control concerns will be discussed.

\subsubsection{Atomizer Capacity}

The total liquid flow required for a specific duct injection application is easily determined based on the flue gas flow rate and the desired approach-to-saturation temperature. The optimum number of atomizers to provide the total liquid flow is not well understood at this time. The liquid capacities of atomizers providing acceptable atomization are usually smali, on the order of 0.08 to 2 GPM. Results of past and ongoing pilot-scale tests indicate that multiple small nozzles perform better than a single large atomizer.

All the facilities to date have used a trial-and-error approach to specify the number of atomizers in the array and the geometry. The exact geometry of the atomizer arrays that provide good performance without deposition is difficult to determine without detailed numerical or physical modeling. At this time there is no metnodology for specifying either the atomizer capacity or the geometry of the atomizer array. Both slurry and water injection schemes will depend on the geometry of the particular flue.

Most researchers reconmend using many small capacity atomizers.3,4.6,24 The most successful pilot-scale duct injection projects have utilized arrays of small capacity atomizers ( 9 to 100 ) to achieve atomization with acceptable amounts of deposition. For flues with short residence times, Bechtel recommends using a large number of ator zers and providing each with multiple discharge orifices. Multiple dscharge oxifices will enhance mixing with the flue gas, increasing heat absorption and quickening drying time.

Results of an analysis of temperatu. parametric testing at the HAL' facility signif:zant limitation on operating the poor ridial mixing of the gas in the fll a core of wet, cooler gas which can then profiles measured during cate that the most ility without wall wetting is

Poor radial mixing produces break through the warmer wall 
envelope. To maximze radial mixing, Dravo recommends using a large number of smali nozkles for humidification. A large number of small nozzles will allow noving the atomizers as close as possible to the wall, while decreasing the liquid-to-gas ratio at each atomizer.

smalier nozzles will decrease the dependence on downstream mixing for proper humidification.

Better mixing will also benefit the dry sorbent injection process. There is some indication ${ }^{12,14}$ that with coplanar humidification and dry sorbent injection, sorbent and flue gas are entrained by the high velocity atomization air, which aids in initial mixing. An array with more smaller atomizers may help distribute the dry sorbent more evenly through the flue cross-section and aid in removal.

LIMB pilot-scale tests 24 at B\&W's Alliance Research Center $6 \times 6$ Humidification Duct studied the effect of both atomizer capacity and atomizer placement on humidification performance and wall wetting. The purpose of the test program was to provide system design validation prior to installation of the full-scale LIMB humidifier at the Edgewater facility. For these tests, B\&W varied the number of atomizers, their capacity, the atomizer-to-atomizer spacings, and the corresponding wall clearances. Based on the results of evaporation measurements, temperature profiles, and visual observation, B\&W concluded that many small. capacity atomizers perform better in terms of wall wetting and droplet evaporation. Improved performance was thought to be caused by two factors. First, a lower capacity atomizer of the same basic design will produce a finer spray than its larger counterpart. Second, using smaller atomizers provides better initial mixing between the water droplets and the flue gas, because the larger number of atomizers distribute the spray over a larger initial flow area.

Results of these IIMB pilot-scale tests also suggest that there is an optimum value for both atomizer spacing and wall clearance. For the atomizer capacities studied $(0.8$ and $1.6 \mathrm{gpm})$, a 12 " atomizer-toatomizer spacing was found to provide the best operation. A minimum wall clearance of $18^{\prime \prime}$ is suggested for the lower capacity atomizers.

Required wall clearance will, in part, be a function of atomizer spray angle and capacity. For example, during shakedown at the seward station facility, Bechtel determined that a minimum wall clearance of 2 $\mathrm{ft}$. from the ceiling and $2-1 / 2 \mathrm{ft}$. from the wall was necessary to avoid deposition. The slurry flow rate through each atomizer was $1.9 \mathrm{gpm}$.

According to the researchers at Dravo, extensive trial-and-error experiments had to be conducted to solve the problem of wall wetting at the HALT facility. Severe wet solids deposition during the early part of the test program was caused in part by too few atomizers and unacceptable wall clearances. The wall wetting problems were aggravated by the small flue size together with minimum required wall clearances.

During their Multi-Nozzle Humidification tests, consol found that droplet drying times were not significantly impaired by atomizer spray plume overlap. Tasts with arrays of 46 and 25 atomizers had significant spray plume overlap. At a 20 to $25^{\circ} \mathrm{F}$ approach-to-saturation temperature, these tests showed comparable droplet drying times to those found for the single atomizer in cylindrical tests. However, the atomizer used during this test program had an extremely small capacity of 0.067 gpin. $\mathrm{B} \& W$ found that for the $1.6 \mathrm{gpm}$ Durajets, droplet coalescence due to jet 
interaction is not a significant problem for atomizer-to-atomizer spacings of $12 "$ or greater.

In summary, there is no specific method to determine the exact geometry or capacity of atomizers in an array to be used for slurry injection or humidification. Detailed numerical or physic .1 modeling could provide this information. Most facilities have usec a trial-anderror approach. Results from these past and ongoing facilities indicate the following general guidelines for atomizer capacity and placement:

- Results from Dravo (HAIT), Bechtel (CZD), and B\&W (LIMB) indicate that many smaller atomizers are more desirable than fewer large atomizers. Multiple small atomizers will help mixing and may help aspirate dry sorbent. There is probably a limit to the total number of atomizers that can be practicaliy used.

- Wall clearance requirements are a function of atomizer capacity. For atomizers with capacities on the order of 0.8 to $2 \mathrm{gpm}$, a minimum atomizer-to-atomizer spacing of 12 " is required and a minimum wall clearance of $18^{\prime \prime}$ to $2 \mathrm{ft}$. is required. Spray plume interactions will not cause problems with atomizers that are of this capacity and $1 \mathrm{ft}$. apart.

- The optimum atomizer array cannot be determined without detailed numerical or physical modeling. This modeling may identify recirculation zones and other problem areas.

- Atomizer headers should be aerodynamic to avoid flyash deposition on the upstream side.

\subsubsection{Atomizer Hydraulic Characteristics ${ }^{25}$}

For successful in-duct humjdification and slurry injection, the mass flux of injected water or slurry must be uniform across the flue cross-section. A poor distribution of liquid can cause localized regions of saturated gas that can lead to wall wetting and wet solids deposition. Several factors influence the ability to control the droplet size and water flow distribution over the flue cross-section. These factors include the sensitivity of individual atomizers to mild variation in operating conditions, the atomizer-to-atomizer uniformity in operating characteristics, and the effect of variable water pressure with vertical elevation in the flue.

The pressure-flow characteristics of a single atomizer or an array of a few atomizers are usually not important because it is possible to monitor and control the air and liquid flow rates to each atomizer. With a large array of atomizers, individual control of flow to each atomizer is not practically feasible. With an array of atomizers, two or more atomizers are connected to a common supply manifold. The control of flow is to the array, and the flow to the individual atomizers in the array is dependent on the liquid pressure distribution in the manifold and the pressure-flow characteristics of the individual atomizers. The uniformity of flow across an array will, in part, depend on the individual atomizers' sensitivity to normal process variations.

A measure of an atomizer's sensitivity is simply the change in liguid flow that results from a change in liquid pressure at a constant air pressure. This change is the slope of the liquid pressure-liquid 
flow curve. The more sensitive the atomizer, or steeper the slope, the more likely an atomizer array will have problems with flow maldistribution. There is not a method to specify exactly an acceptable sensitivity for an array of atomizers. Acceptable sensitivity will depend on both the geometry of the manifold and the type of process control. For large arrays of atomizers, an estimate of maximum acceptable atomizer sensitivity is on the order of 58 of water flow per psi water pressure at full load.

If the sensitivity of a candidate atomizer is unacceptably high, then it can be adjusted by increasing the single-phase liquid flow resistance between the atomizer and the manifold. One method for increasing the hydraulic resistance to the single-phase water flow is to install one or more orifices immediately upstream of the atomizer. B\&W has had success with this method.11,12 It is important that the addition of orifices does not change the spray droplet size distribution.

Another factor that will affect the uniformity of the mass flux and droplet size distribution across the flue is the part-to-part uniformity of the atomizers. Arrays of atomizers require good part-to-part uniformity in atomizer hydraulic and droplet size distribution characteristics. A large number of atomizers will be controlled by a single source of air and liquid. With this geometry, if the pressure-flow characteristics of the atomizers are not identical, then the liquid flow to each atomizer could be substantially different.

Variations in air or liquid flow can affect the droplet size distribution because of the effect these variations will have on $A / W$ ratio. Atomizer-to-atomizer variability can arise solely from differences in the size, shape, angle, and location of the holes in the components that make up the atomizer. At the HAIT facility, Dravo discontinued use of the first set of dual-fluid atomizers because of poor part-to-part uniformity." This non-uniformity caused the initial wall wetting and wet solids deposition problems encountered during sirakedown. Vendor quality control was suspected to cause this initial problem. ${ }^{5}$

The third factor that affects the flue cross-sectional mass flux and droplet size uniformity is the differences in vertical location for atomizers in large arrays. Atomizers in a flue that are located at different elevations and are supplied by a common water or slurry source are subject to flow maldistributions. The maldistribution is caused by variations in the static pressure in the water lines. Atomizers at lower elevations will "see" a higher supply pressure and flow rate than atomizers at upper elevations.

The brute force solution to the elevational flow maldistribution is to measure and control the water flow to each level of atomizers in an array. For arrays with a large number of atomizers, this approach could require a multitude of flow meters and control valves in an active control loop. This type of scheme is susceptible to flow instabilities and is costly and complex. Passive control with the simplest instrumentation is more desirable. This passive control approach has been successfully implemented by $B \& W^{10,11}$ Based on the operating characteristics of the internal mix dual-fluid atomizer used at Edgewater during the IIMB project, it was found that the effect of variable water pressure on flow rate could be offset with air pressure that also varied with height. This type of solution will requixe 
knowledge of the pressure flow characteristics of the atomizers in a given array.

\section{2 .3 Turndown}

Droplet size integrity must be considered when developing a turndown scheme for the atomizers in a commercial duct injection application. For dual-fluid atomizers, the air-to-liquid mass ratio ( $A / W$ ratio) is the most important parameter affecting droplet size. Droplet size performance is usually maintained by operating at a constant $A / W$ ratio; for a given dual-fluid atomizer spray quality will degrade if the $A / W$ ratio is decreased. During turndown, the $A / W$ ratio to the atomizers must remain constant or increase. In addition to maintaining spray quality, turndown schemes should be simple and responsive to sudden load swings.

There are several turndown schemes that maintain droplet size performance. From a control standpoint, the simplest approach would be to maintain constant air pressure and regulate the water flow rate to meet the load demand. While this scheme is simple, it has the highest energy requirement at low loads. To conserve power, it would be best to operate at a constant $\mathrm{A} / \mathrm{W}$ ratio, and turn down both air and liguid with load demands. However, this method may require a complex control system.

A third method to turndown while operating at a constant $A / W$ ratio involves responding to load swings by taking some of the atomizers in an array out of service, while maintaining the same air and liquid flow rates per at izer as exist with full load conditions. There is some question abo. how immediately responsive this type of scheme would be to sudden loau swings.6 In addition, atomizers which have been taken out of service and not properly flushed may be susceptible to pluggage by scale deposition or dried slurry (se section 2.2.5.3). This deposition would degrade future atomizer hydral. .. and droplet size performance.

It is recommended to follow load swings by turning down to 508 load at a constant $A / W$ ratio. Below 508 load, the water flow rate to all atomizers should be reduced while the air pressure is maintained at a constant value. The hydraulic characteristics of candidate atomizers should be supplied by the vendor.

\section{2 .4 Atomizer Alignment}

Atomizer alignment can have a significant effect on humidification and sorbent injection performance. Atomizers placed in a flue, whether singly or in a multi-atomizer array, must be aligned so as to prevent jet impingement on the flue walls, minimize ash deposition on the nozzles, and maximize the mixing between the spray and the flue gas. Good mixing is essential for both humidification and slurry injection to maximize $\mathrm{SO}_{2}$ removal and to ensure complete evaporation.

For atomizers in an array, the atomizers must be aligned to avoid direct impingement of the spray on the walls near the atomizer array plane. Atomizer alignment will be somewhat specific to the application, and will depend on the spray angle of the atomizer and the distance from the atomizer to the wall. The results of initial nozzles tests performed by Gilbert/Commonwealth at the Beverly, Ohio, DITF indicate that for the $2 \times 3$ array of atomizers used, wall wetting can be reduced by 
angling the atomizers inward from the top, bottom, and sides. The amount of tilt for these atomizers was on the order of $5^{\circ}$.

Atomizer alignment is important for single atomizers spraing from a flue centerline. For a small flue, atomizer alignment withill the flue becomes a critical issue as minor deviations from centerline alignments will significantly increase the degree of wall deposition. ${ }^{9}$ Bechtel ${ }^{3}$ found that at their Cambell station facility, single atomizer centerline arrangement made alignment of the atomizer with the flue centerline crucial to control wall deposition. It should be emphasized that these alignment/deposition problems may be somewhat specific to atomizers placed in flues with small cross-sectional flow areas.

\subsubsection{Atomizer Wear, Corrosion, Deposition, and Pluggage}

Droplet size and hydraulic performance are important aspects of atomizers used in an array for humidification and slurry injection. since flow control to the array is global, the flow rate of each atomizer is dependent on its pressure-flow characteristics. Wear, deposition, corrosion, and pluggage of individual atomizers in an array can lead to variations in the part-to-part performance characteristics of the atomizers. Degradations in the flow characteristics of nominally identical atomizers can cause local effects that may lead to deposition on flue walls.

\subsubsection{Wear}

Wear of atomizer components can lead to changes in their hydraulic and droplet size characteristics. These changes may lead to wall wetting and wet solids deposition caused by flow maldistributions and incomplete evaporation. Atomizer wear will be a greater problem with slurry than with water because of the abrasiveness of the solids in the slurry.

$B \& W$ studied the effect of in-service wear on the performance characteristics of humidification atomizers. ${ }^{26}$ Five B\&W DuraJet dual-fluid atomizers from the same airfoil lance were tested for pressure-flow and droplet size characteristics after seven months of operation in the Edgewater IIMB Humidification Duct. The airfoil lance assembly consists of five Durajets plumbed to common air and liquid manifolds and housed in an airfoil-shaped casing. The atomizers were fabricated from $316 \mathrm{ss}$. The hydraulic and droplet size measurements were compared to data measured during Durajet prototype development tests. After the hydraulic and droplet size tests were completed, each atomizer was disassembled and inspected.

Results of the inspection on the individual atomizers indicate that prolonged use during the LIMB Humidification program contributed in varying degrees to both wear and pluggage among those atomizers inspected. On all atomizers, the end cap discharge holes were eroded to the same degree. The increased discharge area changed the hydraulic characteristics of the atomizer by contributing to a decrease in the two-phase hydraulic loss at any given air pressure and water flow rate. This wear did not cause a flow imbalance, only because it was uniform between all five atomizers. Droplet size distribution measurements indicated that this wear, by itself, does not substantially affect. drolet size performance. 
It was recommended that ceramic inserts be used in the end cap discharge holes, as they extend the useful life of these parts, and eliminate problems of flow maldistribution that could arise from "one-at-a-time" end cap replacement. B\&W replaced all the atomizers at the Edgewater facility with ones that used ceramic inserts.

During tests at the HALT facility, Dravo indicated that $316 \mathrm{ss}$ nozzles wore due to erosion caused by both air and water. These atomizers were not equipped with ceramic inserts.

Atomizer wear will be a greater problem with slurry than with water because of the abrasiveness of the solids in the slurry. Bechtel experienced difficulties with atomizer wear and erosion with the two atomizers used at the cambell facility after about ten days of duration tests. ${ }^{3}$ Erosion of the target bolts, which see the impingement of slurry prior to the slurry mixing with the atomizing air, was obvious in both the atomizers. The target bolts were replaced with bolts made of a hardened material, which solved the problem. The inside edge of the discharge hole was also rounded from wear, and replaced. At the seward station CZD facility, calcitic lime used during "continuous run" tests caused significant and rapid erosion of the atomizer discharge tips. Bechtel recommends the use of atomizers with erosion-resistant tips to reduce wear. At the CZD facility, erosion led to non-uniform spray patterns caused by changes in the hydraulic characteristics of the worn nozzles.

To minimize wear for both humidification and slurry atomizers, the materials of construction should be hardened steel with ceramic inserts.

\subsubsection{Atomizor Deposition}

Another factor that can influence flue wall deposition is the buildup of material on the atomizers. Material buildup on the atomizer tip can alter the spray pattern, misdirect the spray, and reduce spray quality. Atomizer deposition can cause flow maldistributions by the partial or complete pluggage of one or several atomizers that are manifolded in an array. Deposition on the atomizer tip will cause dripping.

With in-duct injection of slurry, buildup on the atomizer tips can be caused by the sudden expansions of the air/slurry mixture leaving the atomizer. With dry lime injection upstream of humidification, atomizers are exposed to a high solids content flue gas stream. Because atomizers and headers are sites for water condensation, the solids in the flue gas stream will stick to the wet atomizer components.

The flow patterns within the flue may deposit material on the atomizer tips. Turbulent eddies or recirculation zones may force solids to the wet surfaces of the atomizers, where they can stick. With dualfluid atomizers, the high velocity air/liquid mixture will entrain the surrounding flue gas. For atomizers issuing into small flues, recirculation eddies will form if there is less surrounding flue gas flow than the atomizer can entrain. ${ }^{27}$ These eddies may cause deposition on the atomizer tips.

When Radian" ran tests with upstream sorbent injection at Meredosia, they experienced difficulties with deposits developing both near the front tip and on the back side of the atomizer. The deposits 
that formed on the tip of the atomizer became a problem when they grew out over the front of the atomizer and began interfering with the spray pattern. This atomizer deposition caused wall wetting of the flue walls and initiated wall deposits.

At the start of the E-SO test program at Ohio Edison's R. E. Burger Station, B\&W experienced problems with severe atomizer deposition. During shakedown, slurry atomization employed a $3 \times 2$ array of dual-fluid atomizers. A large recirculation zone caused material deposition on the bottom row of atomizers. This buildup degraded atomization performance and led to severe wet solids deposition on the flue walls. computer modeling was able to predict the recirculation zone. When the atomizer array was changed to the $2 \times 1$ array discussed above, deposition was no longer a problem. After modification, the E-SO $\mathrm{F}$ pilot operated for 400 hours without significant material deposition.

In general, atomizer deposition should be reduced, eliminated, or removed by periodic cleaning." One method to reduce deposition on the atomizer tip is through the use of shielding devices. Commercial atomizers generally do not come equipped with a device to prevent deposition and buildup on the atomizer tip. These atomizers should not be considered for use unless they can be fit into a particular shielding device. Air lances may also be installed to control deposition on the atomizer and manifold surfaces. These lances would control material formation on the cool, moist metal by blowing compressed air on the upstream surfaces. Mechanical devices such as rappers may be used to dislodge material and prevent the buildup of solids.

\subsubsection{Pluggage}

Pluggage of the internal air and liquid passages of dual-fluid atomizers will severely change the hydraulic characteristics and cause flow non-uniformities among atomizers in an array. Atomizer pluggage may be caused by solids in the humidification water or slurry. If the water quality is questionable, a filtering system should be used. Atomizers with very small diameter internal passages should not be used for spraying unfiltered humidification water or unstrained slurry.

At the $\mathrm{E}-\mathrm{SO}_{\mathrm{x}}$ facility, $\mathrm{B} \& \mathrm{~W}$ used two interchangeable in-line strainers for the slaked lime slurry. BSW experienced no problems with atomizer pluggage from the slurry solids. A protocol had to be developed to periodically clean the two strainers.

In April 1991, at the Gilbert/Commonwealth Beverly facility, solids in the humidification water quickly plugged a Parker Hannifin atomizer. This particular atomizer has extremely small diameter internal liquid passages. ${ }^{28}$

Scale from both the lime in the slurry and hardness in the water may deposit on the internal passages of an atomizer and retard air or water flow. Scaling is the crystalline growth of an adherent layer of insoluble salt or oxide on a surface where heat is exchanged. Watexformed scales are derived entirely from ions in the humidification water and may include calcium sulfate, calcium and magnesium phosphates, magnesium silicate, and calcium carbonate. These anhydrous salts have a retrograde solubility in water and may crystallize from solution and deposit on the atomizer and air and water feed line internals as the water temperature increases. ${ }^{29}$ 
Increases in atomization water temperature may occur for a variety of reasons. In the manifold internals, the water may contact with pipes carrying hot, compressed air. In large flues, the water that supplies atomizers closest to the center of the array will "see" higher temperatures for longer periods of time. scaling is most likely to occur in hot quiescent regions, and may be caused by water remaining in the atomizers or lines during down times. Most scales can be removed with mild acid washes; however, these washes may tend to corrode the flue internals and should be used with caution.

During part of Bechtel's Cambell facility duration test, air flow to the spray nozzles was unintentionally decreased from 48 scfm to 41 scfm. This flow decrease was caused by lime scale buildup in the air passages of the nozzles. Bechtel states that washing the nozzles with vinegar contributed to keeping the flue clean on subsequent tests.

Results of the post-LIMB atomizer performance characterization ${ }^{26}$ indicate that scale pluggage had affected the droplet size and hydraulic characteristics of two of the five atomizers from the IIMB airfoil lance assembly inspected during this study. Results of an inspection of the affected atomizers indicate that scale deposition had restricted the air-side discharge area at a wet/dry interface. Based on measured hydraulic and droplet size distribution data, it was concluded this restriction caused undesirable atomizer-to-atomizer variations in hydraulic performance. The variations resulted in a non-uniform distribution of liquid flow, air flow, and, therefore, droplet size, anong the atomizers in the lance assembly. At low approach-tosaturation temperatures, the variation in liquid flow was sufficient to cause local supersaturation of the flue gas and probable wall wetting. The formation of scaly deposits is probably a function of water quality and shlitdown procedures. Recommendations to LIMB operators included reviewing shutdown procedures, developing a means to easily remove and inspect atomizers, improving water quality, and developing a protocol for periodic maintenance through dilute acid cleaning.

\subsubsection{Corrosion ${ }^{30}$}

cold-end corrosion occurs when sulfur and chlorine constituents of the combustion gas condense and rapidly corrode exposed metal surfaces. The temperature at which the sulfuric acid condenses is called the acid dew point. A variety of factors influence the value of this temperature. The presence of ions other than sulfur also affects cold-end corrosion. Chlorides can form hydrochloric acid. If liquid water is present, hydrochloric acid is probably the greatest concern.

Humidification upstream of sorbent injection is more likely to suffer from corrosion caused by acid condensation in the absence of sorbent particles. However, Dravo indicated that at the HALT facility, where humidification occurred downstream of sorbent injection, headers of $304 \mathrm{ss}$ failed under service due to corrosion. These headers had surface temperatures that were below the acid dew point. The header material was replaced with 316 ss.

This type of corrosion was also found at the LIMB facility, where airfoil lances of 304 ss corroded due to acid dew point condensation. To minimize deposition on the atomizer tip, the lances were vented by outside purge air which was drawn through the manifold internally. It is likely that this cool outside air was partially responsible for the corrosion identified. 
It is recommended that atomizers and headers are resistant to cold-end corrosion. Hastelloys and inconels are most resistant to acid condensation corrosion.

\section{2 .6 Vendor Quality Control}

Atomizer veridor quality control is very important in assuring successful duct injection process commercialization. The vendor must be held responsible for the quality of the materials, any droplet size and hydraulic data provided, and the part-to-part repeatability for the atomizers. Vendor quality control must be regulated by the project manager or project engineer in charge of installation for a given process. In the past, there has been some indication that atomizer vendor quality control was not adequate for duct injection technology applications.

The vendor must provice information on the atomizer's droplet size distribution and hydraulic characteristics. The droplet size information should include large droplet mass percent above 100 microns, and the Sauter Mean diameters at the flow rates and $A / W$ ratios that will be used during the process. As a reminder, the spray mass over 100 microns should be limited to 18 . The spray Sauter Mean diameter should be about 25 microns. In addition, it would be helpful if the vendor provided documentation about the technique used to measure the droplet size data.

To minimize wear and corrosion for both humidification and slurry atomizers, the materials of construction should be 316 ss for exposed surfaces with ceramic or other wear-resistant materials located at internal wear points. The vendor should provide documentation about the atomizer materials of construction. This documentation should include any wear data and estimations of the useful life of the atomizer.

It is imperative that the atomizers supplied by the vendor have excellent part-to-part uniformity. Large groups of atomizers will be controlled by a single source of air and liquid. With this geometry, if the pressure-flow characteristics of the atomizers are not substantially identical, then the liquid flow to each atomizer could be different. Variations in air or liquid flow can affect the droplet size distribution because of the affect these variations will have on $A / W$ ratio. Atomizer-to-atomizer variability can arise solely from differences in the size, shape, angle, and location of the holes in the components that make up the atomizer. Poor part-to-part repeatability caused the initial wall wetting problems encountered during shakedown at the HALT facility. Vendor quality control was suspected to cause this initial problem.

\subsection{Sumary of Spray and Functional Performance Criteria for Duct Injection Technology Atomizers}

Wet solids deposition is the most serious operation problem affecting the successful commercialization of the duct injection process. Good operational performance and spray characteristics of slurry and humidification atomizers are critical. in eliminating this problem.

One of the goals of the Nozzle Development Program was to develop atomizer performance criteria that met the constraints of an in-duct retrofit application. The atomizer requirements that were identified to 
meet the in-duct retrofit constraints were separated into two categories. The first set of criteria govern spray performance. These criteria addressed atomizer flow type, droplet size, spray angle and droplet trajectory, and operating air consumption. The second set of criteria adaressed atomizer capacity, hydraulic characteristics, turndown, alignment within the flue, deposition, corrosion and wear characteristics, and vendor ouality control.

Based on the criteria developed in sections 2.1 and 2.2 of this report, the following recommendations regarding atomizers for use with in-duct processas have been developed:

\section{Atomizer Type}

- Dual-fluid type atomizers should be used with duct injection application for both slurry injection and humidification.

\section{Drop Size}

- The droplet size distribution produced by an atomizer is the key parameter determining its success in a duct injection application. The largest acceptable droplet size is determined by evaporation requirements and will. depend on the available drying time in the flue. Based on the Burns and Roe Duct Survey, a majority of utility-scale flues have residence times of 1 second or less. Retrofit humidification or slurry injection systems that are designed to operate at approach temperatures of $20^{\circ} \mathrm{F}$ and have residence times of 1 second or less will require atomizers with sprays that include less than 18 of the mass in droplets over 100 microns, and the mass percent of droplets over 80 microns must be 1 imited to less than 58 . The sauter Mean diameter is defined as the diameter of a droplet that has the same surface-to-volume ratio as the entire spray. The Sauter Mean diameter is a good representative diameter to use when comparing atomizers for evaporation processes. For duct injection type atomizers, the sauter Mean diameter of a spray that has less than 18 of the mass in droplets over 100 microns will generally be less than 25 microns. If the spray Sauter Mean diameter is above 25 microns, then the candidate atomizer will probably not meet the large droplet mass fraction criterion noted above.

Spray Anqle

- Atomizer spray angles should be less than $30^{\circ}$.

\section{Compressed Air Consumption}

- The compressed air requirement must be considered when choosing among candidate atomizers. For duct injection technologies, it has been estimated that the compressed air power cost nay be second only to sorbent costs. Unfortunately, however, for dual-fluid atomizers the air-to-liquid mass ratio (A/W ratio) is one of the key parameters affecting droplet size. With dual-fluid atomizers, droplet size will decrease with an increase in $A / W$ ratio. Besides the $A / W$ ratio, the power cost of the atomizing air wili also depend on the required air pressure.

Comercially available atomizers have operating air pressures that range from 60 to $120 \mathrm{psig.} \mathrm{The} \mathrm{required} A / W$ ratio must be specified by the vendor, and should depend on generating sprays with a droplet size distribution that meets the evaporation requirements for the duct process minimum of large droplets. Based on the amount of power required, a conse vative estimate of maximum acceptable $A / W$ ratio for atomizers with the above range of operating pressures is $0.5 \mathrm{lb} / \mathrm{lb}$. 


\section{Atomizer Capacity and Spacing}

- With regards to atomizer capacity, the exact number of atomizers to provide total liquid flow is not well understood at this time. Results of past and ongoing pilot-scale tests indicate that multiple smali atomizers perform better than a single large atomizer. Most researchers recommend using many sinall capacity atomizers. The most successful pilot-scale duct injection projects have utilized arrays of small capacity atomizers ranging from 9 to 100 to achieve atomization with acceptable amounts of deposition.

- Atomizer-to-atomizer spacing and wall clearance requirements are a function of atomizer capacity. For atomizers on the order of 0.8 to $2 \mathrm{gpm}$, and co-axial injection, minimum atomizer-toatomizer spacings of $1 \mathrm{ft}$. and atomizer-to-wall spacings of 2 ft. are required. However, the optimum atomizer configuration for a given flue geometry cannot be determined without detailed physical or numerical modeling.

Hydraulic Characteristics

- The atomizer hydraulic characteristics are important for controlling the droplet size and water flow distribution across the flue cross-section. A poor distribution of liquid can cause localized regions of saturated gas that can lead to wall wetting and wet solids deposition.

The uniformity of flow across an array will, in part, be dependent on the sensitivity of individual atomizers to normal process variations. One measure of an atomizer's sensitivity is the change in liquid flow that results from a change in liquid pressure at a constant air pressure. For large arrays of atomizers, an estimate of maximum acceptable atomizer sensitivity is on the order of 58 of water flow per psi. water pressure at full load.

- Arrays of atomizers must have good part-to-part uniformity in atomizer hydraulic and droplet size distribution characteristics. Large groups of atomizers will usually be controlled by a" single source of air and liquid. With this geometry, if the pressure-flow characteristics of the atomizers are not substantially identical, then the liquid flow to each atomizer could be significantly different.

- Atomizers in a flue that are located at different elevations and are supplied by a common water or slurry source are subject to flow maldistributions caused by variations in the static pressure in the liquid lines. This elevational flow maldistribution must be corrected through a control scheme, which will depend on the specific atomizers. Where possibie, passive control with the simplest instrumentation is desirabie.

Atomizer Alignment

- Atomizer alignment can have a significant effect on humidification and slurry injection performance. Atomizers must be aligned to avoid direct impingement of the spray on the walls near the array plane. Atomizer alignment will be somewhat specific to application, and will depend on spray angle and distance from the wall. In addition, the required wall clearance may be reduced by tilting the atomizer. 
Wear, Deposition, Plugqage, and Corrosion

- Wear of individual atomizers in an array can lead to variations in the part-to-part performance characteristics of the atomizers. To prevent unacceptable wear, critical wear points in the atomizer should be fabricated with ceramic inserts.

- Atomizer deposition should be reduced, eliminated, or removed by periodic cleaning. One method to reduce deposition on the atomizer tip is through the use of shielding devices. Commercial atomizers generally do not come equipped with a device to prevent deposition and buildup on the atomizer tip. These atomizers should not be considered for use unless they can be fit into a particular shielding device. Air lances may also be installed to control deposition on the atomizer and manifold surfaces. These lances would control material formetion on the cool, moist metal by blowing compressed air on the upstream surfaces. Mechanical devices such as rappers may be used to dislodge material and prevent the buildup of solids.

- Atomizer headers should be aerodynamic to avoid flyash deposition on the upstream side.

- Pluggage of the internal air and liquid passages of dual-fluid atomizers may significantly change the hydraulic characteristics and cause flow non-uniformities among atomizers in an array. Atomizer pluggage may be caused by solids in the humidification water or slurry, or by scale from either the lime in the slurry or hardness in the water.

If the water quality (amount of suspended solids) is questionable, a filtering system should be used. The allowable particulate top size should be 50 microns. Slurry should be strained upstream of the atomizers to remove large particles. Atomizers with narrow internal pessages should not be used for spraying unfiltered humidification water or unstrained slurry. The compressed air used for atomization should be filtered near the atomizer inlet to eliminate tramp materials in the air line.

Scale pluggage may be, in part, related to shutdown and downtime procedures. Protocols should be developed to account for scheduled or unscheduled downtime. Periodic maintenance through dilute acid cleaning may be required.

- Atomizers and headers must be resistant to cold-end corrosion. The materials of construction should be at least as corrosionresistant as 316 ss.

\section{Turndown}

- Atomizer turndown should be based on preserving spray quality. It is recommended to follow load swings by turning down to $50 \%$ load at a constant air-to-liquid ratio. Below 508 load, the liquid flow rate to all atomizers should be reduced while the air pressure is maintained at a constant value.

\section{Quality Control}

- The importance of vendor quality control must be stressed. Vendor information about droplet size and hydraulic performance should be carefuliy monitored. Atomizer part-to-part uniformity should be checked by an independent source. 


\subsection{A COMPARISON OF COMMERCIALLY AVAILABLE ATOMIZERS TO DEVELOPED CRITERIA}

\subsection{Introduction}

The following section documents the results of the atomizer comparison conducted as part of the Nozzle Development subtask 4.1. A number of commercially available atomizexs were judged based on the spray and functional performance criteria that were developed during this program. The atomizers that were considered come from a list of those used or considered for use the various ongoing and past pilot duct injection and related test programs. The atomizer selection standards developed should be used whenever an atomizer is considered for a commercial duct injection application.

\section{2 selection Criteria}

Atomizer cidteria that address the constraints of in-duct injection retrofits were developed in the preceding sections of this report. These spray and functional performance criteria provide general guidelines for both the selection and use of atomizers for duct injection processes. From these criteria, the guidelines that apply specifically to the selection of atomizers for commercial duct injection applications have been established.

The selection guidelines for comparing and ranking commercial atomizers include both functional requirements and practical concerns. The requirements provide the minimum performance level for a commercial atomizer. Atomizers that perform below this level should not be considered for commercial duct injection applications. The practical concerns include items that must be taken into consideration when judging an atomizer, but do not necessarily disqualify a candidate atomizer from selection.

The guidelines for comparing and ranking commercially available atomizers are listed below. These guidelines should be used for both slurry injection and humidification atomizers.

\section{Atomizer Selection Requirements}

1. Suficiently small large droplet mass fraction and Sauter Mean diameter at reasonable air-to-liquid mass ratios

2. Low susceptibijity to internal passage pluggage

\section{Atomizer Selection Practical Concerns}

3. Atomizer tip deposition

2. Spray angle

3. Hydraulic sensitivity

4. Materials of construction

\subsection{Comarcial Atomizers}

The selection guidelines listed above were applied to 22 commercial atomizers. The atomizers under consideration come from a list of those used or screened for use at pilot-scale duct injection test Bites. Table 3.1 contains a list of the tomizers that were analyzed during this program and the source of data and research experience associated with each atomizer. 


\begin{tabular}{|c|c|}
\hline & $\begin{array}{l}\text { TABLE } 3.1 \\
\text { A List of Commercial Atomizers That Were } \\
\text { Compared to Developed Selection Guidelines }\end{array}$ \\
\hline \multicolumn{2}{|r|}{$\begin{array}{l}\text { Atomizers Characterized by B\&W for the Beverdy Duct Injection Test } \\
\text { Facility }\end{array}$} \\
\hline $\begin{array}{l}1 . \\
2 . \\
3 . \\
4 .\end{array}$ & $\begin{array}{l}\text { Lechler } 170.961 .17 \text {. This atomizer is currently used to spray } \\
\text { slurry at the Beverly facility. } \\
\text { B\&W Mini Durajet Mk7 } \\
\text { Parker Hannifin Lime Slurry Nozzle } 60011 \\
\text { Parker Hannifin Humidification Nozzle } 60008\end{array}$ \\
\hline \multicolumn{2}{|r|}{ Atomizers Characterized by BEW During the LIMB Atomization study } \\
\hline $\begin{array}{l}5 . \\
6 . \\
7 . \\
8 . \\
9 . \\
10 . \\
11 . \\
12 . \\
13 . \\
14 .\end{array}$ & $\begin{array}{l}\text { Heat systems } 1100-1 \\
\text { Delavan Swirl Air } \\
\text { BdW Mini DuraJet Mk4 } \\
\text { B\&W Mini DuraJet Mk12. This atomizer was used during the IIMB } \\
\text { anc Coolside pilot studies at the Edgewater facility. } \\
\text { Heat Systems } 900-4 \text {. This atomizer was used by Dravo at the HALT } \\
\text { facility. } \\
\text { Sonic Development ST-33 } \\
\text { Flosonic MS-40 } \\
\text { B\&W Y-Jet } \\
\text { Sp:aying Systems J-12. This atomizer was used during the } \\
\text { Mult-Nozie Humidification test program at the HALT facility. } \\
\text { Sonic Development ST-47 }\end{array}$ \\
\hline \multicolumn{2}{|r|}{ Atomizers Characterixed by UCI for the Meredosia Facility } \\
\hline $\begin{array}{l}15 . \\
16 . \\
17 . \\
18 . \\
19 . \\
20 . \\
21 . \\
22 .\end{array}$ & $\begin{array}{l}\text { Delavan Airo } 30616-17 \\
\text { Delavan Airo } 30616-11 \\
\text { Delavan Airo } 306.15-46 \\
\text { Delavan Bypass } 350351-8 \\
\text { Delavan Bypass } 38635-3 \\
\text { Lechler Sonic } 170.721 .17 \\
\text { Lechler Sonic } 170.641 .17 \\
\text { Bete Fog Spiral } 12 \mathrm{H}-14 \mathrm{~N}-.283\end{array}$ \\
\hline
\end{tabular}

The data used to compare the atomizers came from several sources. The first source was droplet size and hydraulic tests conducted by $B d W$ as part of the IIMB Humidification test program. As part of this project, conoco conducted an atomizer vendor survey in early 1986. From the list of atomizers contained in this survey, B\&W selected the 11 most promising for droplet size testing. ${ }^{31}$ The droplet size test.s took place in 1986 and 1987 . Several of the atomizers characterized during these test have been used at recent duct injection pilot facilities.6,6,11,13

The second source of date was atomizer characterizations done by Babcock \& Wilcox for Gilbert/Commonwealth in support of the scale-up Tests and Supporting Research for Development of Duct Injection Technology. ${ }^{32}$ The G/C test program is currently underway at Beverly, Ohio. As part of this program, B\&W measured the droplet size distribution and hydraulic data for thres styles of atomizers with capacities similar to that reguired for the Beverly, ohio, pilot racility. The three styles of atomizers included a Lechler, a Parker 
Hannifin, and a $B \& W$ Durajet. The results of this test program are documented in Appendix A.

The third source of data was droplet size tests performed at the University of California Irvine combustion Laboratory (UCICL). The purpose of these tests was to identify an atomizer suitable for the 1.7 $M W$ duct injection pilot-scale test program at Central Illinois public Service Company's Meredosia Station. ${ }^{33}$ The University of California characterized a total of eight dual-fluid atomizers.

\section{A Comparison of Candidate Atomizers on the Basis of Large Droplet Mass Fraction and Sauter Mean Diameter at Reasonable Air-to-Liquid Mass Ratios}

The droplet size distribution produced by an atomizer is the key parameter determining its success in a duct injection application. The largest acceptable aroplet size is determined by evaporation requirements and will depend on the available drying time in the flue. Based on the Burns and Roe Duct survey, a majority of utility-scale flues have residence times of 1 second or less. Retrofit humidification or slurry injection systems that are designed to operate at approach temperatures of $20^{\circ} \mathrm{F}$ and have residence times of 1 second or less will require atomizers with sprays that include less than 18 of the mass in droplets over 100 microns, and the mass percent of droplets over 80 microns must be limited to less than $5 \%$. If the above large droplet mass fraction criteria are not met, then the candidate atomizer must not be used for flues with residence times under one second.

The sauter Mean diameter is defined as the diameter of a droplet. that has the same surface-to-volume ratio as the entire spray. The sauter Mean diameter is a good representative diameter to use when comparing atomizers for evaporation processes. For duct injection type atomizers, the Sauter Mean diameter of a spray that has less than 18 of the mass in droplets over 100 microns will generaliy be less than 25 microns. If the spray sauter Mean diameter is above 25 microns, then the candidate atomizer will probably not meet the large droplet mass fraction criterion noted above.

The operating $A / W$ ratio at a given flow rate must be specified by the atomizer supplier. Due to the high power requirement to produce compressed air, the atomizer must meet the above droplet size criteria while operating at an air-to-liquid mass ratio ( $\mathrm{A} / \mathrm{W}$ ratio) of 0.5 lb/lb or less. Based on economics, if the atomizer requires an atomizing air consumption of more than $0.5 \mathrm{Ib} / \mathrm{lb}$ to produce a reasonably fine spray. then it should not be used for duct injection applications.

The atomizers that were characterized by $B \& W$ were tested for droplet size distribution at B\&W's Alliance Research Center Atomization Facility (Appendix C). Droplet size was measured using the Malvern ST2600 Droplet and Particle size Analyzer. For the IIMB Humidification program atomizers, the Malvern instrument was equipped with a $300 \mathrm{~mm}$ lens, which provided a droplet size range of 5 to 550 microns. For the G/C atomizer characterization, the Malvern instrument was equipped with a $600 \mathrm{~mm}$ lens, which provided a droplet size range of 11 to 1100 microns. The measured data was reduced to a droplet size distribution using the Malvern ST2600 Model Independent analysis software.

The droplet size data for the atomizers characterized by UCICL were measured with an Aerometrics Model 2100 single component phase Doppler 
instrument. Unlike the Malvern laser diffraction instrument, which measures a spatially averaged droplet size across the entire spray, the phase Doppler technique measures the droplet size within a very small probe volume. For this comparison, the individual droplet size measurements were area-weighted over the spray cross-section to determine composite average diameters.

Table 3.2 summarizes the droplet size distribution data for the 22 candidate atomizers. The atomizers in this table have been classified by liquid capacity as high, medium, and low capacity. High capacity refers to atomizers with nominal liquid flow rates between 1 and $3 \mathrm{gpm}$. Medium capacity refers to atomizers with nominal fiow rates between 0.2 and $1 \mathrm{gpm}$. Low capacity includes atomizers with nominal liguid flows of less than $0.2 \mathrm{gpm}$. All atomizers were tested with water. Table 3.2 includes the atomizing air flow rate and pressure, the water flow rate and pressure, the air-to-liquid mass ratio ( $A / W$ ratio), the sauter Mean and Mass Median diameter, and two large droplet mass fractions. The last column in Table 3.2 lists the source of data for each atomizer, the spray droplet size measurement location, and the operating conditions for those atomizers that were used at a given pilot facility.

Referring to Table 3.2 , the large droplet mass fractions are presented as weights above nominal $80 \mu$ and $100 \mu$. Because of the two different lenses used during the LIMB and G/C characterizations, $80 \mu$ will refer to either $84 \mu$ (IIMB) or $78 \mu(\mathrm{G} / \mathrm{C})$ and $100 \mu$ will refer to either $113 \mu$ (IIMB) or $100 \mu$ (G/C). The large droplet mass fraction $d$. are not included in Table 3.2 for the atomizers tested by UCICL becaust this information was not reported with the other UCICL data.33 select UCICL large droplet mass fraction data will be reported later in this section for the UCICI atomizers with the lowest sauter Mean diameter.

Figure 3.1 shows the Sauter Mean diameter as a function of air-to-water mass flow ratio ( $\mathrm{A} / \mathrm{W}$ ratio) for the high capality (1-3 gpm) atomizers tested by B\&W. Figure 3.2 shows the large droplet mass fraction (nominal $100 \mathrm{microns}$ ) as a function of $\mathrm{A} / \mathrm{W}$ ratio for these atomizers. Referring to Figure 3.2 , the large droplet mass fraction refers to a mass percent over 100 microns for all the atomizers except the Heat systems $1100-1$ and the Delavan Swirl Air. For these last two atomizers, the large droplet mass fraction refers to a mass percent over 113 microns.

Referring to Figure 3.1, none of the high capacity atomizers tested by $B \& W$ had Sauter Mean diameters that were less than or equal to 25 microns at an $A / W$ ratio of $0.5 \mathrm{lb} / \mathrm{lb}$ or less. The three high capacity atomizers with the lowest sauter Mean diameters were the $B \& W$ Durajet Mk4, the B\&W Durajet Mk7, and the Lechler 170.961.17. At an A/W ratio of $0.5 \mathrm{Ib} / \mathrm{lb}$, these three atomizers had Sauter Mean diameters of 28.5 , 30.9 , and 37.3 microns, respectively. This result indicates that these atomizers will probably not meet the large droplet mass fraction criturion of less than 18 over 100 microns required for atomizers to be used in flues with residence times of 1 second or less. Referring to Figure 3.2 , the large droplet mass fractions for the BhW DuraJet Hk4, the BaW Durajet MK7, and the Lechler 170.961 .17 were $2.78,4.48$, and 7.88 mass over 100 microns.

The Lechler 170.961 .17 atomizer and the B\&W Durajet Mk7 have capacities similar to those required by Gilbert/Commonwealth for the Beverly, onio, test facility. These atomizers have been compared in the past as candidates for this facility (see Appendix A). The Lechler 


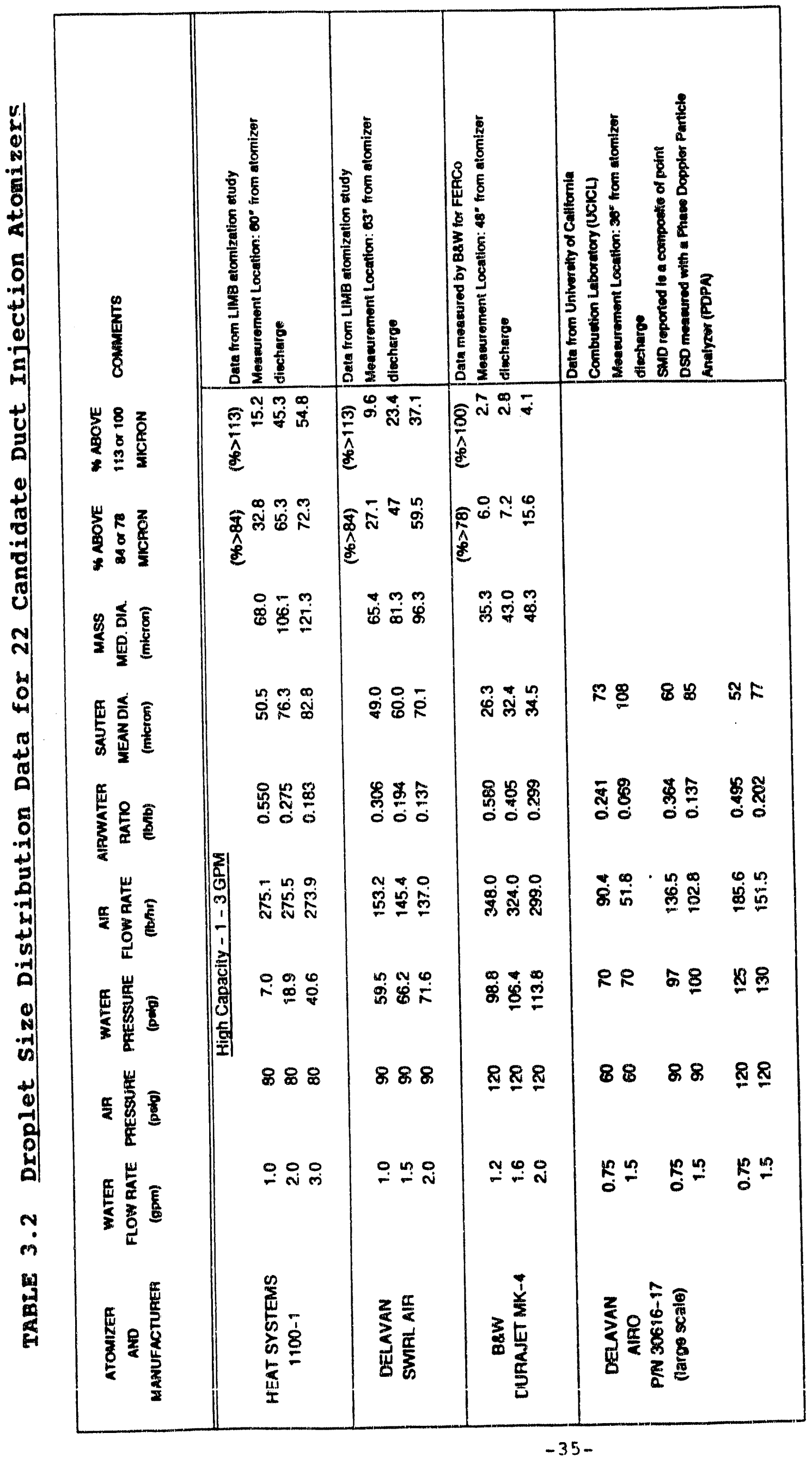




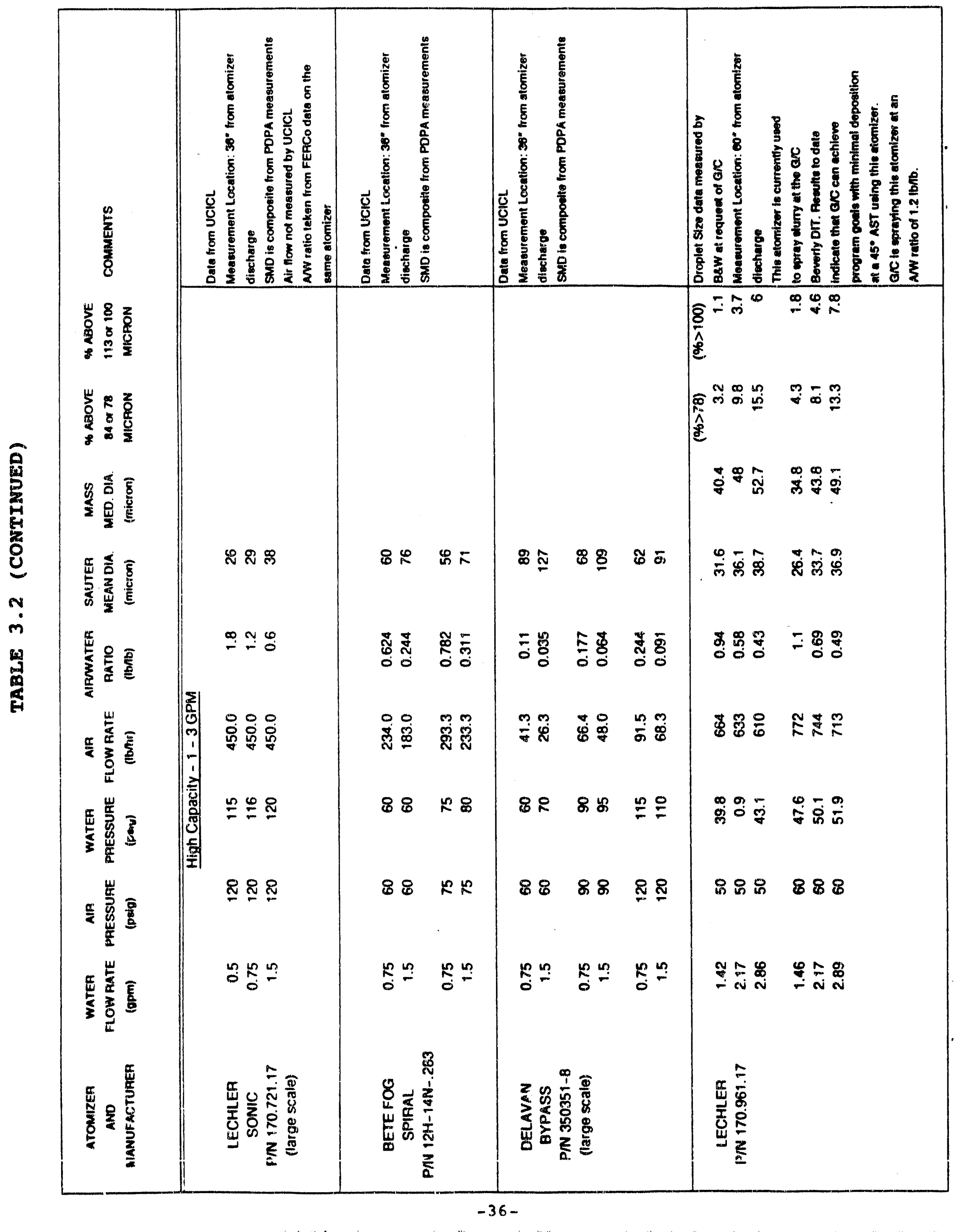




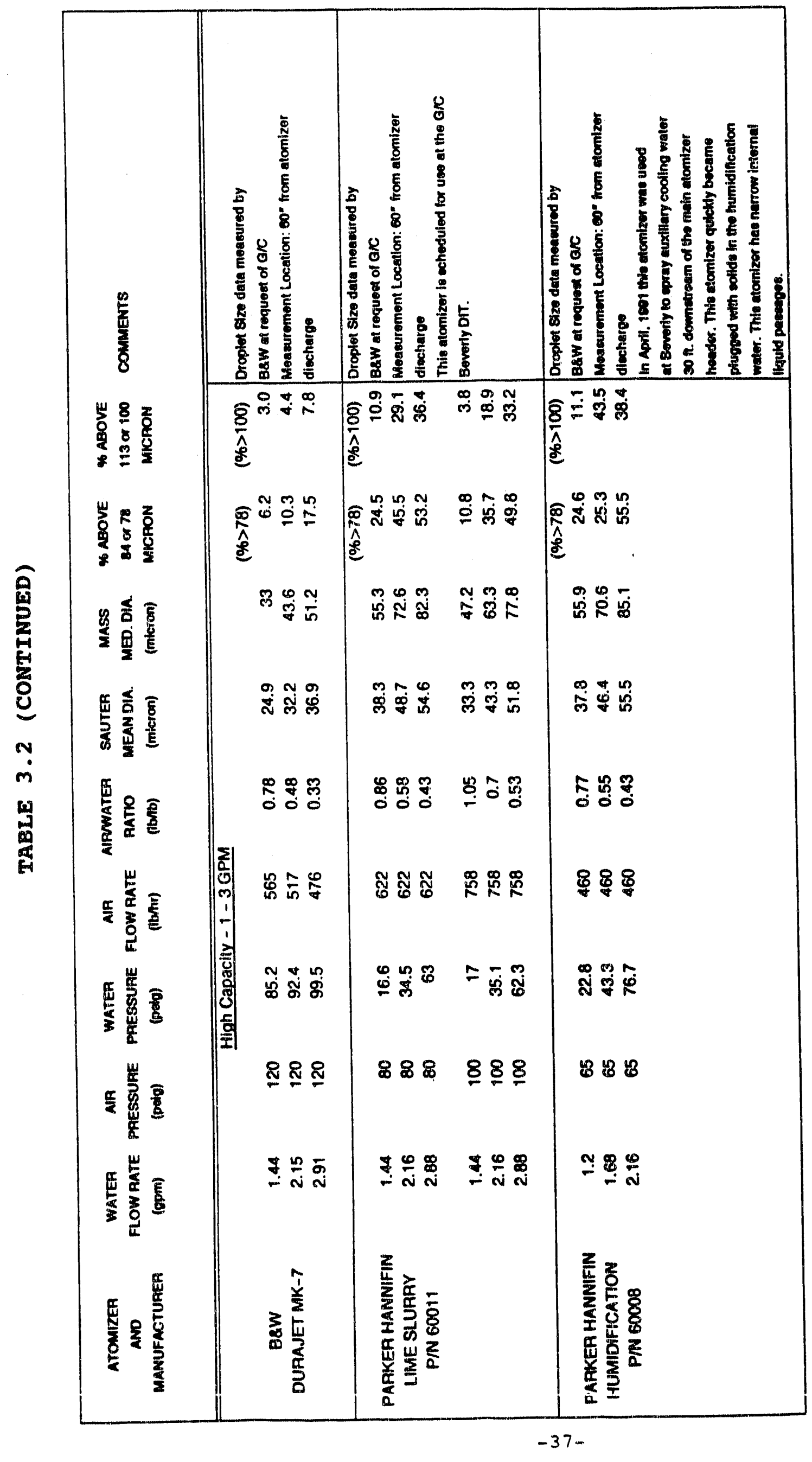




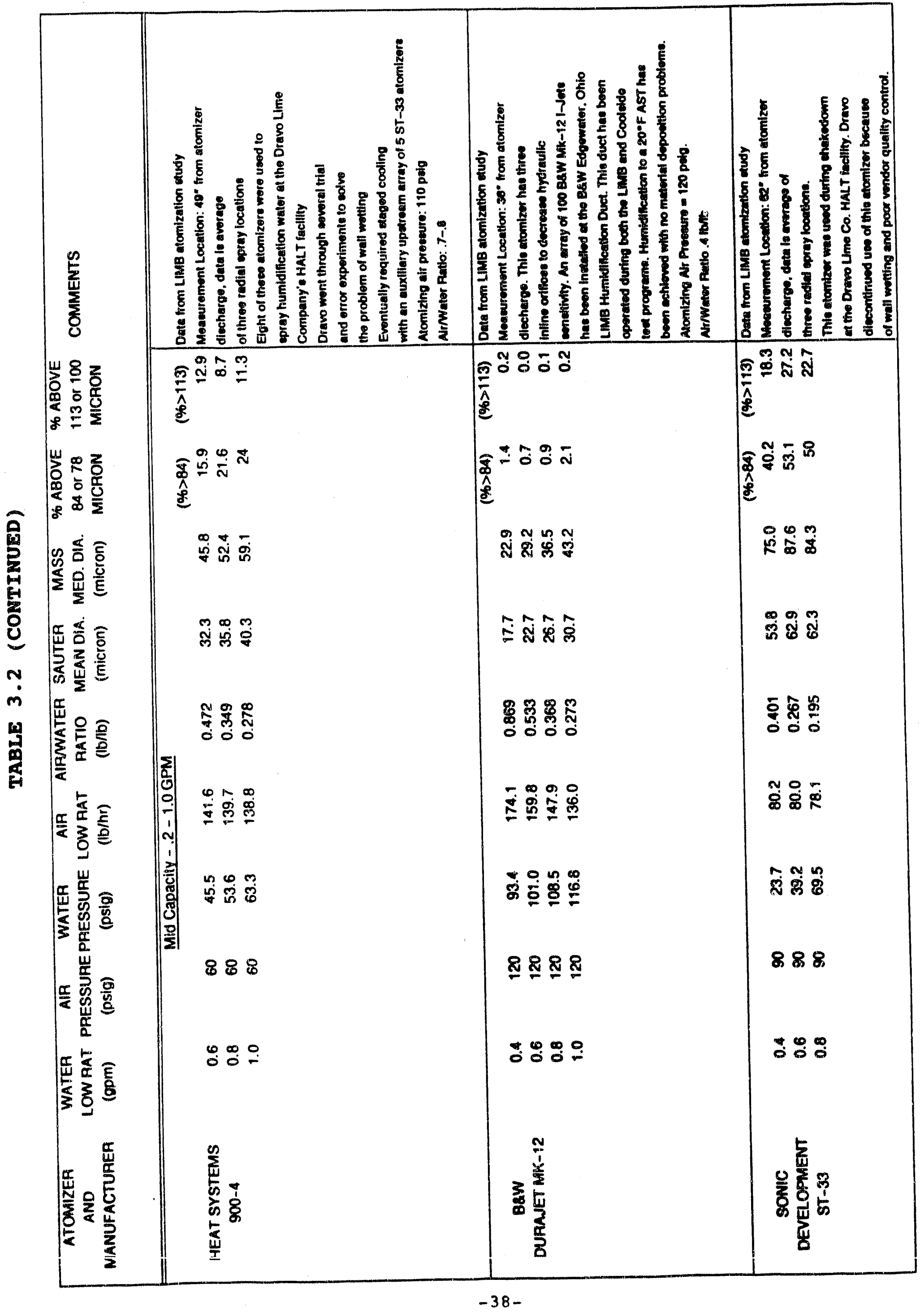




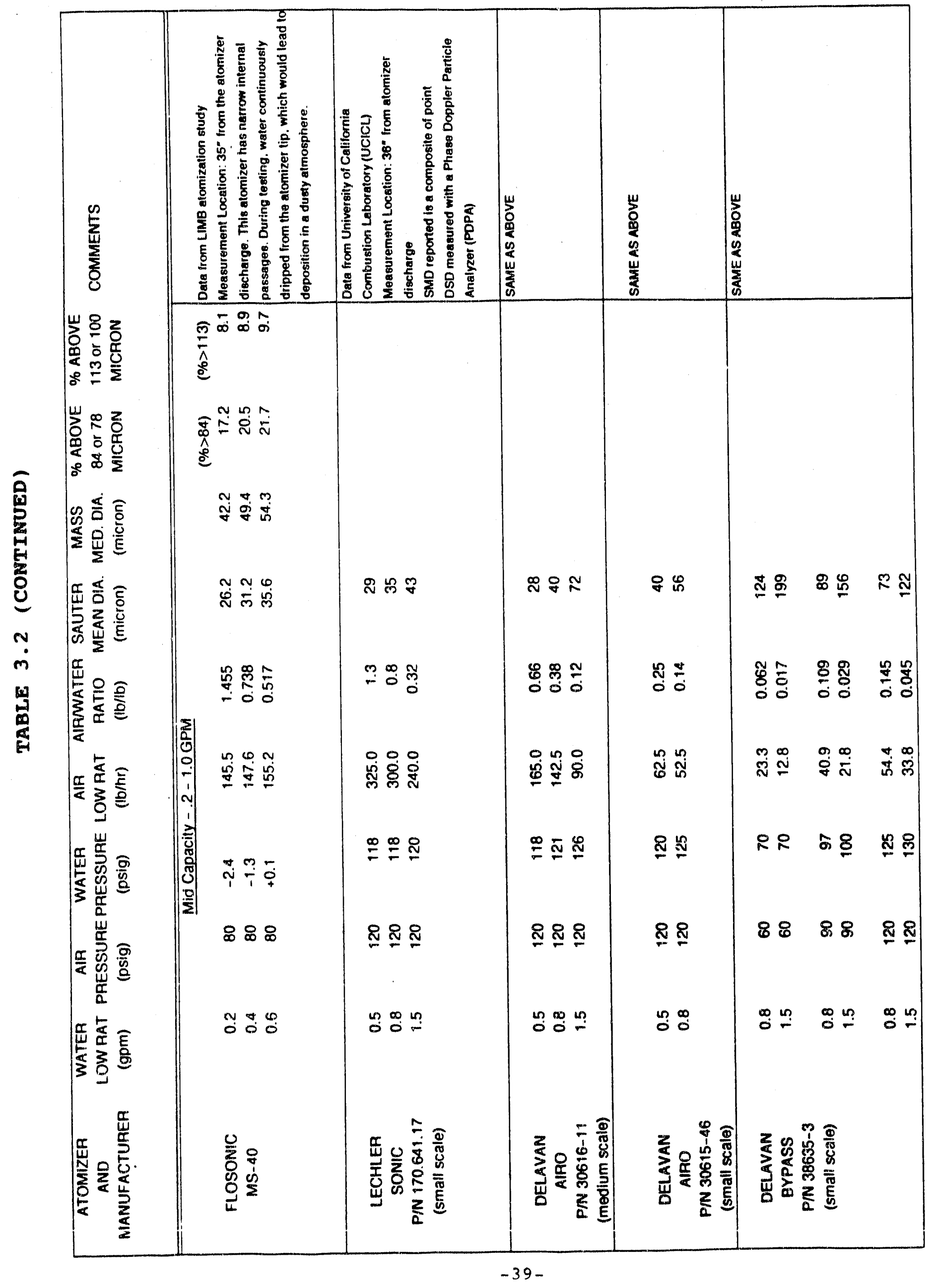




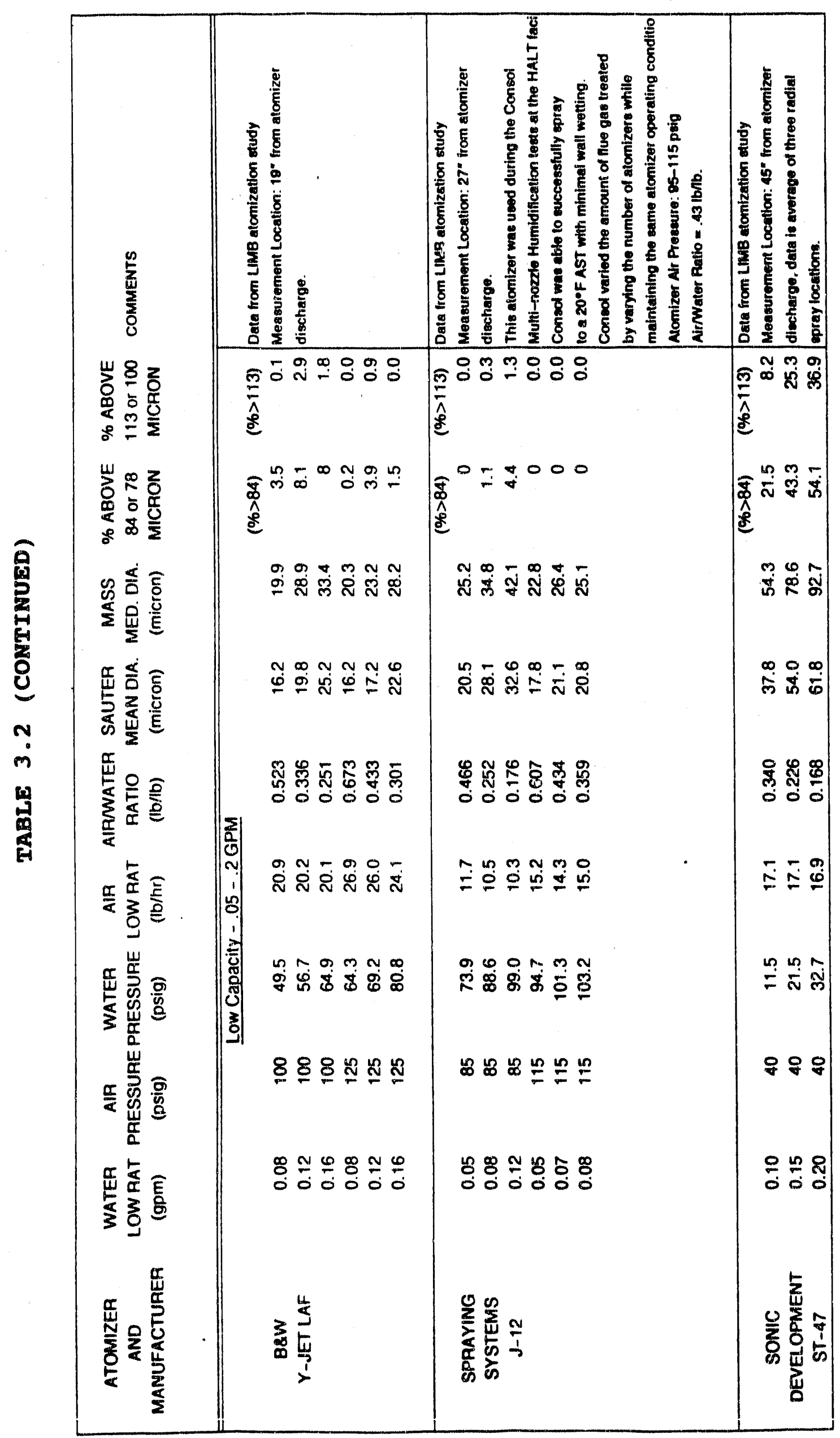




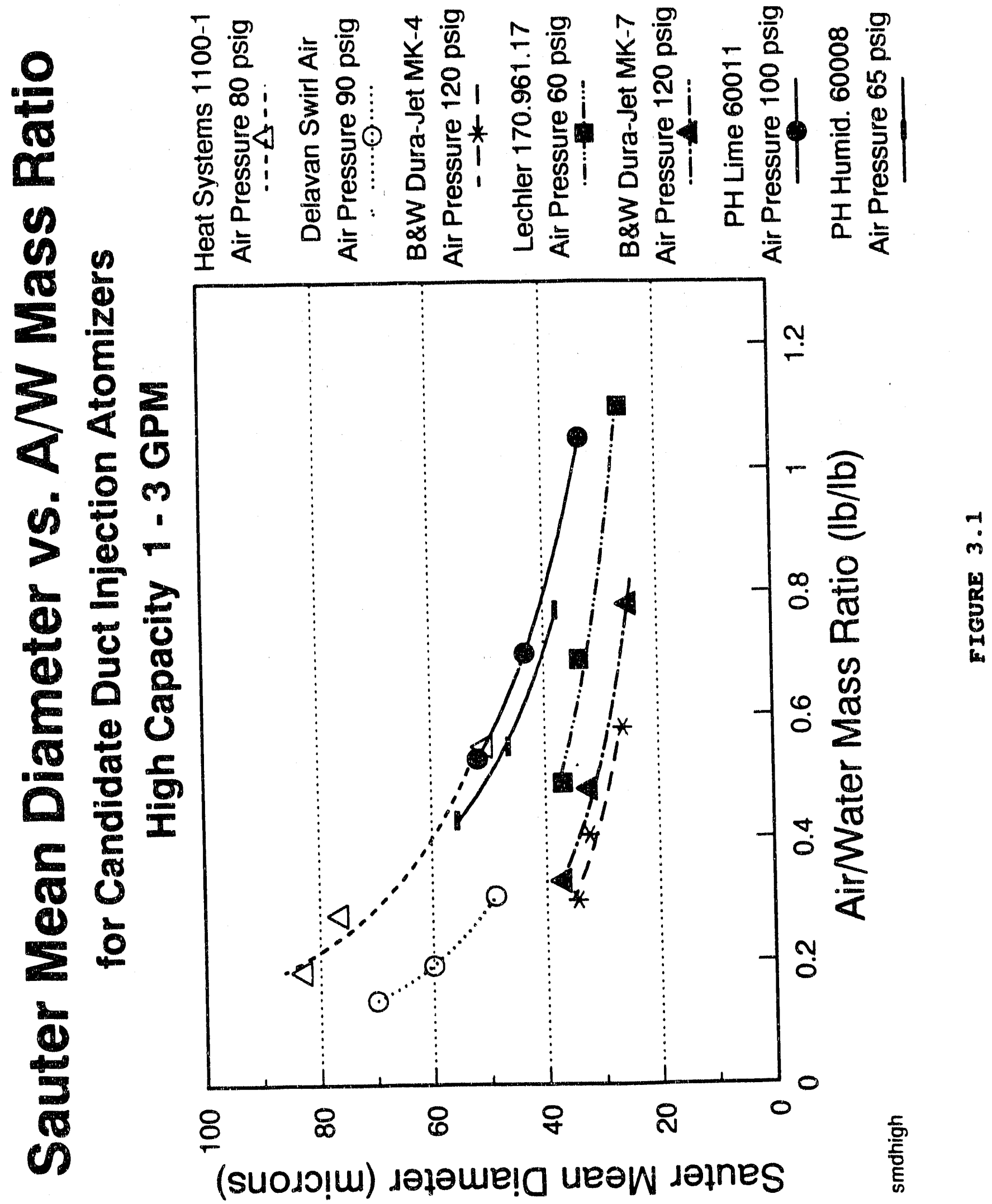




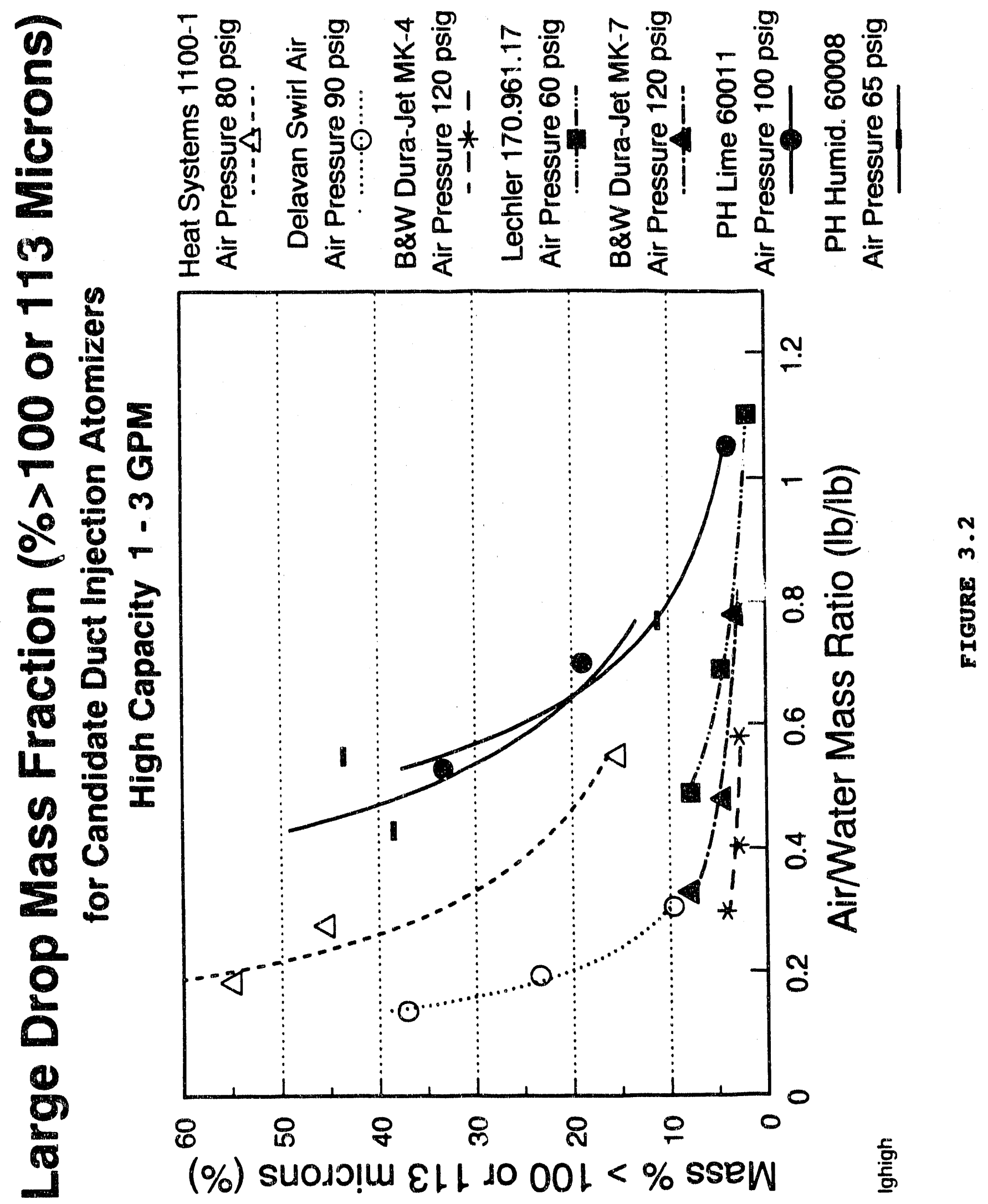


atomizer was chosen for use at the facility. The comparison showed that at a given $A / W$ ratio, the drop sizes for the Lechler atomizer are 5 to 7 microns greater than for the Durajet. Comparison of the droplet size performance on the basis of $A / W$ ratio is a measure of the relative efficiency of the atomizers. However, the $A / W$ ratio does not account for differences in atomizing air pressure that ultimately affect the cost of the atomizing air. The $B \& W$ DuraJet Mk7 was designed to operate at an atomizing air pressure of 120 psig, and the Lechler 170.961.17 was designed to operate at an atomizing air pressure of $60 \mathrm{psig.} \mathrm{So,}$ a.) though the Durajet requires less air flow than the Lechler to achieve a given sauter mean diameter, it also requixes a higher air pressure.

Differences in atomizing air pressure can be inciuded in atomizer comparisons by multiplying the $A / W$ ratios of a given atomizer by the specific energy (Btu per Ib. of air) required to compress the air. Based on two-stage adiabatic compression, the B\&W Durajet atomizer has a specific energy of $84.3 \mathrm{Btu} / \mathrm{lb}$ air, and the Lechler has a specific energy of $69.4 \mathrm{Btu} / \mathrm{lb}$ air. When droplet size performance for the Lechler and Mk7 DuraJet were compared from a required energy standpoint, the relative ranking remained the same, but the difference in performance between the two atomizers was reduced considerably.

Figure 3.3 shows the Sauter Mean diameter as a function of air-to-water mass flow ratio ( $\mathrm{A} / \mathrm{W}$ ratio) for the medium capacity $(0.2-1$ gpm) atomizers tested by $B \& W$. Figure 3.4 shows the large droplet mass fraction as a function of $\mathrm{A} / \mathrm{W}$ ratio for these atomizers. The large droplet mass fraction data presented in Figure 3.4 refers to a mass. percent over 113 microns.

Referring to Figure 3.3, of the four mid-capacity atomizers tested by $B \& W$, only the $B \& W$ DuraJet $M k 12$ had a sauter Mean diameter less than or equal to 25 microns at an $A / W$ ratio of $0.5 \mathrm{lb} / \mathrm{lb}$ or less. At an $A / W$ ratio of $0.5 \mathrm{lb} / \mathrm{lb}$, the $B \& W$ Durajet Mk12 had a Sauter Mean diameter of 23.5 microns. In terms of Sauter Mean diameter, the mid-capacity atomizer with the second best performance was the Heat systems 900-4, which had a Sauter Mean diameter of 31.3 microns at an $A / W$ ratio of 0.5 Ib/lb. Referring to Figure 3.4 , for an $A / W$ ratio of $0.5 \mathrm{lb} / \mathrm{lb}$, the large droplet mass fractions for these two atomizers are 0.08 mass over 113 microns for the $B \& W$ Durajet Mk12 and $11 \%$ mass over 113 microns for the Heat systems $900-4$.

Figure 3.5 shows the Sauter Mean diameter as a function of air-to-water mass flow ratio ( $\mathrm{A} / \mathrm{W}$ ratio) for the low capacity (less than $0.2 \mathrm{gpm}$ ) atomizers tested by $\mathrm{B} \delta \mathrm{W}$. Figure 3.6 shows the large droplet mass fraction as a function of $A / W$ ratio for these atomizers. The large droplet mass fraction data presented in Figure 3.6 refers to a mass percent over 113 microns. Referring to Figure- 3.5 and 3.6 , the B\&W Y-Jet IAF and the Spraying Systems J-12 atomizer both meet the droplet siza distribution restraint for atomizers in flues with less than 1 second residence time. At an $A / W$ mass ratio of $0.51 \mathrm{~b} / \mathrm{lb}$, the $\mathrm{J}-12$ atomizer has a Sauter Mean diameter of 19 microns and a large droplet mass fraction of 0.08 mass over 113 microns. Similarly, the B\&W $Y-J e t$ LAF has a Sauter Mean diameter of 17 microns and a large droplet mass fraction of 0.58 over 113 microns. The J-12 atomizer was used by Consol during the Multi-Nozzle Humidification tests at the HALT facility.

Figure 3.7 shows the composite sauter Mean diameter for those atomizers tested by the University of California, Irvine Combustion Laboratory (UCICL.)"3 These atomizers were candidates for Radian's 


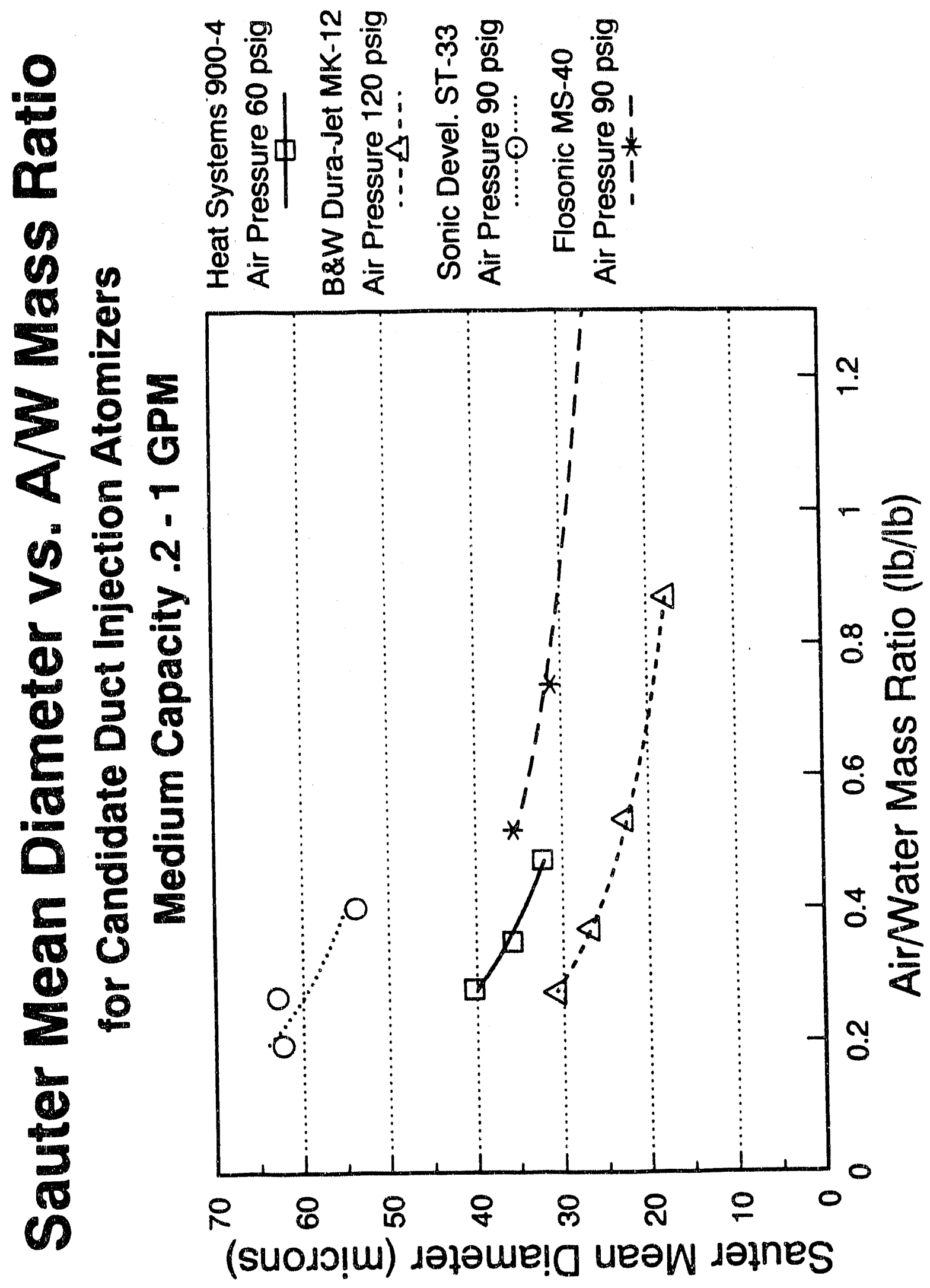

m

 


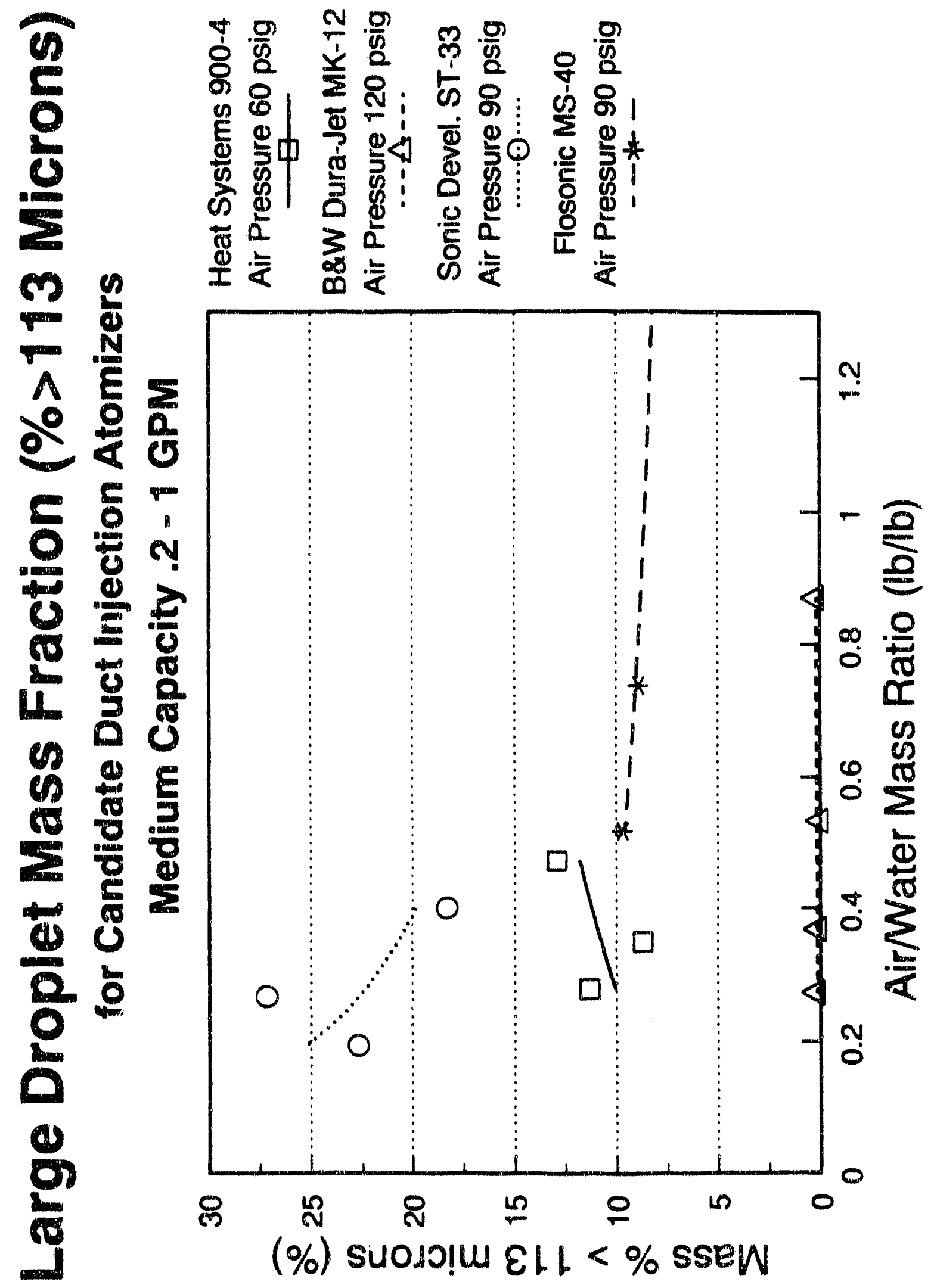

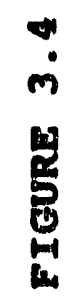




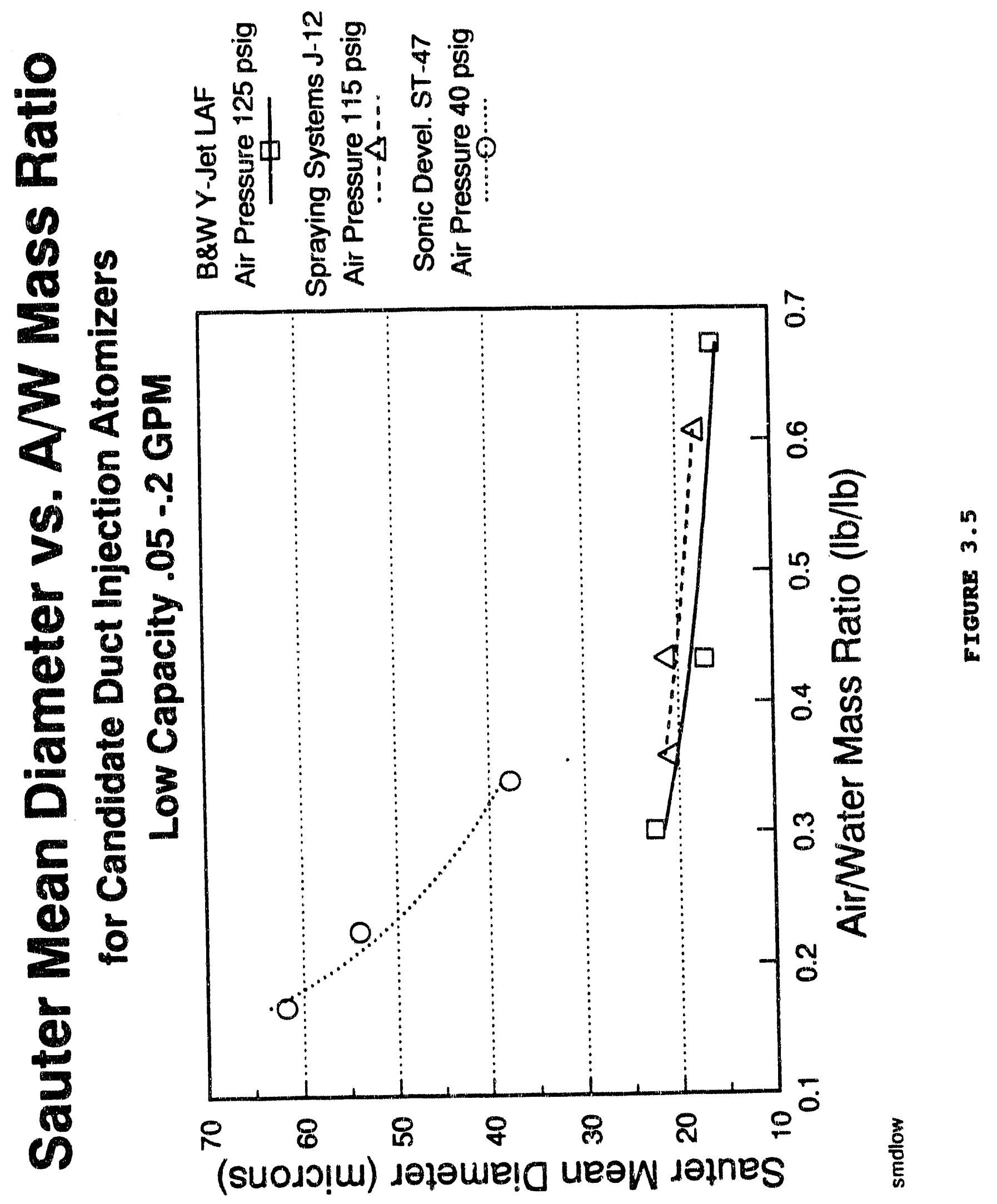




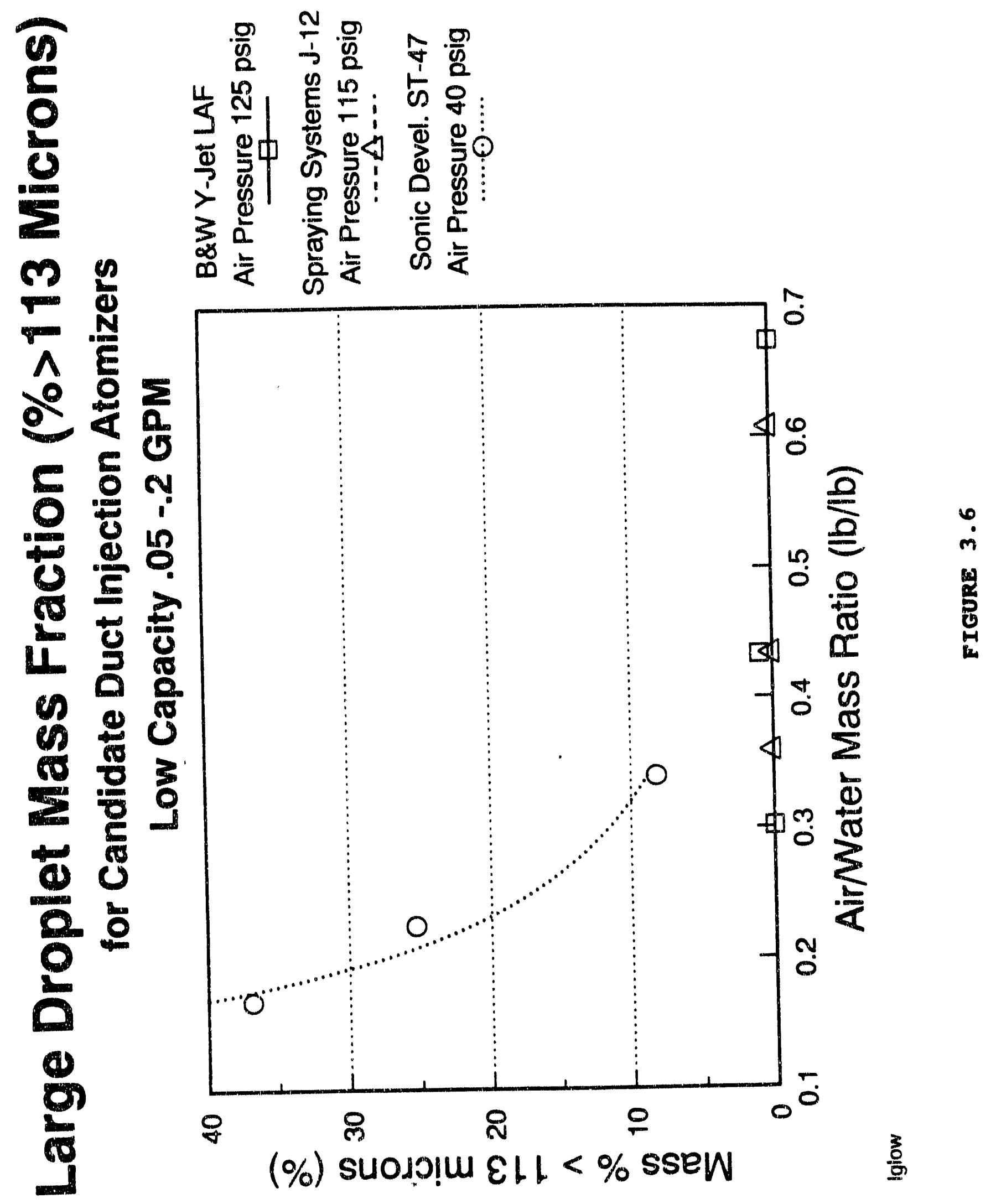




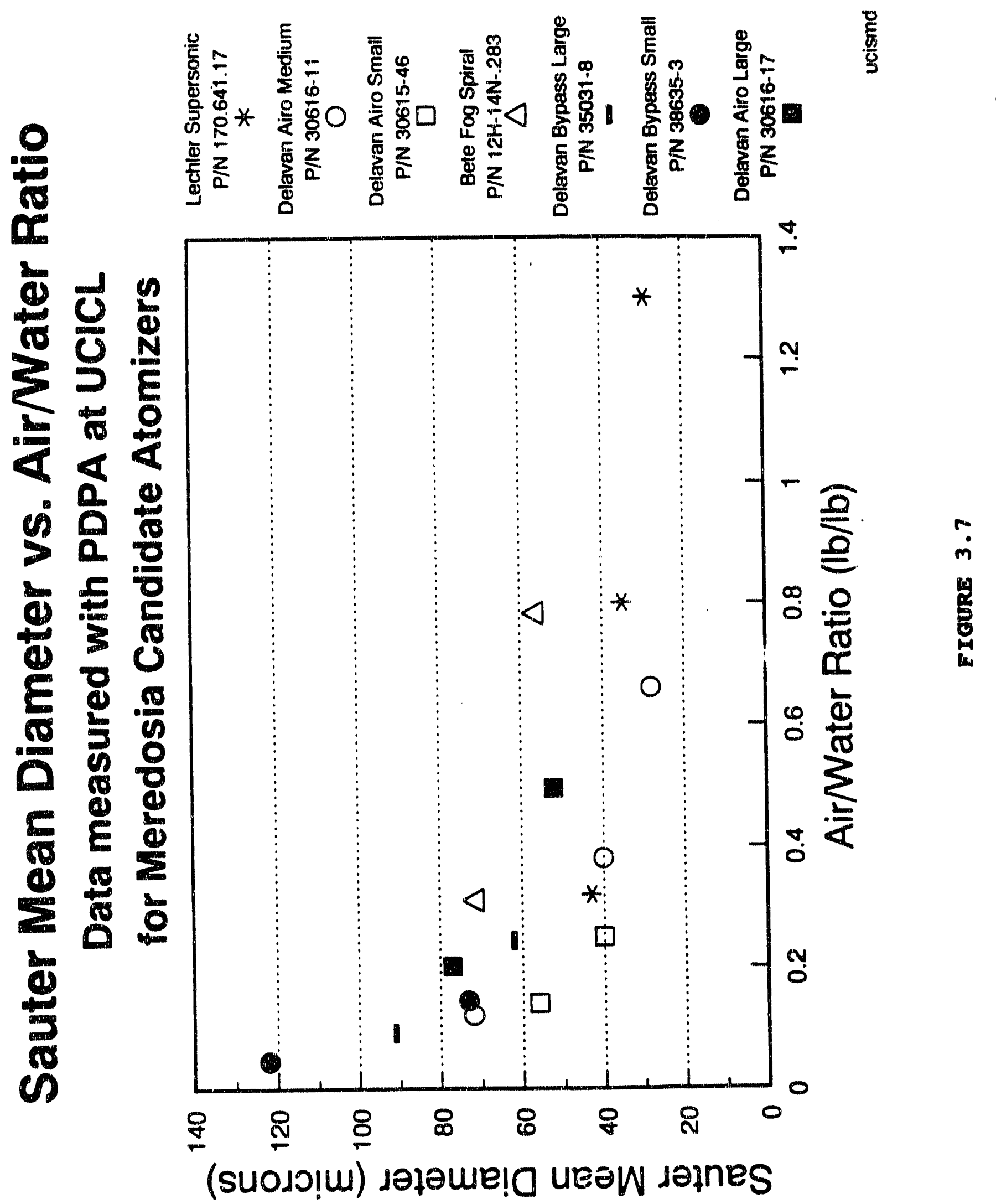


Meredosia facility, which required a $1.5 \mathrm{gpm}$ atomizer. All the atomizers were tested at atomizing ais pressures of 120 psig because this was the air pressure supplied at the Meredosia facility.

Referring to Figure 3.7 , none of the atomizers tested by UCICI had sauter Mean diameters that were less than or equal to 25 microns at an $\mathrm{A} / \mathrm{W}$ ratio of $0.5 \mathrm{lb} / \mathrm{lb}$ or less. The three Meredosia candidate atomizers with the lowest sauter Mean diameters were the Delavan Airo Medium 30616-11, the Delavan Airo Small 30615-46, and the Lechler supersonic 170.641.17. The Lechler atomizer tested by UCICL had about half the capacity of the Lechler atomizer tested by $B d W$. At an $A / W$ ratio of 0.5 $1 b / 1 b$, the sauter Mean diameters for the Delavan Airo Medium and the Lechler Supersonic were about 33 and 38 microns, respectively. The sauter Mean diameter for the Delavan Airo Small'was 40 microns at an $A / W$ ratio of $0.25 \mathrm{lb} / \mathrm{lb}$.

Figure 3.8 shows the composite large droplet mass fraction (mass greater than 100 microns) for the three Meredosia candidate atomizers discussed above. From Figure 3.8 , the data for these atomizers indicate that at an $A / W$ ratio of $0.5 \mathrm{lb} / \mathrm{lb}$, the Delavan Airo Medium had about 0.78 of the spray mass in droplets over 100 microns, and the Lechler had about 0.98 of the spray mass in droplets over 100 microns. At an $A / W$ ratio of 0.25 , the Delavan Airo small had 0.88 of the spray mass in droplets over 100 microns.

Table 3.3 summarizes the droplet size performance for those atomizers that behaved best from each of the capacity groups tested by B.W and for the atomizers tested by UCICI. Table 3.3 shows the water flow rate, sauter Mean diameter, and large droplet mass fraction at an $\mathrm{A} / \mathrm{W}$ ratio of $0.5 \mathrm{lb} / \mathrm{lb}$ for each atomizer, except the Delavan Airo small $30615-46$ which was tested at a maximum $\mathrm{A} / \mathrm{W}$ ratio of $0.25 \mathrm{lb} / \mathrm{lb}$. The water flow rate for each atomizer is given to provide an assessment of the relative capacity of each atomizer at the maximum recommended air consumption.

Referring to Table 3.3 , of the 22 candidate atomizers, only 9 came close to meeting the droplet size distribution criteria developed during this program. Of the atomizers tested by $B \& W_{\text {, only the } B \& W \text { Durajet }}$ Mk12, the spraying Systems J-12, and the B\&W $Y-J e t$ IAF have large droplet mass fractions small enough to meet the requirements for flues with residence times of 1 second or less, when the reasonable air consumption constraint is applied. The data reported by UCICL ${ }^{34}$ indicate that all three Meredosia candidate atomizers listed in Table 3.3 have composite large droplet mass fractions which meet the 1 second residence time flue requirement. This result is surprising, since the sauter Mean diameters for these three atomizers are comparable to the Lechler 170.961 .17 and the $B \& W$ DuraJet Mk7 and MK4 atomizers tested by B\&W. It is recommended that additional testing be performed on these Meredosia candidate atomizers before they are included in a list of atomizers appropriate for flues with 1 second or less residence times.

Referring to Table 3.3 , the three atomizers tested by B\&W which meet the 1 second residence time criteria have relatively small capacities. For example, the B\&W Durajet MK12 has a nominal flow rate of $0.8 \mathrm{gpm}$. This result suggests that a limit in the atomizer liquid capacity to below I gpm may be required for flues with less than 1 second residence times and approach-to-saturation temperatures of $20^{\circ} \mathrm{F}$. However, further investigation will be required to substantiate this hypothesis. 


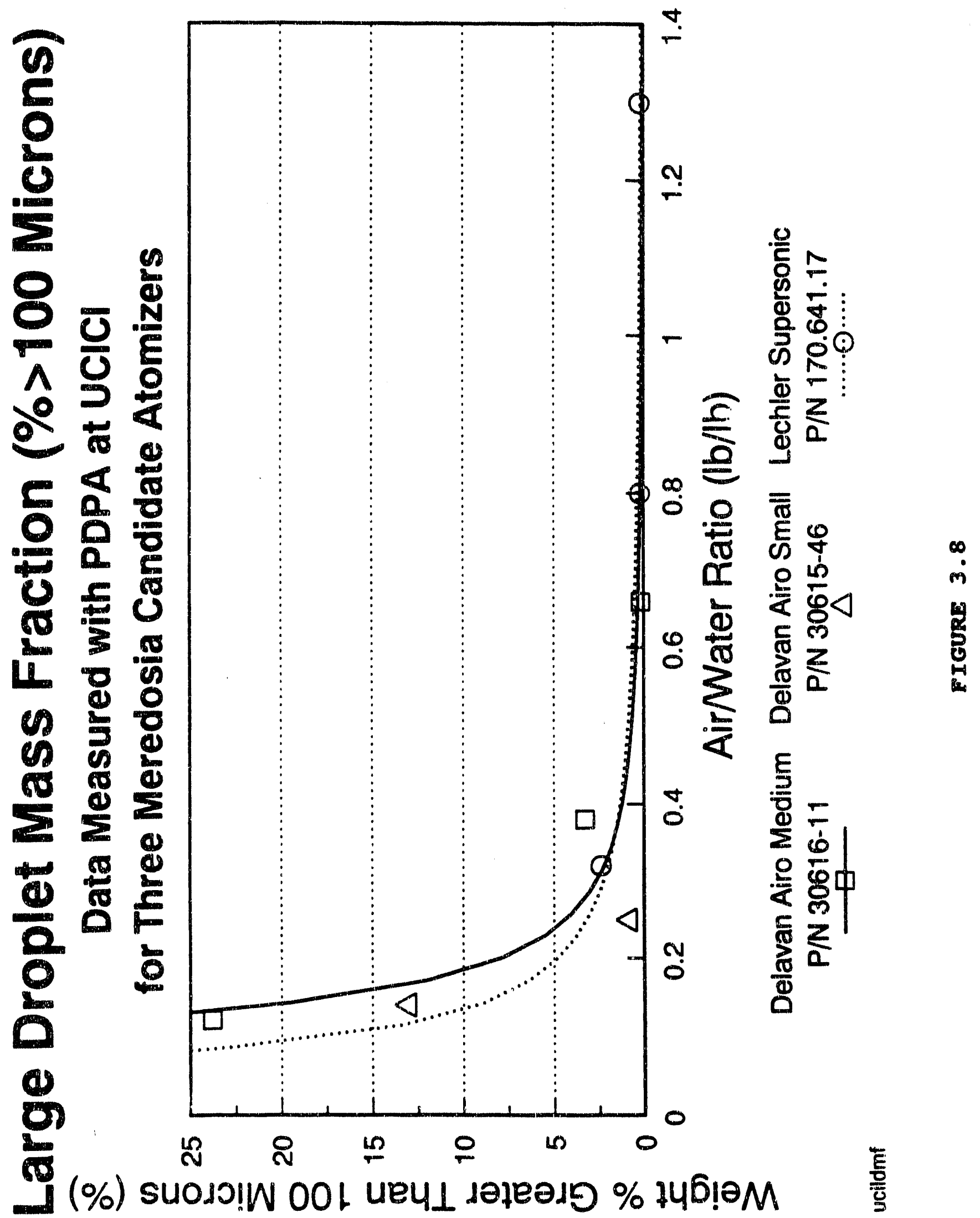




\begin{tabular}{|c|c|c|}
\hline \multicolumn{3}{|c|}{$\begin{array}{c}\text { Large Droplet Mass Fraction and sauter Mean Diameter } \\
\text { at an A/W Ratio of } 0.5 \mathrm{lb} / 1 \mathrm{~b} \text { for } \\
\text { "Best" Candidate Duct Injection Atomizers }\end{array}$} \\
\hline Atomizer and Air Pressure & $\begin{array}{l}\text { Water Flow Rate } \\
(\mathrm{gpm})\end{array}$ & $\begin{array}{l}\text { Large Droplet Mass } \\
\text { Fraction and 8MD }\end{array}$ \\
\hline Atomizers Tested by BCW & & \\
\hline $\begin{array}{l}\text { Lechler } 170.961 .17 \\
(60 \text { psig) } \\
\text { B\&W Durajet Mk7 } \\
\text { (120 psig) } \\
\text { B\&W Durajet Mk4 } \\
\text { (120 psig) } \\
\text { B\&W DuraJet Mk12 } \\
\text { ( } 120 \text { psig) } \\
\text { Spraying Systems J-12 } \\
\text { (115 psig) } \\
\text { B\&W Y-Jet } \\
(125 \text { psig) }\end{array}$ & $\begin{array}{l}1.3 \\
0.60 \\
0.07\end{array}$ & $\begin{array}{l}7.88>100 \text { microns } \\
\text { SMD }=37.3 \text { microns } \\
4.48>100 \text { microns } \\
\text { SMD }=30.9 \text { microns } \\
2.78>100 \text { microns } \\
\text { SMD }=28.5 \text { microns } \\
0.08>113 \text { microns } \\
\text { SMD }=23.5 \text { microns } \\
0.08>113 \text { microns } \\
\text { SMD }=19 \text { microns } \\
0.58>113 \text { microns } \\
\text { SMD }=17 \text { microns }\end{array}$ \\
\hline Atomizers Tested by UCICL & & \\
\hline $\begin{array}{l}\text { Delavan Airo } 30616-11 \\
\text { Medium (120 psig) } \\
\text { Delavan Airo } 30615-46 \\
\text { Small ( } 120 \text { psig) } \\
\text { Lechler supersonic } \\
170.641 .17 \\
(120 \text { psig) }\end{array}$ & $\begin{array}{c}\quad 0.5 \\
\text { at } A / W=0.25 \\
1.72\end{array}$ & $\begin{array}{l}0.78>100 \text { microns } \\
\text { SMD }=33 \text { microns } \\
0.88>100 \text { microns } \\
\text { SMD }=40 \text { microns } \\
\text { at } A / W=0.25 \\
0.98>100 \text { microns } \\
\text { SMD }=38 \text { microns }\end{array}$ \\
\hline
\end{tabular}

One hundred ten (110) B\&W Durajet Mk12 atomizers were used successfully to spray humidification water to a $20^{\circ} \mathrm{F}$ approach-tosaturation temperature at the 105 MW LIMB tumidicant material humidification level was achieved with no significant the residence deposition problems. However, it should bout 2.5 seconds. 3.5 A Comparison of Candidate Duct Injection Atomizers on the Basis of

Pluggage of the internal air and liquid passages of dual-fluid atomizers may severely change the hydraulic and droplet size characteristics and cause flow maldistributions among atomizers in an array. Atomizers with narrow internal passages should not be used to spray unfiltered humidification water or unstrained slurry. 
of th $a$ nine candidate atomizers that had the best droplet size performance, only the Lechler and $B \& W$ Durajet have internal passages that are wide enough to avoid atomizer pluggage from solids in the slurry or unfiltered humidification water that might exist in a commercial application. Both the B\&W Y-Jet LAF and the Spraying systems J-12 are small capacity atomizers with extremely narrow internal passages, and should not be considered for use in the slurry or humidification atomizer array that would be required for a full-scale application. The Delavan Airo appears to also have very narrow internal passages, which may result in pluggage.

Material deposition on the atomizer tip must be avoided because it can lead to partial or complete pluggage and a degradation in the droplet size and hydraulic characteristics of the atomizer. This pluggage will result in flow maldistributions for atomizers in an array. Deposition on the atomizer tip may reduce spray quality and cause dripping.

With in-duct injection of slurry, material deposition on the atomizer can be caused by the sudden expansions of air/slurry mixture leaving the atomizer. Recent improvements in the DuraJet atomizer exit hole design have reduced this type of slurry deposition on the atomizer tip. ${ }^{35}$ These improvements have been tested on the pilot level and have been shown to work. ${ }^{36}$ The Lechler atomizer has not shown any tendency to develop this sort of deposition during slurry spray tests at the Beverly facility. There is no data on the Delavan Airo atomizer's performance with regards to this type of deposition.

With dry lime injection upstream of humidification, atomizers are exposed to a high solids content flue gas stream. The flow patterns within the flue and around the atomizer array may cause material deposition on the atomizer tip. Atomizers and headers are sites for water condensation, and solid particulate in the flue gas is likely to stick to wet atomizer components.

One method to reduce deposition on the atomizer tip is through the use of shielding devices. Commercial atomizers generally do not come equipped with a device to prevent buildup on the atomizer tip. A candidate atomizer should not be considered for use in a duct injection application unless it can be fit into an effective shielding device, or has been proven not to have a tendency toward material buildup.

The B\&W Durajet is designed to be -anifolded into an array with an airfoil-shaped lance. The atomizer hol $\mathrm{s}$, called nacelles, provide shield air to each atomizer. This shie. air protects against solids buildup. The airfoil-shaped lance has an aerodynamic design, and minimizes pressure drop and recirculation across the atomizer axray. The effectiveness of the B\&W airfoil lance design has been demonstrated on a commercial scale during both LIMB and Coolside, where it was used in a 100 atomizer array humidification system at ohio Edison's Edgewater station.11,12

The Lechler and Delavan Airo atomizers have not been designed for use with a shielding device. The Lechler atomizer has not, however, shown a tendency toward tip deposition at the Gilbert/Commonwealth duct injection test facility. It is not known at this time whether material deposition will be problem for this atomizer in commercial-scale application. 
During the Meredosia $1.7 \mathrm{MW}$ pilot tests conducted by Radian, the Delavan Airo atomizer showed a tendency to accumulate tip deposition from the high solids flue gas." ${ }^{14}$ Efforts to install a shielding device only proved marginally successful. The Delavan Airo atomizer probably should not be used in a commercial application unless it can be fit into an effective shielding device.

In summary, of the nine atomizers that performed best on droplet size distribution, only the Lechler and $B \& W$ DuraJet have not shown operational difficulties caused by atomizer tip deposition and pluggage.

\subsection{A Comparison of the Lechlor and BEW Durajet Atomizers on the Basis of Spray Anqle and Droplet Trajectory}

Droplet trajectory influences atomizer performance because the initial direction of the high velocity spray can result in direct impingement of water or slurry on flue walls. In contrast, it is imperative that the spray adequately mix with the surrounding flue gas so that complete drying of the droplets can occur in the limited available residence time.

In order to avoid wall wetting and wet solids deposition, the candidate atomizer must produce a spray with an included spray angle of $30^{\circ}$ or less. If the spray angle is more than $30^{\circ}$, then the atomizer should not be used for duct injection applications. The maximum tolerable spray angle will depend in part on atomizer-to-wall clearances within the flue.

For the lechler and $B \& W$ DuraJet, superficial spray angles were measured from photographs of the spray trajectories for the two atomizers. ${ }^{32}$ The B\&W DuraJet has an included spray angle of $22^{\circ}$. The Lechler atomizer has an included spray angle of $14^{\circ}$. During the comparison tests performed by $B \& W$ for Gilbert/Commonwealth, it was noted that the most visible difference in the operation of the Lechler and $B \& W$ Durajet Mk7 atomizers was the characteristics of the spray pattern. ${ }^{32}$ The spray boundary of the DuraJet expands rapidly near the discharge of the atomizer, followed by a gradual expansion with axial distance. coincident with the rapid expansion is an apparent reduction in spray velocity. Conversely, the lechler atomizer has a very narrow concentrated spray at the atomizer discharge that expanded slowly with distance.

\subsection{A Comparison of the Lechler and BEW Durajet Atomizers on the Basis of Bydraulic Sensitivity}

If the candidate atomizer will be used in an array, then it must have a relatively low hydraulic sensitivity. Atomizers with high hydraulic sensitivities will be more likely to contribute to flow maldistributions across an array. One measure of an atomizer's sensitivity is the steepness of the slope of the liquid pressure-liquid flow curve at constant air pressure. Acceptable sensitivity will depend on both the geometry of the array and the process control scheme. For large arrays of atomizers, an estimate of maximum acceptable atomizer sensitivity is on the order of 58 of water flow per psi water pressure at full load.

With some atomizers, it will be possible to adjust the hydraulic sensitivity by increasing the single-phase liguid pressure drop between the manifold and the atomizer. The single-phase pressure drop can be 
increased by adding one or more orifice sections in the liquid line upstream of the atomizer. If the atomizer has an unacceptably high sensitivity, and if it is not possible to adjust this sensitivity, then the atomizer should not be used for duct injection applications.

The liquid pressure-liquid flow characteristics for the Lechler and B\&W Durajet atomizers are shown in Figure 3.9. The slopes of these pressure flow curves at full and half load are given in Table 3.4. The B\&W Mk12 Mini DuraJet atomizer was modified during the LIMB program to include three in-line orifices, because the original atomizer showed an unacceptably high sensitivity during initial tests. The other Durajet sensitivities listed in Table 3.4 do not reflect this modification.

\begin{tabular}{|c|c|c|c|}
\hline \multicolumn{4}{|c|}{$\begin{array}{l}\text { TABLE } 3.4 \\
\text { Liquid Pressure-Iiquid Flow sensitivities } \\
\text { of the Lechler and B\&W Mini Durajet } \\
\text { Atomizers at Full and Partial Load }\end{array}$} \\
\hline Atomizer & $\begin{array}{c}\text { Flow Rate } \\
\text { (gpm) }\end{array}$ & $\begin{array}{c}\text { slope } \\
(\mathrm{gpm} / \mathrm{psi})\end{array}$ & $\begin{array}{c}\text { slope } \\
\text { (8 of flow/psi) }\end{array}$ \\
\hline Lechler & $\begin{array}{l}1.46 \\
2.89\end{array}$ & $\begin{array}{l}0.28 \\
0.40\end{array}$ & $\begin{array}{l}198 \\
13.88\end{array}$ \\
\hline $\begin{array}{l}\text { B\&W Mk } 7 \\
\text { Mini Durajet }\end{array}$ & $\begin{array}{l}1.44 \\
2.91\end{array}$ & $\begin{array}{l}0.10 \\
0.11\end{array}$ & $\begin{array}{l}6.98 \\
3.88\end{array}$ \\
\hline $\begin{array}{l}\text { B\&W Mk } 4 \\
\text { Mini Durajet }\end{array}$ & $\begin{array}{l}1.2 \\
1.6\end{array}$ & $\begin{array}{l}0.05 \\
0.05\end{array}$ & $\begin{array}{l}4.08 \\
3.08\end{array}$ \\
\hline $\begin{array}{l}\text { B\&W MK1 } 2 \\
\text { Mini Durajet }\end{array}$ & $\begin{array}{l}0.4 \\
0.8\end{array}$ & $\begin{array}{l}0.03 \\
0.03\end{array}$ & $\begin{array}{l}7.58 \\
3.88\end{array}$ \\
\hline
\end{tabular}

Referring to Table 3.4 , all capacities of the BaW Mini Durajet exhibit an acceptable full load hydraulic sensitivity. The slope for the Lechler atomizer ranges between 13.88 and 198 of flow per psi, which is an unacceptably high hydraulic sensitivity. Use of the atomizer without modifications will likely lead to flow maldistribution problems, including atomizer overloading, local degradation of drop size, and local cold zones in the flue which may cause wall wetting and wet solids deposition. It is likely that the hydraulic sensitivity can be decreased by installing orifices in the liquid passages between the manifold and atomizer, which would increase the single-phase pressure drop upstream of the atomizers.

\subsection{Materials of Construction for the Lechler and Bcw Durajet Atonizers}

To minimize wear for both humidification and slurry atomizers, the materials of construction should be at least as corrosion-resistant as $316 \mathrm{ss}$ with ceramic inserts. If the candidate atomizer is not fitted with a wear-resistant material, it should not be used for duct injection applications. Both the B\&W Mini Durajet and the Lechler atomizers have been fitted with wear-resistant materials. 


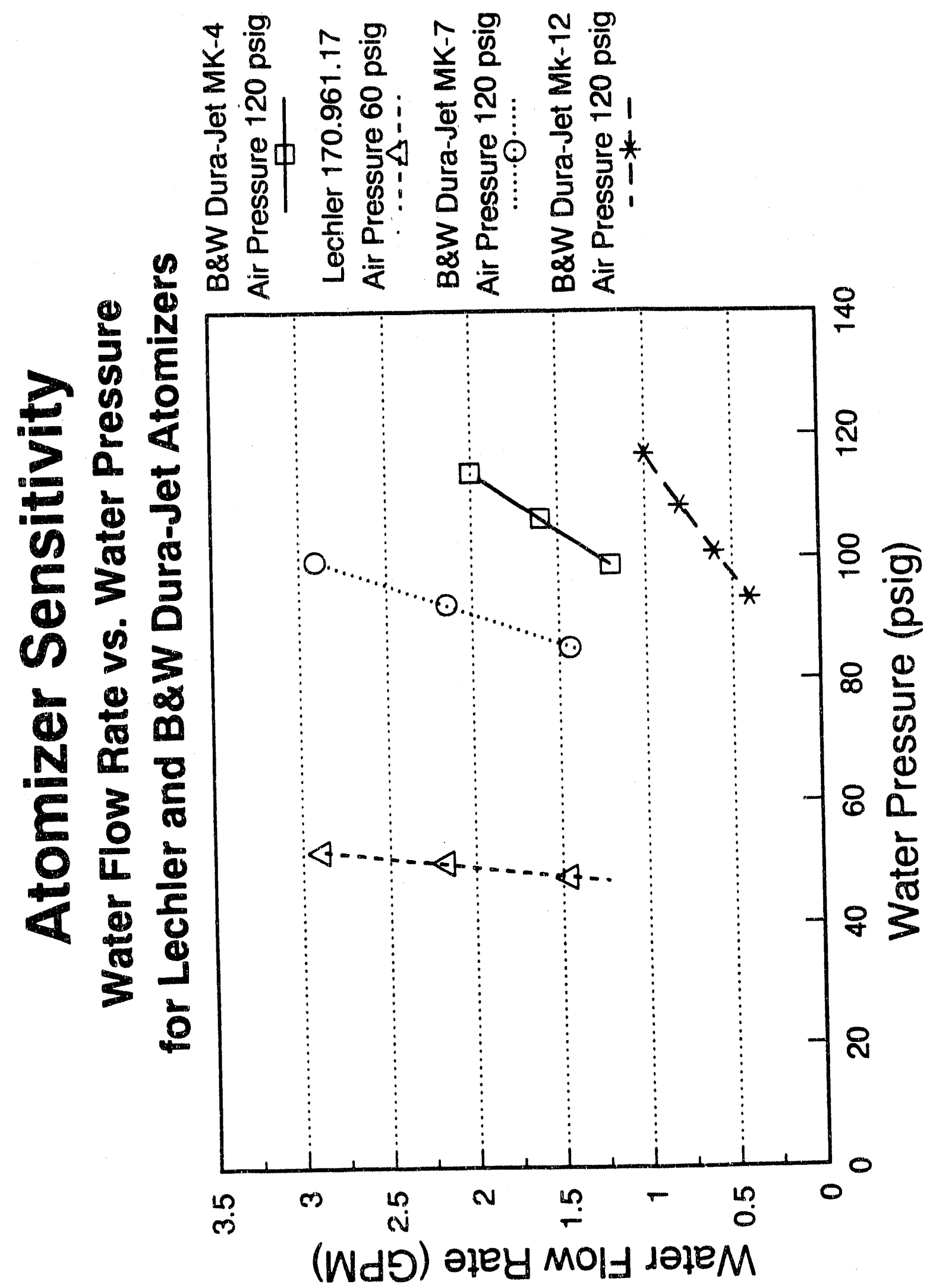

早

蛋 


\subsection{Sumnary of the comnercial Atomizor Comparison to selection Criteria}

The key to controlling wet solids deposition and optimizing $\mathrm{SO}_{2}$ removal for the in-duct injection retrofit process is through appropriate selection of the atomizers used for slurry injection or humidification. Inadequate atomizer performance led to wet solids deposition problems in most of the pilot-scale programs to date. One of the goals of Nozzle Development Task 4.1 was to determine if any commercially available atomizers were able to meet the constraints imposed by an in-duct retrofit application. Twenty-two (22) commercial atomizers were compared to developed selection criteria. These selection critaria were chosen from the more general spray and functional performance criteria developed during this program. The selection criteria address a number of material and spray characteristics. These characteristics include droplet size distribution, atomizing air consumption, pluggage and deposition, spray angle, hydraulic sensitivity, and materials of construction.

The droplet size distribution criteria are the most important for duct injection applications. For complete evaporation to occur in the less than 1 second residence times available in most utility-scale flues, the mass of droplets over 100 microns must be limited to 18 . Results of analyses performed by $B \& W$ indicate the atomizers that produce sprays with Sauter Mean diameters of less than 25 microns will probably meet the large droplet mass fraction requirement. Only those atomizers that had acceptable droplet sizes and large droplet mass fractions were judged on the basis of the other selection criteria.

of the 22 candidate atomizers, only 9 came close to meeting the droplet size distribution criteria developed during this program for flues with 1 second residence times. Of the atomizers tested by B\&W, only three -- the B\&W DuraJet Mk12, the spraying systems J-12, and the B\&W Y-Jet LAF - - have large droplet mass fractions with less than 18 of the spray mass in droplets over 100 microns, given an $A / W$ mass ratio of $0.5 \mathrm{lb} / 1 \mathrm{~b}$ or less. These atomizers all have sauter Mean diameters that are less than 25 microns.

The data reported by UCICL 34 indicate that two capacities of the Delavan Airo (30616-11 and 30615-46) atomizer and the Lechler supersonic $(170.641 .17)$ atomizer have composite large droplet mass fractions which meet the 1 second residence time flue requirement. This result is surprising, since the Sauter Mean diameters for these three atomizers are all over 32 microns and are comparable to atomizers tested by $B \& W$ that have a greater large aroplet mass fraction. It is recomended that additional testing be performed on these Meredosia candidate atomizers before they are included in a list of atomizers appropriate for flues with 1 second or less residence times.

of the candidate atomizers that performed best on the basis of droplet size, only the Lechler atomizer tested by B\&W (170.961.17) and the B\&W Durajet (all capacities) have internal passages that are wide enough to avoid atomizer pluggage from solids in the slurry or unfiltered humidification water that might exist in a commercial application. Of these atomizers, only the 0.8 gpm B\&W Mkl2 DuraJet has a droplet size distribution which meets the 1 second residence time constraint at an $A / W$ ratio of $0.5 \mathrm{lb} / \mathrm{lb}$. The other Durajets and the Lechles: atomizer would not be appropriate for flues with such a short residence, but may be suitable for a commercial application with a longer residence time. 
The Lechler 170.961 .17 atomizer and the B\&W DuraJet Mk7 have capacities similar to those required by Gilbert/Commonwealth for the Beverly, Ohio, test facility. These atomizers have been compared in the past as candidates for this facility (see Appendix A). The comparison showed that at a given $A / W$ ratio, the Mass Median and Sauter Mean diameters for the Lechler atomizer are 5 to 7 microns greater than for the Durajet. The Lechler atomizer was chosen for use at the Beverly facility. As expected, G/C reports that the Lechler atomizer must be operated at high $A / W$ ratios $(1.1 \mathrm{lb} / \mathrm{lb})$ to avoid material deposition problems resulting from incomplete evaporation in the 1 second residence time flue.

The Lecher and B\&W Mini DuraJet atomizers are both adequately designed to avoid material deposition on the atomizer tip. The Lechler atomizer has a large exit orifice, and tests at Beverly have not indicated that tip deposition will be a concern with this atomizer. Recent modifications to the Durajet design have eliminated slurry deposition from the atomizer tip. In addition, the DuxaJet is designed to be fit into a shielding device.

Both the Lechler and B\&W DuraJet atomizers have included spray angles of less than $30^{\circ}$. The $B \& W$ Durajet spray angle is $22^{\circ}$, and the Lechler spray angle is $14^{\circ}$. It is likely that the B\&W Durajet atomizer will provide better liquid-flue gas mixing, because the Lechler has such a narrow concentrated spray.

When compared on the basis of pressure-flow characteristics, all the B\&W Durajet atomizers exhibit an acceptable hydraulic sensitivity. The Lechler atomizer has an unacceptably high hydraulic sensitivity. This atomizer should not be used in an array unless proper modifications are applied. Use of the atomizer without modification will lead to flow maldistribution problems, including atomizer overloading, local

degradation of droplet size, and cold zones which may cause wall wetting and wet solids deposition.

To minimize wear and corrosion for both humidification and slurry atomizers, the materials of construction should be at least as corrosion-resistant as 316 ss with ceramic inserts. If the candidate atomizer is not fitted with a wear-resistant material, it will wear quickly. Both the B\&W Mini DuraJet and the Lechler atomizers have been fitted with wear-resistant materials. Both these atomizers have been used for extended tests with ceramic inserts, and wear has not been a concern.

In conclusion, of the commercial atomizers considered as part of this program, the only comnercially available atomizer which meets the constraints and requirements imposed by in-duct retrofit technologies with 1 second or less residence times and an approach-to-saturation temperature of $20^{\circ} \mathrm{F}$ is the $\mathrm{B} \& \mathrm{~W}$ MK12 DuraJet. If the residence time constraint is relaxed, or the approach-to-saturation temperature is increased, then it is possible that the Lechler (170.961.17) and larger capacities of the B\&W DuraJet atomizers may be appropriate. 


\section{REPERENCES}

1. Peterson, J. R., Durham, D. D., and Vlachos, N. S., "Fundamental Investigation of Duct/ESP Phenomena: Topical Report No. 1 Literature Review", DOE Contract No. DE-AC22-88PC88850, May 9, 1989 .

2. Babcock \& Wilcox, "Material Deposition on Duct Walls/Turning Vanes", Status Report prepared for United Engineers Constructors, Ine., DOE Contract NO. DE-AC22-88PC88852, December 1989.

3. Bechtel National, Inc.; "Desulfurization by the Confined zone Dispersion Process", DOE Contract NO. DE-AC22-85PC81009, April 1988 .

4. Babu, M., College, J., Forsythe, R., Berbert, R., Kanary, D., Kerivan, D., and Lee, K., "5-MW Toronto HALT Pilot Plant Testing", DOE Contract NO. DE-AC22-85PC81012, December 1988 .

5. Babcock \& Wilcox, Personal Communication with M. Babu of the Dravo Lime Company, August 7, 1991.

6. Stouffer, M., "Multi-Nozzle Humidification Tests", DOE Contract No. DE-AC22-85PC81012, December 1988 .

7. Samuel, E. A., Murphy, K. R., and Demian, A., "A 12-MW-Scale Pilot Study of In-Duct Scrubbing (IDS) Using a Rotary Atomizer", DOE Contract NO. DE-AC22-85PC81010, January 1989.

8. United Engineers and Constructors, "Duct Injection Technology Development Technical Update No. 16 ", October 1990.

9. Babcock \& Wilcox, Personal Communication with A. R. Bolmes.

10. Babcock Wilcox, Personal Communication with K. E. Redinger.

11. Nolan, P. S., Purdon, T. J., Peruski, M. E., Santucci, M. T. DePero, M. J., Hendriks, R. V., and Lachapelle, D. G., "Results of the IIMB Demonstration at Edgewater", Proceedings, EPA/EPRI $1990 \mathrm{SO}_{2}$ Control symposium, New orleans, LA, May 1990.

12. Kanary, D. A., Statnick, R. M. Y Yoon, B., McCoy, D. C., Wi.thum, J. A. and Kudlac, G. A., "Coolside Process Demonstration the Ohio Edison Company Edgewater Unit 4 - Boiler 13", Proceedings, EPA/ERRI $1990 \mathrm{SO}_{2}$ Control Symposium, New Orleans, LA, May 1990.

13. Babcock Wilcox, Personal Communication with G. A. Rudlac.

14. McGuire, I. M., and Brown, C. A., "Fundamental Investigation of Duct/ESP Phenomena: 1.7 MW Pilot Parametric Testing Results", DOE Contract No. DE-AC22-88PC88850, February 11, 1991.

15. Gilbert/Comnonwealth and SRI, "Results of Tests Conducted at the DITF - Task 3.1 Evaluation of system Performance". Presented at Fourth Meeting, Duct Injection Technology Working Group, Marietta, OH, May 7-8, 1991. 
16. Masters, X., Spray Drying Handbook 4th Edition, Balsted Press, New York, 1985 .

17 Perry, R. H., and Green, D., Perry's Chemical Enqineer's Handbook, 6th Edition, McGraw-Hili, Inc., 1984 .

18. Henzel, D. S., "Duct Configuration Survey Results", Office of Managenent and Budget Control No. 1910-1400, Alugust 1988.

19. Himes, R. M., "rundamental Investigation of Duct/EsP Phenomena: Flow Visualization Topical Report No. 3, Volure 2 Duct Hunidification Atomizer Performance Evaluation in Hot Flow Physical Modnl", DOE Contract No. DE-AC22-88PC88850, January 1991.

2U. Mugele, R. A., and Evans, H.D., "Droplet size Distribution in Sprays", Industrial and Enqineering Chemistry, Vol. 43, No. 6, June 1951 , p. 1317.

21. Lefebvre, A. H., Atomization and Sprays, Hemisphere Publishing Corp., New York, 1989 .

22. Simmons, H. C., "The Correlation of Drop-size Distributions in Fuel Nozzle Sprays Part I: The Drop-Size/Volume Fraction Distribution", Engineering for Power, Vol. 99 , No. 3, July 1977.

23. Jankura, B. J., Holmes, M. J., and Winters, P. J., "E-SO Technology Evaluation - Atomization Literature Review", BeW Report No. RDD: 89:4360-34-01:01, Alliance, OH, March 30, 1989.

24. Amrhein, G. T., and Winters, P. J., "LIMB Demonstration: Final Report - Task's system Design validation", BdW Report No. $R D D: 87: 4298-50-01: 01$, Alliance, $\mathrm{OH}$, November $20,1987$.

25. Bailey, R. T., "Control of Atomizer Water Flows for the IIMB Humidification Duct", B\&W Report No. RDD:87:4298-01-01:01, Alliance, OH, October 27, 1988.

26. Ilan, R., "Post IIMB Performance Characteristics of Humidifiction Duct. Atomizers", B\&W Report No. RDD:90:4354-3B-01:01, Alliance, OH, June 22, 1990.

27. Beer, J. M., and Chigier, N. A, Combustion Aerodynamics, Robert E. Krieger Pubíishing Company, Maiabar, FI, 1983.

28. Gilbert/Commonwealth, Inc. Monthly Report No. 31 for Scale-up Test and Supporting Research for Duct Injection Technology Development, DOE Contract NO. DE-AC22-88PC88851, May 29, 1991.

29. McCoy, J. W., The Chemical Treatment of Cooling Watex, chemical Publishing Company, New York, 1974.

30. Babcock \& Wilcox, "Corrosion of Materials in Flue Gas Path", Status Report prepared for United Engineers Constructors, Inc., DOE Contrect NO. DE-AC22-88PC88852, December 1989.

31. Winters, P. J., "IIMB Humidification - Atomization Data", B\&W Report No. RDD':298-35-01:01, Alliance, OH, February 12, 1988. 
32. Bailey, R. T., "Droplet Size Data for Lechler and B\&W I-Jet Atomizers for the Beverly, Ohio, Pilot Facility", BeW Report No. RDD:90:4572-78-01:01, Alliance, OH, March 14, 1990.

33. Brown, C. T., Sowa, W. A., Samuelsen, G. S., "Fundamental Investigation of Duct/ESP phenomena: Flow Visualization Topical Report No. 3, Volume 1 Drop Size and Velocity Measurements of Duct Bumidification Atomizers", DOE Contract No. DE-AC22-88PC88850, November 1990.

34. Babcock Wilcox, Personal Communication with Dr. William sowa of University of California, Irvine Combustion Laboratory, cotober 30 , 1991.

35. Holmes, M. J., "Low Pressure Atomizer - Summary Report", B\&W Report No. RDD: 90:3720-03-01:01, Alliance, OH, August 9, 1989.

36. Amrhein, G. T., "Final Report: Pilot-Scale IIDS Demonstration", OCDO Grant No CDO/D-87-60, April 1991. 


\section{APPENDIX A}

DROPLET SIZE DATA FOR LECKLER AND BEW I-JET ATOMIZERS FOR THE BEVERIY, OHIO, PILOT FACILITY 


\section{BACKGROUND AND SUMMARY OF RESULTS}

As part of the U.S. Department of Energy's Program for Duct Injection Technologies for $\mathrm{SO}_{2}$ Control, Gilbert/Commonwealth will be conducting scale-up research and supporting studies at a 12 MW pilot facility in Beverly, Ohio. Operation of this facility will require in-duct humidification and lime slurry injection. This report compares the drop size test data for three styles of atomizers with liquid capacities similar to that required for the Beverly, ohio, pilot facility.

A previous report (1) presented test data for the Parker-Hannifin atomizers that were originally scheduled for installation at the Beverly pilot plant. The measured drop size data showed a full load Sauter Mean diameter that was substantially larger than design criteria. At the request of Gilbert/Commonwealth, a Lechler atomizer and B\&W I-Jet atomizer were tested to determine if these atomizers provided a smaller drop size distribution than that provided by the Parker-Hannifin atomizer.

The Lechler atomizer was provided by Gilbert/Commonwealth. The I-Jet atomizer, designated the Mk-7, was originaliy fabricated as part of the LIMB Humidification Program. It was not designed for commercial installation at the operating pressures and flows corresponding to the Beverly pilot plant, but it had a liquid capacity similar to that required at Beverly.

Similar to the data for the Parker-Hannifin atomizer, the drop size data for the Lechler and 1-Jet atomizers was sensitive to both downstream measurement position and the number density of the spray (i.e., laser beam obscuration).

The drop size data for the three atomizers measured at the same axial position in the spray were compared on the basis of air-to-water flow ratio. The comparison showed that at any given $A / W$ ratio, the Parker-Hannifin atomizer provided the largest average drop size and the B\&W I-Jet provided

(1) "Drop Size Data for Parker-Hannifin Atomizers," R. T. Bailey, B\&W Report RDD:90:4572-53:01:01, October 4, 1989. 
the smallest. The average drop size for the Lechler atomizer was 5 to 7 microns greater than for the I-Jet.

These atomizers were also compared on the basis of energy required for atomization (Btu per lb of liquid) that accounts for differences in the atomizing air pressures for the three atomizers. The relative ranking of the three atomizers in this comparison was the same as with the $A / W$ comparison, but the differences were smaller.

Finally, the liquid pressure-liquid flow sensitivity of the three atomizers was compared, as this parameter determines the potential for flow maldistribution in a manifolded atomizer array. The Parker-Hannifin atomizer had the most desirable hydraulic characteristics with a pressure-flow sensitivity of about $12 \mathrm{lb} / \mathrm{hr}$ per psi at full load. The Lechler atomizer had the least desirable sensitivity at $176 \mathrm{lb} / \mathrm{hr}$ per psi, while the I-Jet was midway between the two at $52 \mathrm{lb} / \mathrm{hr}$ per psi. 


\section{EQUIPMENT AND PROCEDURES}

The Lechler atomizer (S/N 170.961.17) provided by Gilbert/Commonweaith is of the dual fluid type with a single tapered discharge hole. The atomizer forms a single solid cone of spray that expands slowly with distance from the atomizer. The water is injected coaxially with the discharge hole, while the air is injected tangentially through multiple holes. The I-Jet is similar in concept, but the air-liquid mixture is atomized through four discharge holes. The four holes are distributed around the axis of the atomizer and are directed at an angle of 12-1/2 degrees from the axis of the atomizer.

The drop size distributions were measured at 3 feet and 5 feet downstream of the atomizer discharge. Each atomizer was tested both with and without a spray shield. The purpose of the spray shield was to reduce the error in measured drop size distribution caused by multiple light scattering in a high number density spray. For the Lechier atomizer, the spray shield consisted of a 4-inch diameter tube which collected and deflected about $1 / 2$ of the spray from the point of measurement. For the I--Jet atomizer, two methods of shieiding were used. First, the spray through one of the four holes was collected at the atomizer discharge and deflected from the point of measurement. Second, a curved piece of sheet metal located about 2 feet downstream of the atomizer was used to deflect about $1 / 2$ of the spray.

Each atomizer was tested at water flow rates of 720,1040 , and $14401 \mathrm{~b} / \mathrm{hr}$ which represented $50 \%, 75 \%$, and $100 \%$ of full load for the lime injection atomizers. The atomizing air pressure ranged from 50 to 80 psig for the Lechler atomizer and from 80 to $120 \mathrm{psig}$ for the I-Jet atomizer. Droplet size was measured using the Maivern ST2600 Droplet Size Analyzer equipped with a $600 \mathrm{~mm}$ lens. This provided a droplet size range of approximately 11 to 1100 micrometers.

The measured data was reduced to droplet size distribution using the Model Independent analysis software. The Two Parameter analysis software was not used to reduce any of the test data. The data provided in this report is that indicated by the Malvern Droplet size Analyzer. The data has not been adjusted for errors possibly caused by multiple light scattering. 


\section{TEST RESULTS}

\section{Atomizer Spray Pattern}

The most visible difference in the operation of the three atomizers was the characteristics of the spray. The spray boundaries of both the ParkerHannifin and I-Jet atomizers expanded rapidly near the discharge of the atomizer, followed by a gradual expansion with distance. Coincident with the rapid expansion was a reduction in spray velocity. The Lechler atomizer, with a single large discharge hole, had a very narrow concentrated spray at the atomizer discharge that expanded slowly with distance.

Pictures of the spray trajectories taken in the atomization facility are shown in Figure 1. From these photographs, the superficial spray angles were measured and are shown in the figure. The included angle of the spray for the Parker-Hannifin and I-Jet atomizers is nearly the same with angles of 25 and 22 degrees. The 14-degree spray angle for the Lechler atomizer is much smaller.

\section{Droplet Size Distribution}

Tabulated test data for the Lechler and I-Jet atomizers are contained in Tables 1 and 2, respectively. These tables include the atomizing air flow rate and pressure, the liquid flow rate and pressure, the Sauter Mean diameter, two large droplet mass fractions, and the laser light obscuration associated with the measurement.

The complete size distributions for the Lechler and I-Jet atomizers as provided by the Malvern Analyzer are contained in Appendices 1 and 2 , respectively. The Run Numbers in Tables 1 and 2 provide the cross-reference to the size distribution data in Appendices 1 and 2.

The Sauter Mean diameter is plotted as a function of the air-to-water $(A / W)$ flow ratio for the Lechler atomizer in Figure 2. The data in Figure 2 represents unshielded measurements at air pressures of 50 and 60 psig, at the three liquid flow rates, and at 3 and 5 feet downstream of the atomizer. For 
both downstream distances, the data at the different air pressures and liquid flows all tend to fall on a single curve. This shows that the Sauter Mean diameter is essentially a function of only the $A / W$ ratio.

The effect of downstream distance on the measured Sauter Mean diameter is clearly evident in Figure 2. The data at a distance of 5 feet is about 9 microns greater than at 3 feet for the same test condition.

Figure 3 is analogous to Figure 2, but the data represents measurements obtained using the spray shield. The data in Figure 2 show exactly the same trends as in Figure 2. The Sauter Mean diameter is a function of only the $A / W$ ratio, and the Sauter Mean diameter measured at 5 feet averages about 9 microns greater than at 3 feet. The data measured with a spray shield in place averaged about 3 microns greater than without a spray shield.

For the Lechler atomizer, the droplet size was also measured at "off centerline" positions at a downstream distance of 5 feet and without a spray shield. Figure 4 shows the variation in Sauter Mean diameter with position in the spray for two test conditions. At each test condition, the diameters have been normalized to their respective centerline values. The diameters measured off axis range up to $35 \%$ higher than the centerline value. This variation could result from the variation in laser beain obscuration which decreases with off-axis distance.

The average effects of shielding and downstream distance on the measured Sauter Mean diameters are given in Table 3 for the Lechler atomizer. This data shows that axial position has a larger effect on the measured diameters than the use of a shield. This occurs even though shielding has a greater effect on obscuration than position. This result supports the premise that some phenomena other than obscuration influences the measured data.

As reported for the Parker-Hannifin atomizers, the variation in Sauter Mean diameter with position in the spray cannot be entirely explained by evaporation, droplet coalescence, or obscuration. It may be caused by a dependence of droplet velocity on droplet size that is changing with downstream distance. 
The Sauter Mean diameters for the Mk-7 I-Jet measured without a spray shield are shown in Figure 5 , and with a spray shield in Figure 6 . The I-Jet Sauter Mean diameter data shows the same general dependence on air pressure, $A / W$ ratio, axial position, and shielding as the Lechler atomizer.

Table 4 shows the separate effects of axial position (with fixed shielding geometry) and of shielding (at fixed axial position) for the I-Jet atomizer. Although the magnitude of these effects is slightly different than for the Lechler atomizer, the overall trend is the same.

Figure 7 is a comparison of droplet size data measured for the Lechl. and I-Jet atomizers, as well as the Parker-Hannifin atomizer from the previous test. The data for the different atomizers presented in this figure were all measured using a shield at an axial location of 5 feet. At any given $A / W$ ratio, the Parker-lannifin atomizer provides the largest mean drop size, wh' 'e the I-Jet provides the smallest. The drop sizes for the Lechler atomizer are 5 to 7 microns greater than for the I-Jet.

Comparison of the droplet size performance of atomizers on the basis of $A / W$ ratio is a measure of the relative efficiency of the atomizers. Droplet size is the desired product of atomization, while the air flow per pound of liquid $(A / W$ ratio) required to generate the drop size is a measure of cost. However, the $A / W$ ratio does not account for differences in atomizing : $r$ pressure that ultimately affects the cost of the atomizing air. So, al though the I-Jet atomizer requires the least air flow to achieve a given Sauter Mean diameter, it al so requires the highest pressure air.

Differences in atomizing air pressure can be included in atomizer comparisons by multiplying the $A / W$ ratios for a given atomizer by the specific energy (Btu per ib of air) required for compression of the air. The data for the three atomizers shown in Figure 7 was reanalyzed using this approach. The assumed compressor operating conditions for the three atomizers are given in Table 5. For each atomizer, a single compressor discharge pressure has been assumed that is capable of meeting all atomizer operating conditions while al so providing some overhead for line losses. 
The Sauter Mean diameter data for the three atomizers shown in Figure 7 is re-plotted in Figure 8 as a function of the atomization energy required (Btu per ib of liquid). The relative ranking of the three atomizers remains unchanged from Figure 7, but the difference in performance between the I-Jet and Lechler atomizers has been reduced considerably.

\section{Atomizer Hydraulic Characteristics}

Aside from atomization performance, another important aspect of atomizers used for humidification is the hydraulic characteristics. With arrays of atomizers, liquid flow control to each individual atomizer is not feasible. Rather, the flow to the atomizer array is controlled, and the flow to the individual atomizers in the array is dependent on the liquid pressure distribution in the manifold and the pressure-flow characteristics of the individual atomizers. For humidification, the distribution of flow among atomizers in an array is critical. "Overloading" of a single atomizer with fluid will cause localized degradation of drop size, and a local "cold" zone in the duct that can lead to deposition.

A measure of an atomizer's sensitivity is simply the change in liquid flow that results from a change in liquid pressure li.e., the slope of the pressureflow curvel at a constant air pressure. The greater this slope, the more likely an atomizer array will have problems with flow maldistribution.

The liquid pressure-liquid flow characteristics of the Parker-Hannifin, Lechler, and I-Jet atomizers are shown in Figure 9. it is evident from figure 9 that these three atomizers span wide range of liquid pressures and pressure-flow sensitivity. The slopes of the pressure-flow curves for these atomizers at full and half load are given in Table 6. The Parker-Hannifin atomizer sensitivity ranges from 0.8 to $3.2 \%$ of flow per psi and is the best of the three. The slope for the Lechler atomizer ranges from 12 to $24 \%$ of flow per psi, which is extremely large. The Mk-7 I-Jet at $3.6 \%$ and $7.2 \%$ per psi is about midway between the other two. 
The sensitivity of the Mk-7 I-Jet atomizer expressed as percent of flow per psi is nearly identical to the MK-12 I-Jet atomizers installed in the LIMB Humidification Duct at Edgewater, Ohio. The Mk-12 atomizers at Edgewater are manifolded in groups of about 20 and have not shown obvious flow maldistribution problems at approach to saturation temperatures of about $25^{\circ} \mathrm{F}$.

The liquid pressure-flow characteristics of an atomizer can be modified without changing droplet size performance by installing one or inore orifices in the liquid entrance to the atomizer. 
The narrow, high velocity spray trajectory of the Lechler atomizer was markedly different from the other atomizers. All else constant, spray trajectory and velocity will likely influence the installed performance. The manner and degree that these parameters affect performance remains speculative.

The Mk-7 I-Jet atomizer provided the smallest droplet size distribution on the basis of $A / W$ ratio and on the basis of energy required per pound of liquid atomized. The Lechler atomizer had nearly the same drop size performance as the I-Jet, while the drop size for the Parker-Hannifin atomizers was substantially greater than the others.

As tested, the Parker-Hannifin atomizer had the best liquid pressure/ liquid flow characteristics for a manifolded atomizer arrangement. As tested, the pressure-flow characteristics of the Lechler atomizer can be considered unacceptable for a manifolded atomizer arrangement. The flow sensitivity to pressure for this atomizer could be reduced substantially with the addition of an orifice(s) in the liquid entrance. The pressure flow sensitivity of the Mk-7 I-Jet atomizer has been demonstrated as acceptable in a manifolded atomizer arrangement.

$$
\begin{aligned}
& \text { Rafali beiliy } \\
& \text { R. T. Bailey }
\end{aligned}
$$

Reviewed and Approved By

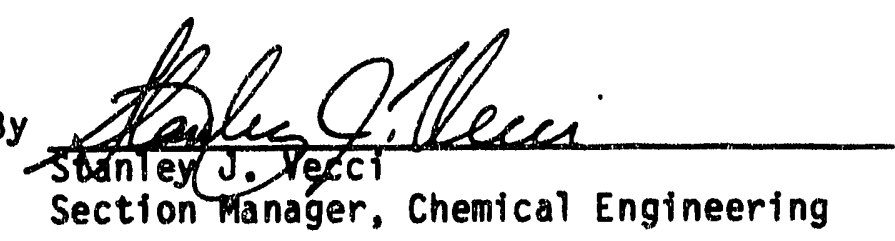

$\mathrm{RTB} / \mathrm{smb}$ 
Table 1. Measured Tost Data for the Lechlei Atomizer

\begin{tabular}{|c|c|c|c|c|c|c|c|c|c|}
\hline $\begin{array}{c}\text { RUN } \\
\text { NUMBER }\end{array}$ & $\begin{array}{c}\text { AIR } \\
\text { PRESSURE } \\
\text { (osig) }\end{array}$ & $\begin{array}{l}\text { WATEA } \\
\text { FLOW RATE } \\
\text { (b/hr) }\end{array}$ & $\begin{array}{c}\text { WATER } \\
\text { PRESSURE } \\
\text { (psig) }\end{array}$ & $\begin{array}{c}\text { AIR } \\
\text { FLOW RATE } \\
(\mathrm{b} / \mathrm{hr})\end{array}$ & $\begin{array}{c}\text { AIRWATER } \\
\text { PATIO } \\
(\mathrm{b} / \mathrm{b} \mathrm{b}) \\
\end{array}$ & $\begin{array}{c}\text { SAUTER } \\
\text { MEAN DIA } \\
(\omega)\end{array}$ & $\begin{array}{l}\% \text { ABOVE } \\
129.3 \mu\end{array}$ & $\begin{array}{c}96 \text { ABOVE } \\
100.3 \mu\end{array}$ & $\begin{array}{l}\text { OBSCUR- } \\
\text { ATION } \\
(\%) \\
\end{array}$ \\
\hline 36 INCHE & SWTTH SHIE & ED;AT SPRA & AY CENTERI & INE & & & & & \\
\hline 218 & 50.3 & 718 & 39.3 & 667 & 0.93 & 23.25 & 0.0 & 0.1 & 0.80 \\
\hline 219 & 50.2 & 1088 & 41.9 & 627 & 0.58 & 26.40 & 0.1 & 0.5 & 0.81 \\
\hline 220 & 50.5 & 1430 & 43.6 & 608 & 0.43 & 27.59 & 0.2 & 0.5 & 0.81 \\
\hline 215 & 60.0 & 710 & 46.8 & 782 & 1.10 & 20.38 & 0.1 & 0.2 & 0.64 \\
\hline 216 & 60.3 & 1088 & 49.5 & 749 & 0.69 & 22.96 & 0.0 & 0.1 & 0.80 \\
\hline 217 & 59.7 & 1436 & 51.8 & 709 & 0.49 & 24.47 & 0.1 & 0.3 & 0.83 \\
\hline 36 INCHE & SWTTHOUT & SHIELD;AT S & SPRAY CEN & TERLINE & & & & & \\
\hline 212 & 50.2 & 712 & 39.3 & 670 & 0.94 & 18.80 & 0.0 & 0.0 & 0.92 \\
\hline 213 & 50.2 & 1088 & 41.7 & 622 & 0.57 & 22.03 & 0.0 & 0.1 & 0.95 \\
\hline 214 & 50.0 & 1448 & 43.5 & 599 & 0.41 & 24.95 & 0.0 & 0.3 & 0.95 \\
\hline 209 & 60.4 & 728 & 47.1 & 784 & 1.08 & 18.46 & 0.0 & 0.1 & 0.92 \\
\hline 210 & 60.3 & 1082 & 49.1 & 746 & 0.69 & 20.37 & 0.0 & 0.0 & 0.95 \\
\hline 211 & 60.2 & 1436 & 52.2 & 700 & 0.49 & 22.24 & 0.0 & 0.0 & 0.96 \\
\hline $60 \mathrm{INCHE}$ & SWITH SHIE & ELD; AT SPRA & AY CENTERI & LINE & & & & & \\
\hline 224 & 50.3 & 710 & 39.8 & 664 & 0.94 & 31.56 & 0.2 & 1.1 & 0.61 \\
\hline 225 & 50.3 & 1084 & 41.9 & 633 & 0.58 & 36.14 & 0.7 & 3.7 & 0.63 \\
\hline 226 & 50.3 & 1430 & 43.1 & 610 & 0.43 & 38.68 & 9.8 & 6.0 & 0.64 \\
\hline 221 & 60.2 & 729 & 47.6 & $r 72$ & 1.06 & 26.40 & 0.7 & 1.8 & 0.62 \\
\hline 222 & 60.1 & 1084 & 50.1 & 744 & 0.69 & 33.96 & 2.8 & 4.6 & 0.65 \\
\hline 223 & 60.3 & 1444 & 51.9 & 713 & 0.49 & 36.95 & 5.4 & 7.8 & 0.66 \\
\hline $60 \mathrm{INCHE}$ & SWTTHOUT & SHIEID; AT S & SPRAY CEN & TEALINE & & $\therefore$ & & & \\
\hline 206 & 50.6 & 704 & 39.5 & 666 & 0.95 & 30.07 & 0.0 & 0.6 & 0.82 \\
\hline 227 & 50.5 & 722 & 39.4 & 675 & 0.93 & 29.87 & 0.0 & 0.5 & 0.83 \\
\hline 207 & 50.1 & 1081 & 41.5 & 618 & 0.57 & 32.82 & 0.2 & 2.4 & 0.87 \\
\hline 228 & 50.4 & 1090 & 41.9 & 643 & 0.59 & 32.64 & 0.6 & 3.0 & 0.89 \\
\hline 208 & 50.0 & 1442 & 43.5 & 595 & 0.41 & 33.59 & 1.0 & 6.0 & 0.91 \\
\hline 229 & 50.5 & 1438 & 43.8 & 606 & 0.42 & 33.88 & 1.6 & 5.8 & 0.91 \\
\hline 205 & 60.5 & 719 & 47.2 & 781 & 1.09 & 25.81 & 0.0 & 0.0 & 0.81 \\
\hline 232. & 60.5 & 722 & 47.3 & 786 & 1.09 & 26.93 & 0.0 & 0.1 & 0.85 \\
\hline 204 & 60.3 & 1086 & 50.1 & 750 & 0.69 & 29.39 & 0.1 & 0.7 & 0.86 \\
\hline 231 & 60.4 & 1081 & 49.6 & 753 & 0.70 & 29.80 & 0.1 & 0.9 & 0.89 \\
\hline 203 & 60.5 & 1441 & 52.2 & 716 & 0.50 & 31.21 & 0.1 & 1.9 & 0.90 \\
\hline 230 & 60.4 & 1447 & 51.9 & 722 & 0.50 & 31.32 & 0.5 & 2.0 & 0.92 \\
\hline 200 & 80.4 & 708 & 62.6 & 1008 & 1.42 & 20.93 & 0.0 & 0.0 & 0.84 \\
\hline 201 & 80.5 & 1076 & 65.5 & 970 & 0.90 & 24.05 & 0.0 & 0.0 & 0.90 \\
\hline 202 & 80.5 & 1436 & 68.3 & 945 & 0.66 & 26.15 & 0.0 & 0.2 & 0.93 \\
\hline
\end{tabular}


Table 1. (Continued) Measured Test Data for tho Lechler Atomizer

\begin{tabular}{|c|c|c|c|c|c|c|c|c|c|}
\hline $\begin{array}{l}\text { RUN } \\
\text { NUMEER }\end{array}$ & $\begin{array}{l}\text { AlA } \\
\text { PESSURE } \\
\text { (osio) }\end{array}$ & $\begin{array}{c}\text { WATEA } \\
\text { FLOW RATE } \\
\text { (16/hr) }\end{array}$ & $\begin{array}{l}\text { WATER } \\
\text { PRESSURE } \\
\text { (osig) }\end{array}$ & $\begin{array}{c}\text { AIR } \\
\text { FLOW AATE } \\
\text { (1b/hr) }\end{array}$ & $\begin{array}{c}\text { AIRWWATEA } \\
\text { RATIO } \\
(\mathrm{b} / \mathrm{b}) \\
\end{array}$ & $\begin{array}{l}\text { SAUTER } \\
\text { MEAN DUA } \\
(\omega)\end{array}$ & $\begin{array}{c}\text { \% ABOVE } \\
129.3 \psi\end{array}$ & $\begin{array}{c}\text { ABOVE } \\
100.3 \mu\end{array}$ & $\begin{array}{c}\text { OBSCUR- } \\
\text { ATION } \\
(\%)\end{array}$ \\
\hline \multicolumn{6}{|c|}{60 INCHES WTHOUT SHIELD; 7 INCHES ABOVE CENTERLINE } & \multirow[b]{2}{*}{34.77} & \multirow[b]{2}{*}{0.4} & \multirow[b]{2}{*}{1.6} & \multirow[b]{2}{*}{0.59} \\
\hline 233 & 50.3 & 722 & 39.6 & 672. & 0.93 & & & & \\
\hline 234 & 50.4 & 1091 & 42.1 & 641 & 0.59 & 39.95 & 1.2 & 4.3 & 0.6 \\
\hline 235 & 50.4 & 1439 & 44.2 & 614 & 0.43 & 46.37 & 2.3 & 7.9 & 0.42 \\
\hline 238 & 60.5 & 719 & 47.5 & 792 & 1.10 & 29.14 & 0.7 & 1.8 & 0.47 \\
\hline 237 & 60.5 & 1075 & 49.8 & 755 & 0.70 & 37.28 & 0.7 & 2.5 & 0.55 \\
\hline 236 & 60.3 & 1433 & 51.9 & 721 & 0.50 & 41.52 & 1.2 & 4.0 & 0.46 \\
\hline \multicolumn{6}{|c|}{60 INCHES WTTHOUT SHIELD; 7 INCHES BEL.OW CENTERLINE } & \multirow[b]{2}{*}{35.83} & \multirow[b]{2}{*}{0.1} & \multirow[b]{2}{*}{1.3} & \multirow[b]{2}{*}{0.6} \\
\hline 239 & 50.3 & 713 & 39.7 & 675 & 0.95 & & & & \\
\hline 240 & 50.4 & 1085 & 41.9 & 641 & 0.59 & 42.89 & 1.4 & 6.6 & 0.58 \\
\hline 241 & 50.3 & 1445 & $\$ 4.1$ & 611 & 0.42 & 40.09 & 1.0 & 7.6 & 0.69 \\
\hline 244 & 60.4 & 725 & 47.4 & 789 & 1.09 & 30.69 & 0.1 & 0.7 & 0.69 \\
\hline 243 & 60.4 & 1088 & 50.0 & 754 & 0.69 & 36.99 & 0.9 & 3.4 & 0.66 \\
\hline 242 & 60.3 & 1451 & 52.0 & 719 & 0.50 & 39.35 & 1.3 & 5.4 & 0.71 \\
\hline \multicolumn{6}{|c|}{60 INCHES WTTHOUT SHIELD; 5 INCHES BELOW CENTERLINE } & \multirow[b]{2}{*}{33.17} & \multirow[b]{2}{*}{0.3} & \multirow[b]{2}{*}{1.6} & \multirow[b]{2}{*}{0.72} \\
\hline 245 & 50.4 & 719 & 39.7 & 671 & 0.93 & & & & \\
\hline 246 & 50.3 & 1082 & 41.9 & 641 & 0.59 & 38.87 & 1.5 & 5.6 & 0.72 \\
\hline 247 & 50.4 & 1445 & 44.0 & 608 & 0.42 & 38.79 & 2.1 & 7.0 & 0.79 \\
\hline 250 & 60.4 & 719 & 47.6 & 792 & 1.10 & 26.91 & 0.6 & 1.7 & 0.78 \\
\hline 249 & 60.6 & 1082 & 50.2 & 755 & 0.70 & 34.78 & 0.5 & 2.8 & 0.78 \\
\hline 248 & 60.5 & 1433 & 52.3 & 720 & 0.50 & 34.58 & 0.9 & 4.1 & 0.82 \\
\hline \multicolumn{6}{|c|}{60 INCHES WTTHOUT SHIELD; 3 INCHES BELOW CENTERLINE } & & & & \\
\hline 251 & 50.4 & 712 & 39.6 & 676 & 0.95 & 30.79 & 0.2 & 0.9 & 0.78 \\
\hline 252 & 50.4 & 1091 & 41.9 & 643 & 0.59 & 35.12 & 0.8 & 3.7 & 0.82 \\
\hline 253 & 50.3 & 1454 & 44.1 & 608 & 0.42 & 35.00 & 1.1 & 5.5 & 0.88 \\
\hline 256 & 60.6 & 725 & 47.7 & 787 & 1.08 & 27.32 & 0.0 & 0.2 & 0.83 \\
\hline 255 & 60.4 & 1088 & 50.1 & 754 & 0.69 & 31.82 & 0.3 & 1.9 & 0.85 \\
\hline 254 & 60.3 & 1442 & 52.2 & 719 & 0.50 & 32.28 & 0.4 & 2.8 & 0.89 \\
\hline
\end{tabular}

Conversion to SI Units:

\begin{tabular}{|lll|}
\hline From: & To: & Multiply By. \\
psig & Pa(gage) & 6895 \\
$\mathrm{lb} / \mathrm{hr}$ & $\mathrm{kg} / \mathrm{s}$ & $1.26 \mathrm{E}-4$ \\
\hline
\end{tabular}

RDD4572/CRD1230 
Table 2. Measu:gd Test Data for the B\&W MK-7 i-Jet Atomizer

\begin{tabular}{|c|c|c|c|c|c|c|c|c|c|}
\hline RUN & $\begin{array}{l}\text { NR } \\
\text { PESSURE } \\
\text { (Dodo) }\end{array}$ & $\begin{array}{l}\text { WATEA } \\
\text { FLOW AATE } \\
\text { (bo/nn }\end{array}$ & $\begin{array}{l}\text { WATER } \\
\text { PRESSURE } \\
\text { (p) }\end{array}$ & $\begin{array}{c}\text { AR } \\
\text { LOW RATE } \\
\text { (bMnn) }\end{array}$ & $\begin{array}{l}\text { AlRWATER } \\
\text { PATIO } \\
\text { (ib/b) }\end{array}$ & $\begin{array}{l}\text { BAUTEA } \\
\text { UEAN DAA } \\
(y)\end{array}$ & $\begin{array}{l}\text { ABOVE } \\
120.3 \mu\end{array}$ & $\begin{array}{c}\text { \% ABOVE } \\
\text { 100.3W }\end{array}$ & $\begin{array}{l}\text { OBSCUR- } \\
\text { ATION } \\
\text { (\%) }\end{array}$ \\
\hline \multicolumn{5}{|c|}{36 INCHES WITH ONE HOLE SHIEIOED } & & & & & \\
\hline 118 & 80.0 & 7228 & 80.5 & 384 & 0.53 & 24.75 & 1.2 & 2.7 & 0.77 \\
\hline 110 & 79.9 & 1085 & 65.8 & 342 & 0.32 & 30.32 & 1.8 & 4.8 & 0.8 \\
\hline 120 & 80.0 & 1448 & 70.9 & 301 & 0.21 & 35.14 & 3.7 & 9.0 & 0.82 \\
\hline 123 & 100.3 & 725 & 74.4 & 483 & 0.67 & 21.89 & 0.4 & 1.3 & 0.79 \\
\hline 122 & 100.3 & 1084 & 80.9 & 439 & 0.41 & 26.08 & 0.9 & 2.5 & 0.82 \\
\hline 121 & 100.2 & 1436 & 86.1 & 397 & 0.28 & 30.46 & 1.4 & 4.3 & 0.86 \\
\hline 124 & 120.4 & 711 & 87.8 & 586 & 0.82 & 20.03 & 0.1 & 0.6 & 0.80 \\
\hline 125 & 120.4 & 1071 & 92.0 & 539 & 0.50 & 23.88 & 0.5 & 1.6 & 0.84 \\
\hline 126 & 120.2 & 1440 & 101.2 & 490 & 0.34 & 27.8 & 0.2 & 1.2 & 0.87 \\
\hline \multicolumn{5}{|c|}{36 INCHES $\sqrt{1}$ TH FLAT SHIELD } & & & & & \\
\hline 136 & 80.3 & 728 & 61.0 & 386 & 0.53 & 26.09 & 2.4 & 4.7 & 0.74 \\
\hline 137 & 80.3 & 1079 & 66.6 & 342 & 0.32 & 29.99 & 3.7 & 7.1 & 0.75 \\
\hline 138 & 80.2 & 1430 & 71.5 & 306 & 0.21 & 38.66 & 5.7 & 12.1 & 0.72 \\
\hline 139 & 100.4 & 737 & 75.3 & 481 & 0.65 & 23.18 & 3.4 & 4.3 & 0.78 \\
\hline 140 & 100.6 & 1100 & 81.4 & 437 & 0.40 & 31.64 & 17.4 & 18.4 & 0.82 \\
\hline 141 & 100.6 & 1436 & 86.8 & 393 & 0.27 & 32.7 & 13.2 & 16.5 & 0.83 \\
\hline \multicolumn{5}{|c|}{36 IACHES WIHOUT SHIELD } & & & & & \\
\hline 142 & 80.5 & 722 & 61.2 & 386 & 0.53 & 22.29 & 0.6 & 1.9 & 0.9 \\
\hline 143 & 80.0 & 1076 & 66.2 & 339 & 0.31 & 26.78 & 2.3 & 5.3 & 0.92 \\
\hline 144 & 80.0 & 1442 & 71.0 & 302 & 0.21 & 33.37 & 1.5 & 9.8 & 0.94 \\
\hline 145 & 100.2 & 717 & 74.6 & 485 & 0.68 & 18.78 & 0.2 & 0.9 & 0.91 \\
\hline 146 & 100.2 & 1085 & 81.3 & 437 & 0.40 & 25.45 & 0.1 & 0.6 & 0.93 \\
\hline 147 & 100.3 & 1436 & 86.8 & 395 & 0.27 & 27.69 & 0.3 & 4.5 & 0.94 \\
\hline 148 & 119.9 & 716 & 87.8 & 581 & 0.81 & 18.22 & 0.1 & 0.5 & 0.91 \\
\hline 149 & 120.8 & 1070 & 85.1 & 531 & 0.50 & 21.52 & 0.2 & 0.9 & 0.93 \\
\hline 150 & 120.5 & 1432 & 101.5 & 491 & 0.34 & 25.84 & 0.1 & 2.2 & 0.95 \\
\hline
\end{tabular}


Table 2.(Continued) Measured Test Data for the B\&W MK-7 I-Jet Atomizer

\begin{tabular}{|c|c|c|c|c|c|c|c|c|c|}
\hline $\begin{array}{c}\text { AUN } \\
\text { NUMAER }\end{array}$ & $\begin{array}{l}\text { AlA } \\
\text { RESSUAE } \\
\text { (parig) }\end{array}$ & $\begin{array}{l}\text { WATEA } \\
\text { LOWRATE } \\
\text { (bomr) }\end{array}$ & $\begin{array}{l}\text { WATEA } \\
\text { PRESSURE } \\
\text { (o\&da) }\end{array}$ & $\begin{array}{c}\text { AR } \\
\text { FLOW AATE } \\
\text { (b/mn) }\end{array}$ & $\begin{array}{l}\text { ARWATEA } \\
\text { PATTO } \\
(\mathrm{b} / \mathrm{b})\end{array}$ & $\begin{array}{c}\text { MAUTER } \\
\text { MEE DA DA } \\
\text { (U) }\end{array}$ & $\begin{array}{c}\text { \$ ABOVE } \\
129.3 \mu\end{array}$ & $\begin{array}{c}\text { \% ABOVE } \\
100.3 y\end{array}$ & $\begin{array}{c}\text { OASCUR- } \\
\text { ATION } \\
(\%)\end{array}$ \\
\hline \multicolumn{5}{|c|}{ CO INCHES WITH ONE HOLE SHIELDED } & & & & & \\
\hline 100 & 80.1 & 713 & 59.1 & 387 & 0.54 & 31.16 & 1.8 & 5.6 & 0.67 \\
\hline 101 & 80.7 & 1070 & 64.8 & 340 & 0.32 & 39.87 & 4.5 & 10.8 & 0.7 \\
\hline 102 & 80.0 & 1451 & $70 . ?$ & 306 & 0.21 & 46.89 & 8.8 & 19.6 & 0.73 \\
\hline 105 & 100.4 & 748 & 72.2 & 478 & 0.67 & 28.17 & 0.8 & 4.2 & 0.68 \\
\hline 104 & 100.3 & 1000 & 79.2 & 427 & 0.39 & 25.77 & 2.8 & 7.2 & 0.73 \\
\hline 103 & 100.3 & 1445 & 85.4 & 387 & 0.27 & 41.52 & 5.4 & 12.8 & 0.77 \\
\hline 106 & 120.5 & 721 & 85.2 & 565 & 0.78 & 24.89 & 1.2 & 3.0 & 0.70 \\
\hline 107 & 120.4 & 1075 & 82.4 & 517 & 0.48 & 32.18 & 1.5 & 4.4 & 0.75 \\
\hline 108 & 120.5 & 1454 & 99.5 & 476 & 0.33 & 36.92 & 2.8 & 7.8 & 0.79 \\
\hline \multicolumn{5}{|c|}{60 INCHES WITHOUT SHIELD } & & & & & \\
\hline 127 & 80.4 & 730 & 61.3 & 383 & 0.53 & 27.92 & 1.5 & 5.1 & 0.86 \\
\hline 128 & 80.4 & 1077 & 67.2 & 347 & 0.92 & 34.59 & 2.7 & 8.0 & 0.91 \\
\hline 129 & 80.5 & 1439 & 71.6 & 315 & 0.22 & 39.35 & 5.6 & 14.5 & 0.95 \\
\hline 132 & 100.1 & 725 & 75.0 & 480 & 0.66 & 23.93 & 0.6 & 1.9 & 0.85 \\
\hline 131 & 100.2 & 1075 & 81.3 & 438 & 0.41 & 29.99 & 1.0 & 3.6 & 0.87 \\
\hline 130 & 100.4 & 1442 & 87.0 & 392 & 0.27 & 35.26 & 2.6 & 8.5 & 0.90 \\
\hline 133 & 120.6 & 713 & 88.5 & 583 & 0.82 & 22.36 & 0.1 & 0.5 & 0.85 \\
\hline 134 & 120.8 & 1070 & 86.0 & 538 & 0.50 & 28.09 & 0.4 & 2.5 & 0.88 \\
\hline 135 & 120.5 & 1454 & 102.4 & 492 & 0.34 & 32.95 & 0.8 & 5.0 & 0.90 \\
\hline
\end{tabular}

Conversion 10 SI Units:

\begin{tabular}{|llc|}
\hline From: & To: & Multiply By: \\
psig & Pa(0ago) & 6895 \\
$1 \mathrm{~b} / \mathrm{hr}$ & $\mathrm{ko} / \mathrm{s}$ & $1.26 \mathrm{E}-4$ \\
\hline
\end{tabular}


TABLE 3

Effect of the Spray Shield and Axial Location on the Measured Sauter Mean Diameters for the Lechler Atomizer

Parameter

Effect of Measurement Position, $3 \mathrm{ft}$. to $5 \mathrm{ft}$. Without a Shield

Effect of Measurement Position, $3 \mathrm{ft}$. to $5 \mathrm{ft}$. With a Shield.

Effect of Installing a Spray Shielding t $3 \mathrm{ft}$.

Effect of Installing a

Spray Shield at $5 \mathrm{ft}$.
Average Increase in Sauter Mean Dianeter and the Standard Deviation of the Average Average (microns)

$$
9.5
$$$$
1.2
$$

3.0 1.1

3.3 2.2

TABLE 4

Effect of the Spray Shield and Axtal Location on the Measured Sauter Mean Diameters for the MK -7 I-Jet Atomizer

\section{Parameter}

Effect of Messurement

Position, $3 \mathrm{ft}$. to $5 \mathrm{ft}$.

Without Shield

Effect of Measurement Pasition, $3 \mathrm{ft}$. to $5 \mathrm{ft}$. With Shield.

Effect of Installing Spray Shielding at $3 \mathrm{ft}$.

Effect of Installing a Spray Shieid at 5 pt.
Average Increase in Sauter Mean Diameter and the Standard Deviation of the Average Average (microns) Std. Dev. (microns)

5.9

1.5

8.5

2.2

0.7

4.8

1.6 
TABLE 5

Compressor Operating Conditions for Determining Compressed Air Energy Requirements for the Three Atomizers

\begin{tabular}{|c|c|c|c|c|}
\hline Atomizer & $\begin{array}{c}\text { Inlet } \\
\text { Temperature } \\
\text { (F) } \\
\end{array}$ & $\begin{array}{c}\text { Inlet } \\
\text { Pressure } \\
\text { (psia) } \\
\end{array}$ & $\begin{array}{c}\text { Discharge } \\
\text { Pressure } \\
\text { (psta) } \\
\end{array}$ & $\begin{array}{c}\text { Specific } \\
\text { Energy* } \\
\text { (Btu/lb air) } \\
\end{array}$ \\
\hline $\begin{array}{l}\text { Lechler and } \\
\text { Parker-Hannifin }\end{array}$ & 80 & 14.7 & 114.7 & 69.4 \\
\hline Mk-7 I-Jet & 80 & 14.7 & 164.7 & 84.3 \\
\hline
\end{tabular}

TABLE 6

Liquid Pressure - Liquid Flow Sensitivities

of the Three Atomizers at Full and Half Load

\begin{tabular}{|c|c|c|c|}
\hline Atomizer & $\begin{array}{l}\text { Flow Rate } \\
(1 \mathrm{~b} / \mathrm{hr})\end{array}$ & $\begin{array}{c}\text { Slope } \\
(10 / \mathrm{hr} / \mathrm{ps} 1) \\
\end{array}$ & $\begin{array}{c}\text { Slope } \\
\text { (\% of flow/psi) }\end{array}$ \\
\hline Parker-Hannifin & $\begin{array}{r}720 \\
1440\end{array}$ & $\begin{array}{l}22.9 \\
11.9\end{array}$ & $\begin{array}{l}3.2 \\
0.8\end{array}$ \\
\hline Mk-7 I-Jet & $\begin{array}{r}720 \\
1440\end{array}$ & $\begin{array}{l}52.0 \\
52.0\end{array}$ & $\begin{array}{l}7.2 \\
3.6\end{array}$ \\
\hline Lechler & $\begin{array}{r}720 \\
1440\end{array}$ & $\begin{array}{l}176.0 \\
176.0\end{array}$ & $\begin{array}{l}24.4 \\
12.2\end{array}$ \\
\hline
\end{tabular}




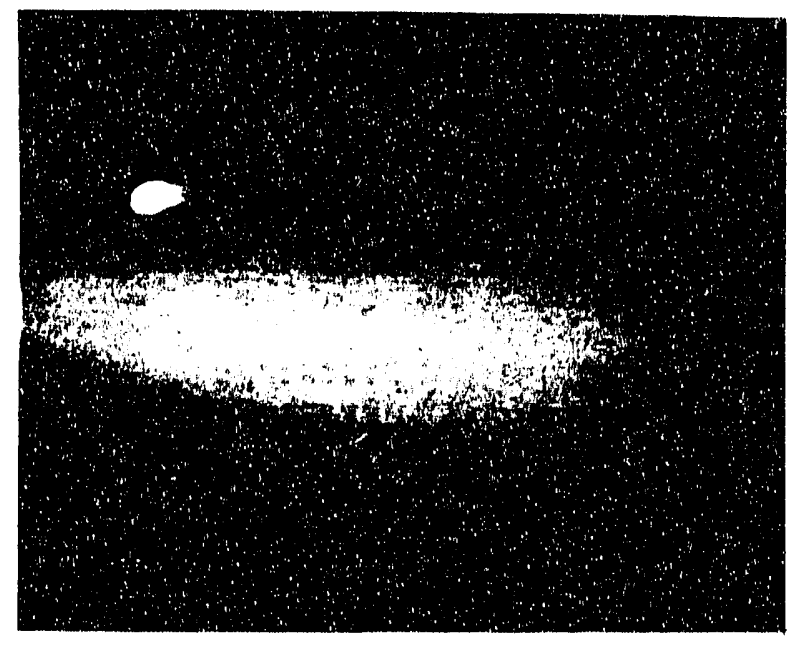

Parker-Hannifin $80 \mathrm{psig} ; 1440 \mathrm{lb} / \mathrm{hr}$ Spray Angle $=25-1 / 2^{\circ}$

Mk-7 I-Jet

$120 \mathrm{psig} ; 1440 \mathrm{lb} / \mathrm{hr}$ Spray Angle $=22^{\circ}$

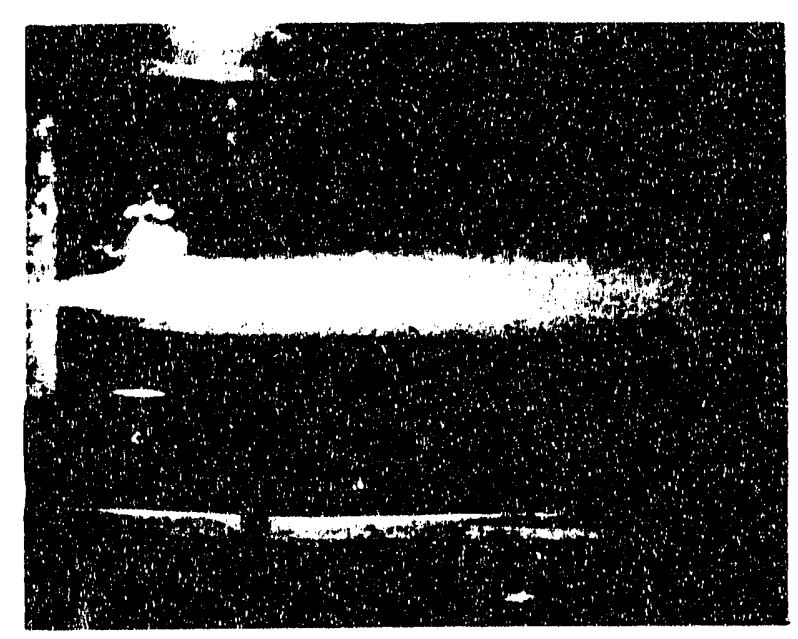

Lechler

60 psig; $1440 \mathrm{lb} / \mathrm{hr}$ Spray Angle $=14^{\circ}$

FIGURE 1. Spray Patterns of the Three Types of Atomizers 


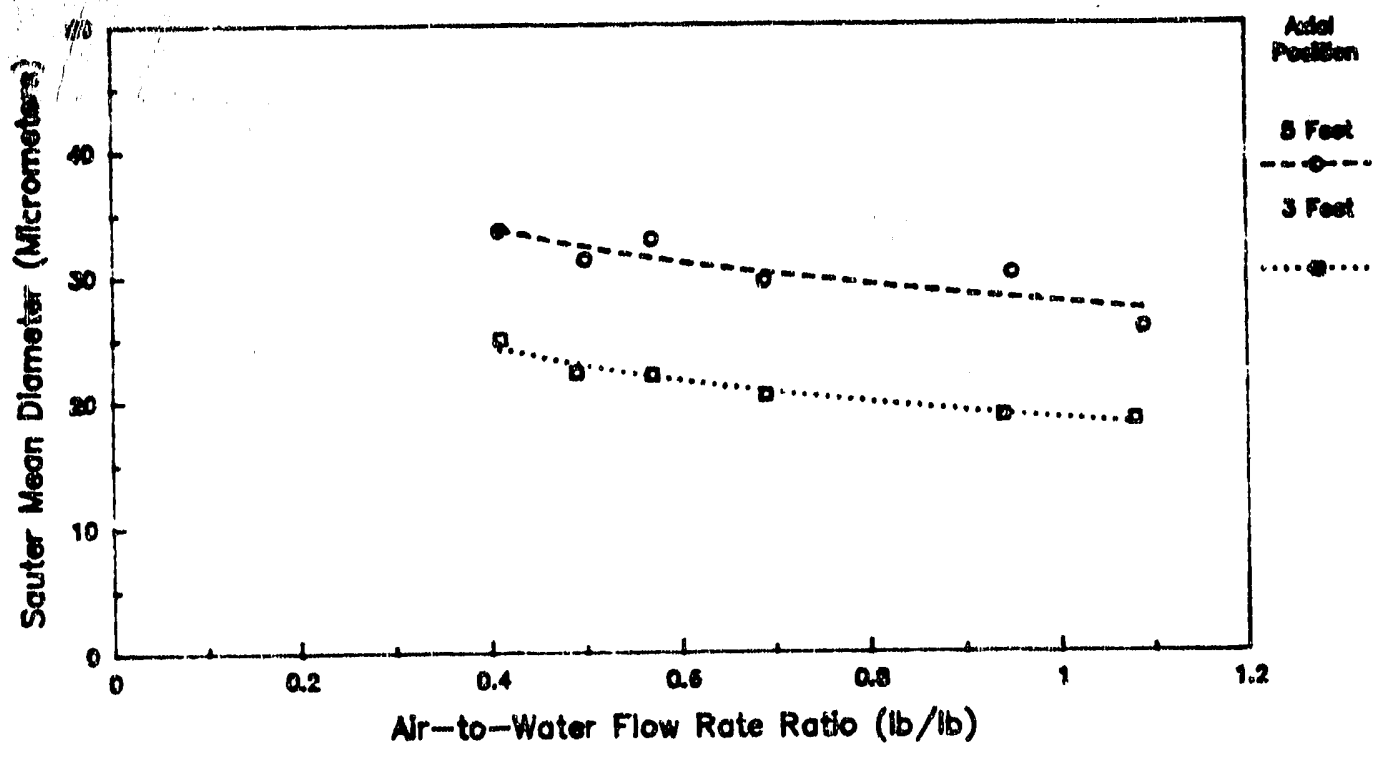

Lrentans

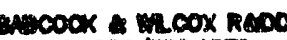
Cod 1230/1004572

FIGURE 2. Variation of Sauter Mean Diameter With $A / W$ Ratio and Axial Position for the Lechler Atomizer Without a Spray Shield

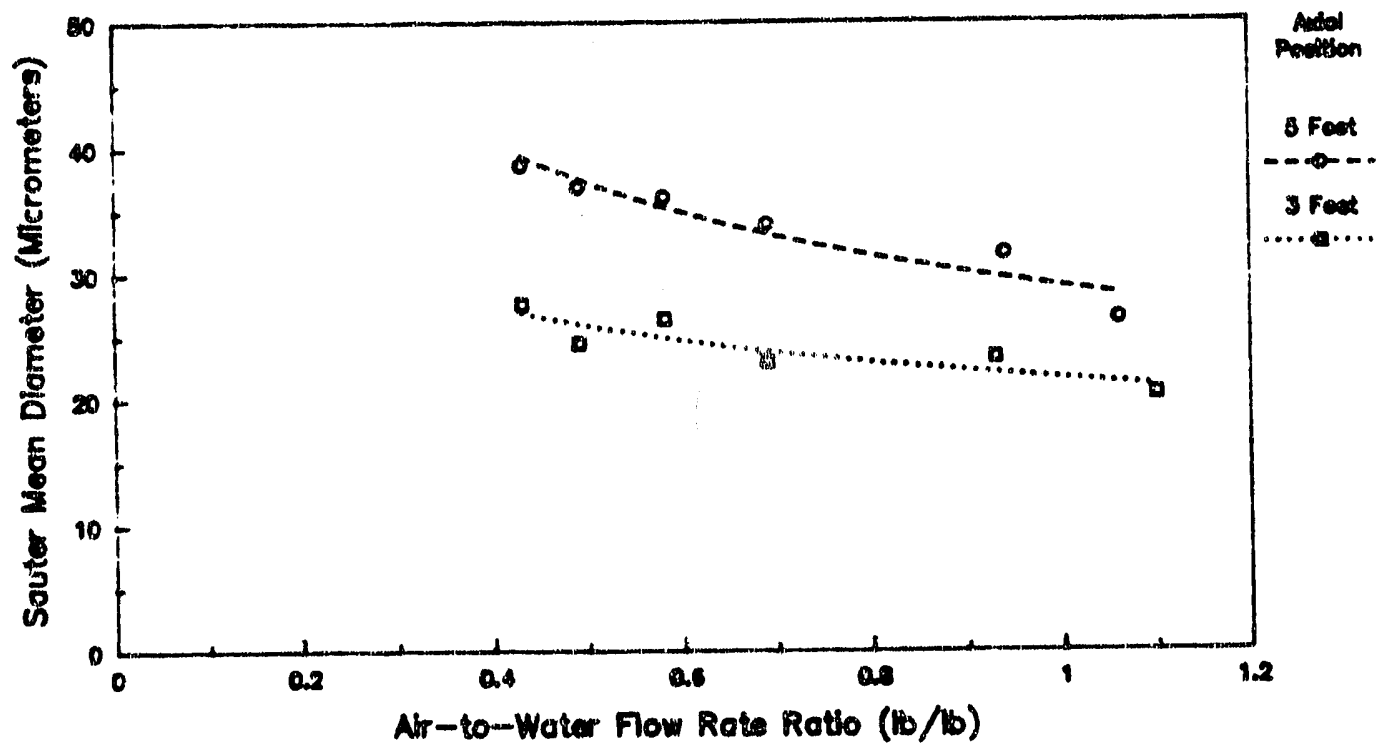

Lowantivis

FIGURE 3. Variation of Sauter Mean Diameter With $A / W$ Ratio and Axial Posirion for the Lechier Atüinizer with a Spraj Shis?d 

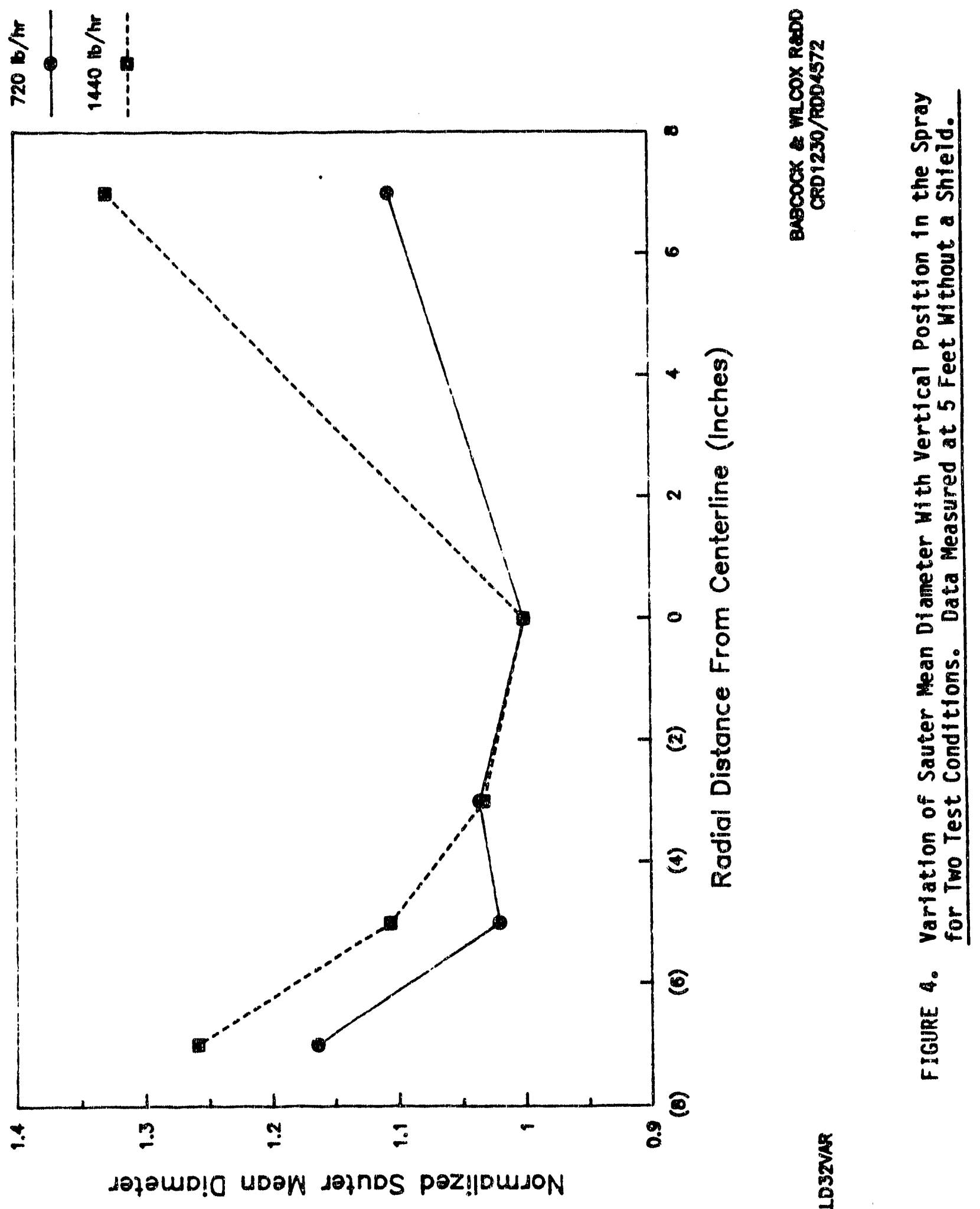

瓷 


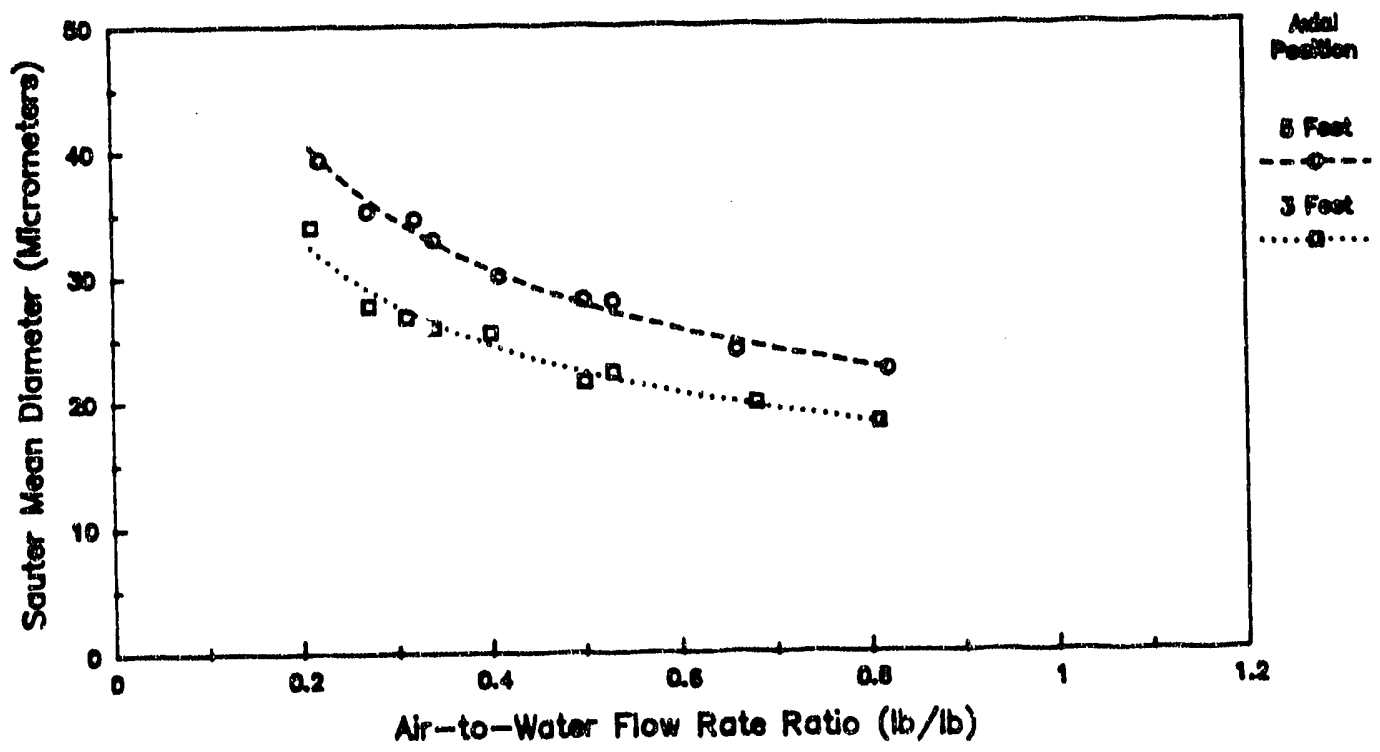

unns

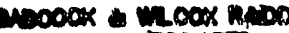
Copi2so/mostort:

FIGURE 5. Variation of Sauter Mean Diameter With A/W Ratio and Axial Position for the Mk-7 I -Jet Atomizer Without a Spray Shield

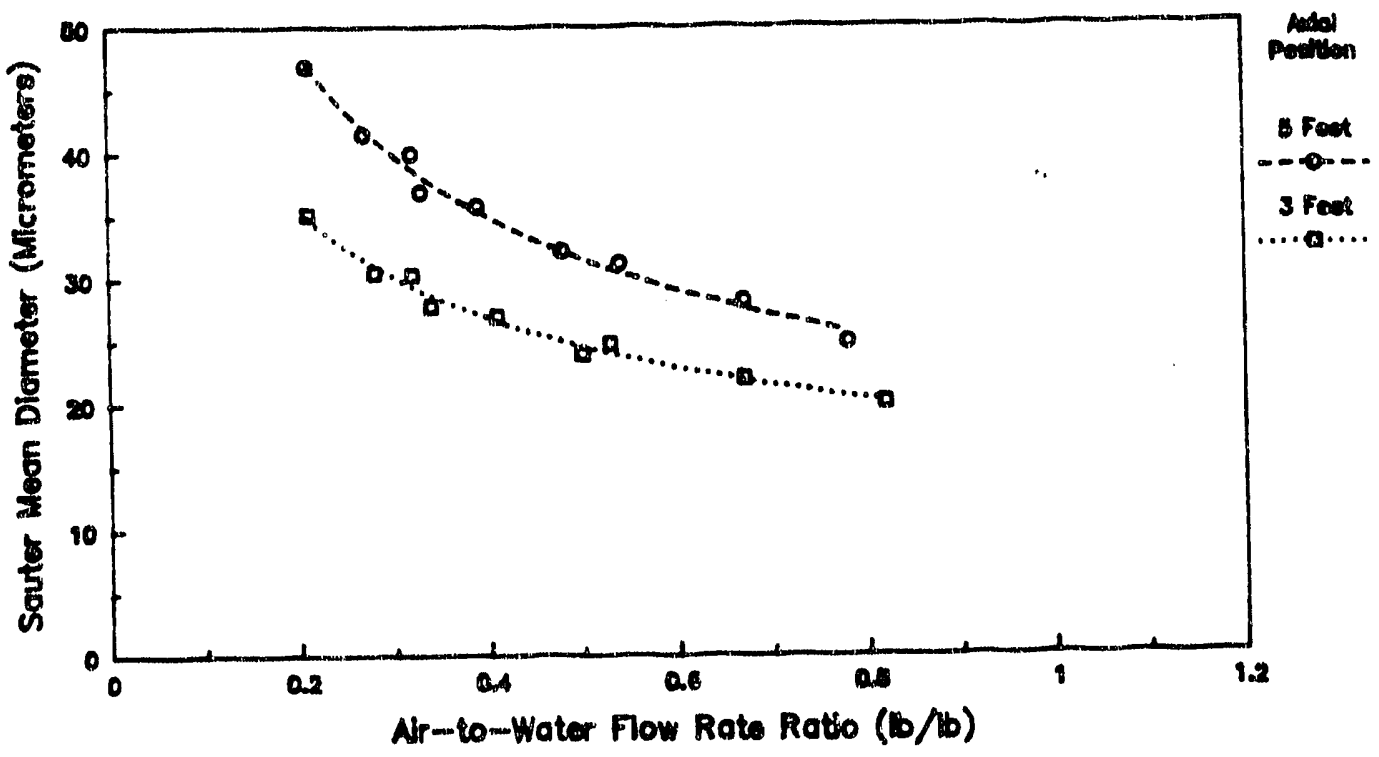

Mxrom

mocoox ancox nem ciol200/4004072

FIGURE. 6. Variation of Sauter Mean Diameter With A/W Ratio and Axial Position for the MK-7 I-Jet Atomizer Hith a Spray Shield 


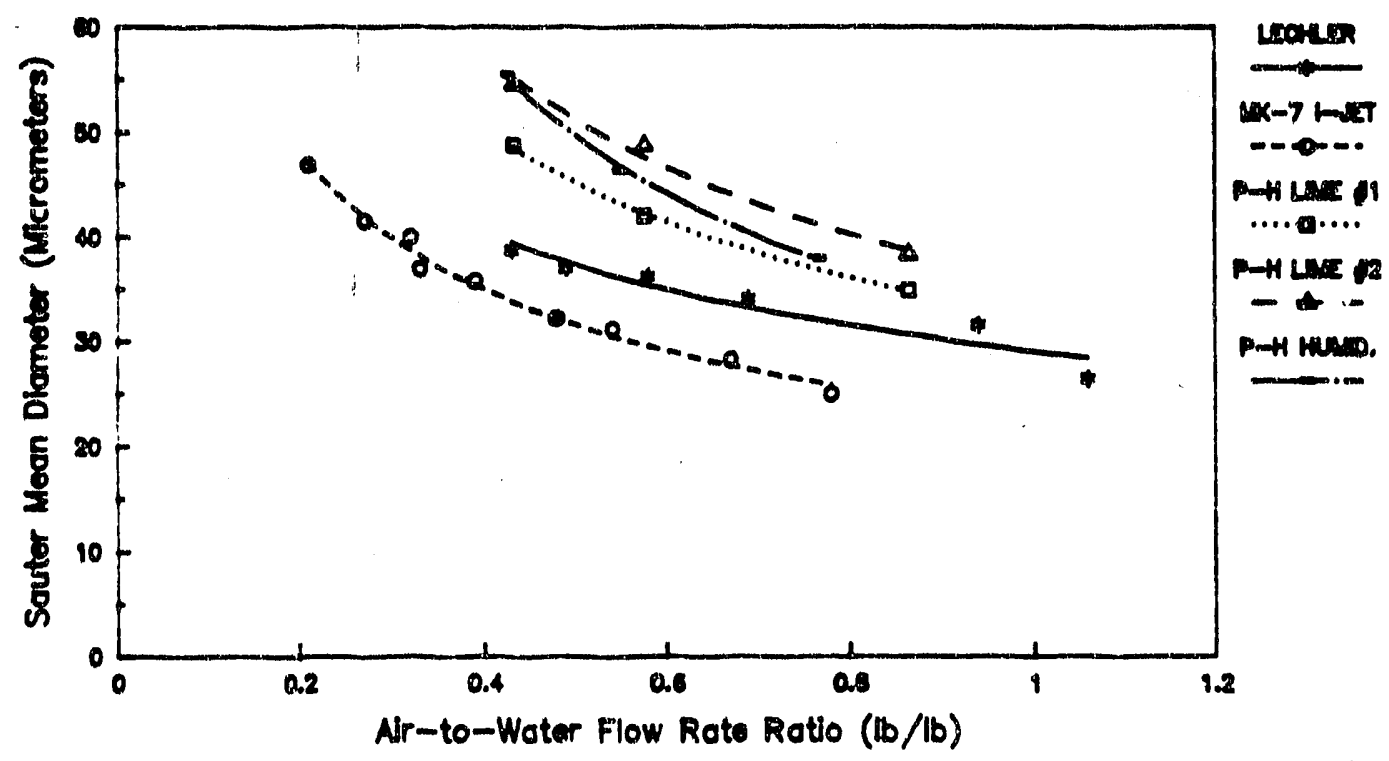

neows

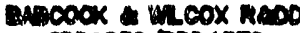
$01230 / 1004872$

FIGURE 7. Comparison of the Sauter Mean Diameters for the Three Types of Atomizers on the Basis of A/W Ratio. All Data Was Measured at 5 Feet With a Spray Shield.

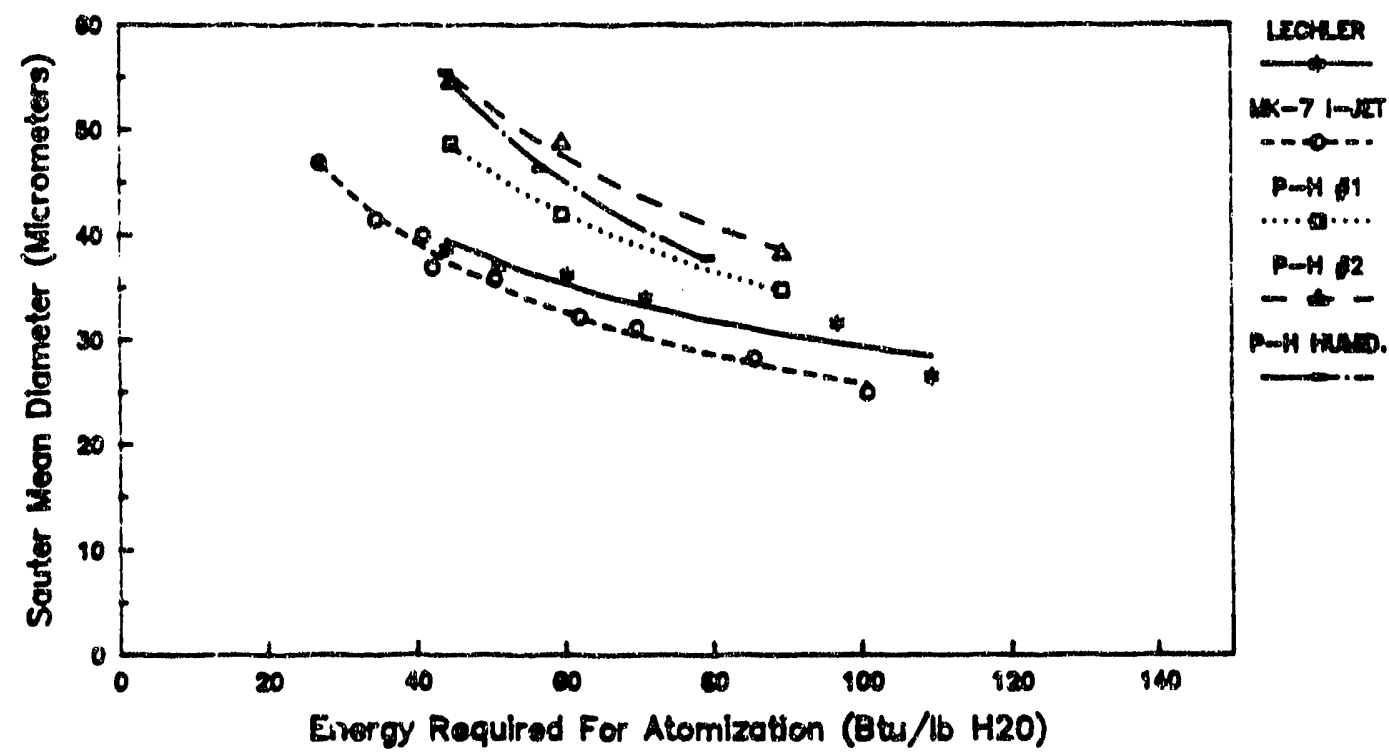

EPALI

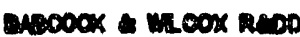

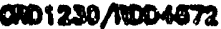

FIGURE 8. Comparison of the Sauter Mean Diameters for the Three Types of Atomizers on the Basis of Energy Required for Atomization. All Data Was Measured at 5 Feet with a Spray Snieid. 

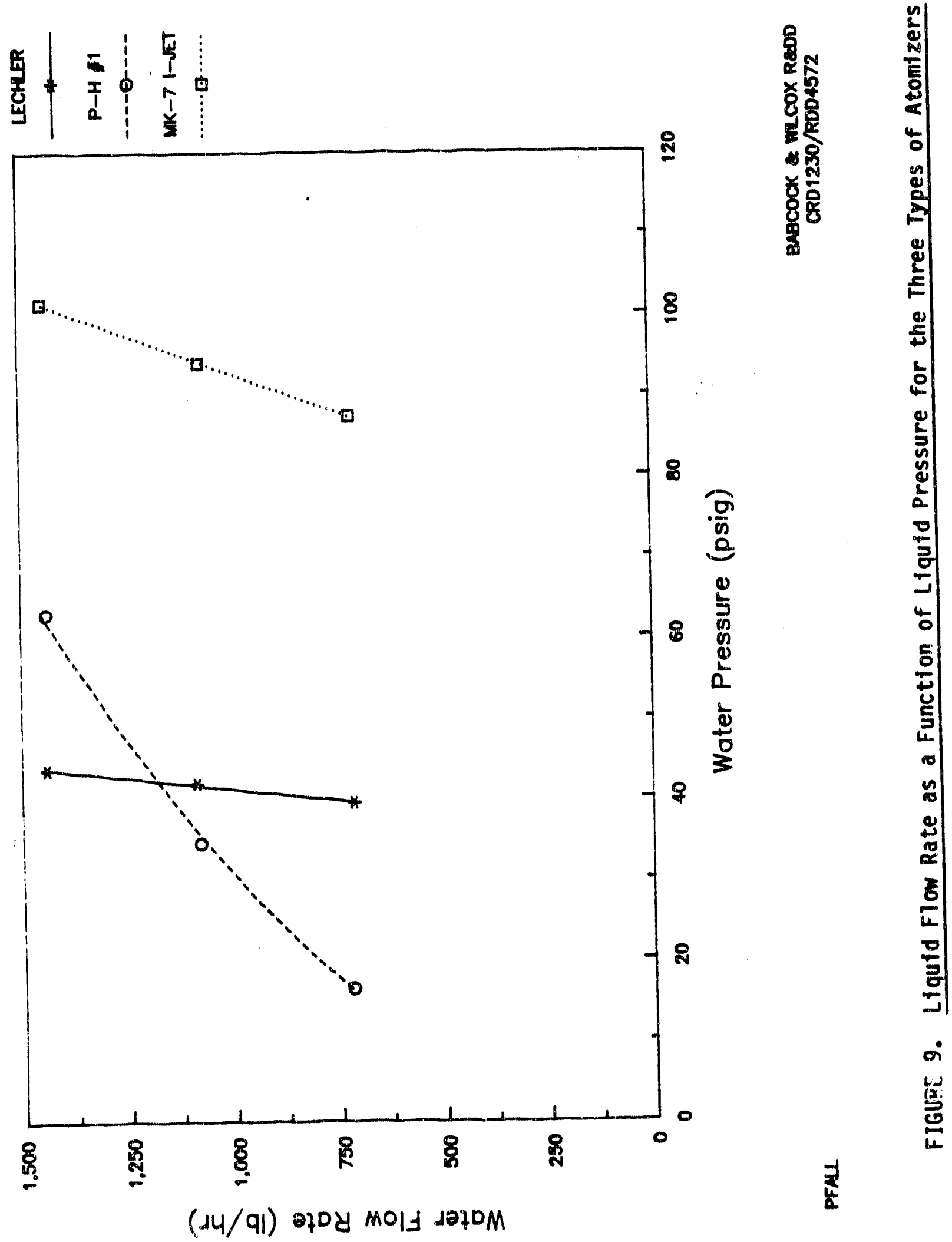

촐

$$
\text { A }-23
$$




\section{APPENDIX B}

THRUST DATA FOR LECHLER, PARKER HANNIFIN, AND BEW I-JET ATOMIZERS 
The following report documents the results of thrust tests on four duct injection atomizers. These tests provide atomizer velocity and momentum data for input to the second Generation Duct Injection Model. Babcock \& Wilcox is developing this model for united Engineers and Constructors as part of the U.S. Department of Energy's Duct Injection Technology Development Program.

The reactive forces (thruets) of four different atomizers were measured at the Alliance Research Center's Atomization Facility. The four atomizers are appropriate for duct injection type applications. The atomizers tested were a Parker Hannifin, a Lechler, and two Babcock Wilcox I-Jets -- the Mak-7 and the MK-12.

The BWW, Lechler, and Parker Hannifin atomizers studied during this test program covered a range of flow types. Based on the type of atomizer, a specific simplified form of the momentum equation was derived that related momentum force (thrust) to the flow rates of air and water. The constants in the momentum equation for each atomizer were empirically determined by a linear least squares regression of the data to the respective model.

Forces that were calculated using the semi-empirical (curve-fit) equations were in good agreement with the measured data. The standard error of the estimated reaction force was 11.98 for the I-Jet atomizers, 6.18 for the Lechler atomizer, and 3.78 for the Parker Hannifin atomizer.

The correlations generated by the linear regression analysis axe atomizer specific. To evaluate the ability to generalize to atomizers of different capacity or slightly different geometry, the constants in the momentum equation for the I-Jet and Lechler atomizers were estimated based on flow areas and fluid properties. This approach was not used on the Parker Hannifin atomizer because of an incomplete understanding of the flow patterns at the atomizer discharge, and uncertainties in the flow areas and air splits.

For the I-Jet and Lechler atomizers, the correlated and estimated values of the constants in the momentum equation were in reasonably good agreement, with differences of 168 and 288 , respectively. 
The results of the analysis indicate that the momentum force produced by I-Jets of any arbitrary capacity can be estimated with reasonable accuracy.

For the Lechler and Parker Hannifin atomizers, the equations relating atomizer momentum and air and liquid flow rate are pecific for those atomiaers tested.

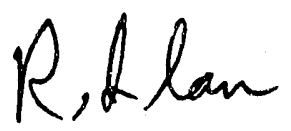

R. Ilan

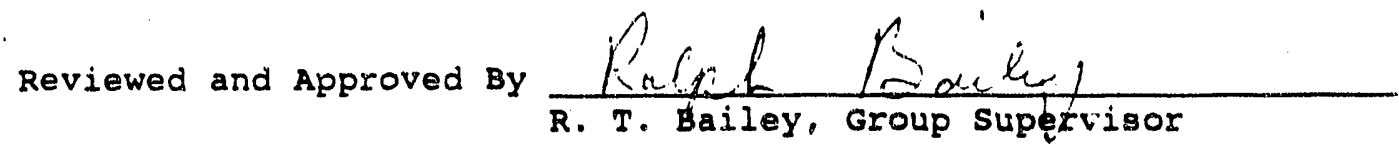




\section{Introduction}

There is a need for quantitative atomizer velocity and momentur data to support ongoing BCW modeling efforts. Mosentum is an important term in the current generation model (DRYMO); it drives the mixing process, entrainnent. and jet mpreading. Due to constrainte on the model' grid aize, the control volume umed to represent an atomizer is typically an order of magnitude larger than the nozzle diameter of the atomizer. Thus, at atomizer control volumes, the flue gan ontrained by the atomizer must be input as a boundary condition. Assumptions made to estimate initial flue gas entrainment in the duct usually underpredict the preseure increase downetrean of the atomizer plane.

The average atomizer exit velocity is required boundary condition for DRMO. To date, this velocity cannot be directly monured, and there is a large degree of uncertainty in its predicted value. However, a sperficial atomizer exit velocity which assumes a homogeneous two-phase flow mixture can be calculated from momentum dat coupled with flow rate information. This calculation does not require any aseumptions about pressure in the exit plane of the nozzle.

One mothod of obtaining both momentum and velocity date for an tomizer is by anuring it thrust or reactive force. The thruste produced by four different commexcial atomizers were masured at the Alliance Research Conter's Atomization Facility. The atomizer teeted were a Parker Bannifin, Iechler, and two BCW I-Jets -- the MR-7 and MRK-12.

\section{Test Apperatus and Method}

The atomizers were tested at the Alliance Research Center's Atomization Facility (Appendix A). For ach of the atomizer tented, the momentum force (thrust) was mosured dirsctly by oparating the atomien while lt was placed on digital cale. Figure 1 how the BCW MK-12 I-Jet in the toot otand with the digital scale beneath. Bigh preseure flexiblo hose was used for air and water upply lines. Steel rollere were placed betwoen the test otand and the scale. The use of these high preseure lines and the steel rollere made it possible to avoid the complicated calibration reguired to offet the effect of both preswure in the supply lines and tart-up ixpulsive disturbances on the seale readinge. Prior to operation, the acale was taried to of foet the weight of the atomizer.

The Lechler tomizer (S/N 199,005,23) im dual Eluid type with a eingle tapered discharge hole. The atomizer form a ingle eolid cone of epray. The water in injected coaxially with the diecharge hole, and the air in injected radially through multiple holes. The Parker Bannifin atomizer ( $8 / \mathrm{N} 60003$ ) is a dual fluid, external mix type that form a minglo wolid cone mpay at the atomizer' discharge. The Parker Bannifin and lochlez atomizers ware upplied by Gilbert/Comnonwealth from their Buverly, Ohio, facility.

With the BCW I-Jet, the air-liguid mixture is atamized through four discharge holes in the atomizer end cap. The discharge holes are diutributed around the axis of the tomizer and are directed at an angle of 12.5 degraes from the atomizer'axis. The two I-Jet at mizers tastad had nominal liquid

$$
\begin{aligned}
& -3- \\
& B-5
\end{aligned}
$$




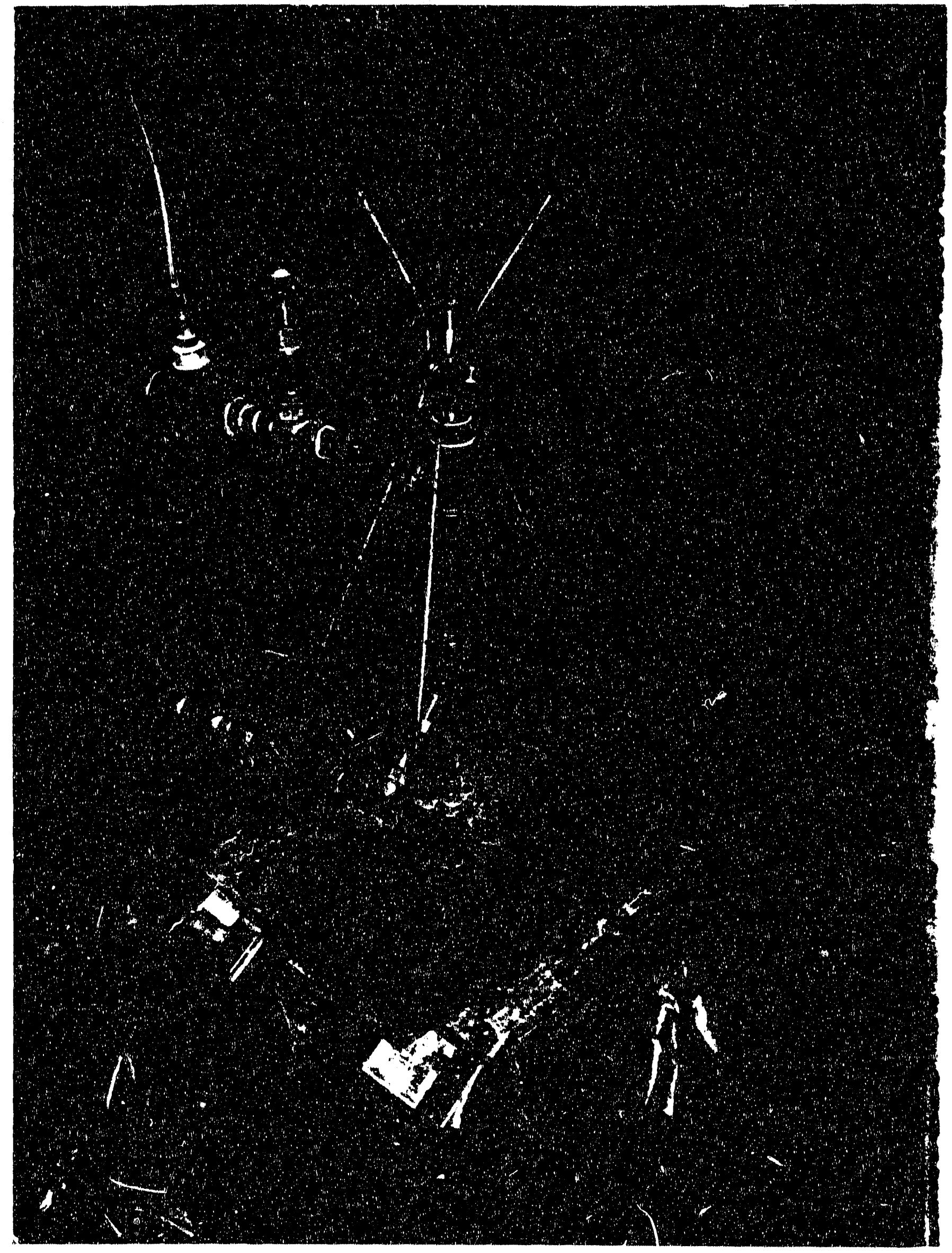

FIGURE 1. Zizunt Teat stand With BCM HX-12 I-Jat

$$
\begin{aligned}
& -4- \\
& B-6
\end{aligned}
$$


capacities of 400 and $1200 \mathrm{Ib} / \mathrm{hr}$. The I-Jet atomizers wero oxiginaliy fabricated a part of the IIMB Eumidification Program.

For each atomizar tested, the air presesure and watex flow rates were varied and the momontum force at onch condition was mesured. Thexe were two purposes to tenting each atamizer at veveral conditions. whe fixet purpose was to provide quantitative aventum and velocity information over a range of flow condition that imulate differont degreos of bunidification. The second purpose was to determine, by analyeis of the data, if tbere is a reamonably traightforward method for calculating atomizer momentum from alr and water flow rater.

The BEW IRK-7 I-Jet was tested at water flow ratoo of 180,960 , and 1440 lb/hr, which topresent 108,808 , and 1208 of full $10 a d$. The kn-12 I-Jet, which has amaliex capacity, wall tested at water flow rates of 120,240 , and $480 \mathrm{lb} / \mathrm{hr}$. The atomizing air preseure for both I-Jets rangeal from 60 to 120 psig. The parker gannifin atomizer, which has a imilar capacity to the var-7 I-Jet, was tented at water flow rates of $480,720,960$, and $14401 \mathrm{~b} / \mathrm{hx}$, Atomizing air pressures for the Parker Bannifin atomizer were 60 und 70 pig. The Iechler atamizer also has a capacity oimilax to the MK-7 I-Jet and tho Parker Bannifin atonizer. The Lechler atomizor was tontod at water flow rates of 720,1080 , and $2440 \mathrm{db} / \mathrm{hr}$ and at atomizing air praseures of 50 and 60 paig.

\section{Resulte and Discuselon}

Tabulated teat date for the Lechler, Parkex gannifin, and BcW ImJet atomizer are contained in rable 1. This teble includes atomiring flow conditione, and the measured montum force at ach condition. Tuble 1 also contains calculated value of total mas flow rate and low quality, and a calculated mparicial exit velocity. The quality at each condition in defined as the mass flow rate of al divided by the total mass flow rate. The superficial exit velocity is defined as the momentum force divided by the total mass flow rate. Thio velocity calculation will be dimcuesed in further detail below.

\section{Mtomiger Momentur Anelreis}

For each type of atomizer tooted, correlation analysen were performed on the momoneun date to deterwine the relationship between tho air and liquid flow rates and the etomizer momontum. Although the throe typer of atomizers have uimilar capacities, each has different flow eharactoristice governing their operation. The BEW I-Jet and the Lechlex atconizer are both internally mixed atomizers. Bowever, because of the difference in the diecharge holo dimension batween the two atomizers, the I-Jet atoujizer operates under a choked flow condition, while the Isechler doow not. The Paxker Bannifin is an externally nixed air ansint ntomizer. The air lapinges on the liguid outside the atcmizer' diecharge orffices. Becaue of the variation in atomizer type, three neparate form of the momentum equation war developed to predict atomizer nomentura. 
TABLE 1 - Momenturn Data For Thrust Test on B\&W, Lechlar, and Parker Hannifin Atomizers Custom DOEJUEC

Project Number : 4572

\begin{tabular}{|c|c|c|c|c|c|c|c|c|c|c|}
\hline $\begin{array}{c}\text { Run } \\
\text { Number }\end{array}$ & $\begin{array}{l}\text { Run } \\
\text { ID }\end{array}$ & $\begin{array}{l}\text { Air } \\
\text { Press } \\
\text { (psig) }\end{array}$ & $\begin{array}{l}\text { Liquid } \\
\text { Press } \\
\text { (psig) } \\
\end{array}$ & $\begin{array}{l}\text { Liquid } \\
\text { Flow } \\
\text { (b/hr) }\end{array}$ & $\begin{array}{c}\text { Air } \\
\text { Flow } \\
\text { (b/hr) }\end{array}$ & \begin{tabular}{c|} 
Total \\
Mass Flow \\
(b)hr)
\end{tabular} & $\begin{array}{c}\text { Quality } \\
(x)\end{array}$ & $\begin{array}{c}\text { Air/Water } \\
\text { Ratio } \\
\text { (b/lo) }\end{array}$ & $\begin{array}{l}\text { Momentum } \\
\text { Force } \\
\text { (bi) }\end{array}$ & $\begin{array}{c}\text { Exit } \\
\text { Velocity } \\
\text { (t/s) }\end{array}$ \\
\hline 1 & MK1260 & 59.8 & 43.0 & 121 & 96 & 217 & 0.443 & 0.797 & 1.23 & 657 \\
\hline 2 & MK1260 & 60.0 & 49.6 & 230 & B3 & 313 & 0.267 & 0.364 & 1.34 & 498 \\
\hline 3 & MK1260 & 59.6 & 60.9 & 485 & 58 & 543 & 0.107 & 0.118 & 1.46 & 312 \\
\hline 34 & $M K 1280$ & 80.0 & 57.0 & 113 & 131 & 243 & 0.536 & 1.157 & 1.64 & 781 \\
\hline 35 & $M K 1280$ & 80.1 & 65.8 & 248 & 111 & 359 & 0.309 & 0.446 & 1.78 & 575 \\
\hline 37 & MK12100 & 100.1 & 72.7 & Til & 158 & 269 & 0.589 & 1.431 & 2.14 & 923 \\
\hline 38 & MK 12100 & 100.8 & 83.0 & 244 & 138 & 383 & 0.361 & 0.565 & 2.40 & 727 \\
\hline 30 & MK12100 & 100.5 & 86.0 & 477 & 108 & 585 & 0.184 & 0.226 & 2.62 & 520 \\
\hline 40 & MK12120 & 120.3 & 113.3 & 495 & 132 & 627 & 0.211 & 0.267 & 3.21 & 594 \\
\hline 41 & MK12120 & 119.5 & 96.9 & 254 & 164 & 418 & 0.393 & 0.647 & 2.97 & 823 \\
\hline 42 & MK12120 & 120.3 & 8.5 .7 & 114 & 188 & 302 & 0.623 & 1.653 & 2.71 & 1039 \\
\hline 43 & MK760 & 60.0 & 42.8 & 447 & 333 & 780 & 0.426 & 0.743 & 4.64 & 690 \\
\hline 44 & MK760 & 59.6 & 49.3 & 961 & 272 & 1233 & 0.221 & 0.284 & 5.25 & 493 \\
\hline 45 & MK760 & 59.3 & 55.4 & 1464 & 226 & 1690 & 0.134 & 0.155 & 5.34 & 366 \\
\hline 46 & MK780 & 80.2 & 71.1 & 1412 & 321 & 1733 & 0.185 & 0.228 & 7.32 & 490 \\
\hline 47 & MK780 & 78.6 & 63.5 & 960 & 367 & 1327 & 0.277 & 0.382 & 6.91 & 604 \\
\hline 48 & MK780 & 81.8 & 55.6 & 430 & 446 & 876 & 0.509 & 1.037 & 6.56 & 868 \\
\hline 49 & MK>100 & 95.8 & 66.8 & 509 & 503 & 1012 & 0.497 & 0.988 & 8.27 & 947 \\
\hline 50 & MK7100 & 100.6 & 80.0 & 1000 & 465 & 1466 & 0.318 & 0.465 & 8.96 & 709 \\
\hline 51 & MK7100 & 102.3 & 89.3 & 1490 & 414 & 1904 & 0.218 & 0.278 & 9.45 & 575 \\
\hline 52 & MK7120 & 120.0 & 101.6 & 1476 & 490 & 1966 & 0.249 & 0.332 & 11.90 & 702 \\
\hline 54 & LECHGO & 59.2 & 44.2 & 726 & 773 & 1499 & 0.516 & 1.064 & 10.24 & 792 \\
\hline 55 & LECHGO & 62.8 & 49.6 & 1100 & 778 & 1878 & 0.414 & 0.707 & 11.92 & 736 \\
\hline 56 & LECHGO & 59.0 & 48.7 & 1457 & 700 & 2157 & 0.324 & 0.480 & 12.01 & 646 \\
\hline 57 & LECH5O & 50.5 & 41.6 & 1416 & 613 & 2028 & 0.302 & 0.433 & 9.77 & 558 \\
\hline 58 & LECHSO & 49.2 & 38.9 & 1107 & 626 & 1732 & 0.361 & 0.565 & 9.06 & 606 \\
\hline 59 & LECH5O & 49.2 & 36.8 & 734 & 666 & 1400 & 0.476 & 0.907 & 8.29 & 687 \\
\hline 64 & PH7O & 70.8 & 15.8 & 487 & 611 & 1097 & 0.556 & 1.255 & 5.11 & 540 \\
\hline 65 & PH7O & 70.0 & 35.0 & 740 & 602 & 1342 & 0.449 & 0.814 & 5.39 & 466 \\
\hline 66 & PH7O & 70.1 & 59.2 & 965 & 608 & 1573 & 0.386 & 0.630 & 5.56 & 410 \\
\hline 67 & PH7O & 68.9 & 144.9 & 1450 & 596 & 2046 & 0.294 & 0.411 & 5.91 & 335 \\
\hline 68 & PH6D & 60.8 & 35.0 & 741 & 538 & 1279 & 0.421 & 0.726 & 4.54 & 411 \\
\hline 69 & PH6O & 60.7 & 60.7 & 979 & 538 & 1517 & 0.355 & 0.549 & 4.68 & 358 \\
\hline 70 & PH60 & 60.6 & 146.0 & 1455 & 535 & 1990 & 0.269 & 0.367 & 5.0 .4 & 294 \\
\hline 71 & PH6O & 59.6 & 14.7 & 473 & 537 & 1010 & 0.532 & 1.135 & 4.35 & 499 \\
\hline
\end{tabular}

$-6-$

$B-8$ 
For the I-Jet. and Lechler atomirere, the conetante in the mamentum aguation were determined by two different wathods. The first method ostimated the constinte by calculating values baued on the respective flow areas and fluid propertiea. The second thod somi-ampirically determined the constants by a linear leadt equares regremoion (curve fit) of the moasured data to the rospective model. The conetants that were ovaluated by a curve fit to the dat are epecific for the atonizers tested during this program. The values determined by the above two nethods were compared to ovaluate the ability to generaliza to different capacities or slightly different geometries.

Due to the complexity of the fluid mehanice governing the Parkax gannifin atomizex, the conetants in the nomntum equation were determined only by ami-empirical curve fit of th" dita to a suitable model, and are opecific to the atomizar atudied in this program.

\section{Mamentum analedis for the Bev I-Jet Atondeer}

The aseumptions used to determine the form of the equation relating atomizer womentur force and maso flow for the Biw I-Jet atomizer are based on the "Bomogeneous Frozen" model of critical two-phase flow. The model assumes choked flow in the tonizer discharge holes, inentropic expaneion of the gas phase, and negligible vaporization of the diquid phave. The nodel ralaten the discharge preseure to the total mase flux through the discharge holen and obtains the following equation(1):

$$
p_{d}^{2}=\left(\frac{C_{1}}{A_{d}^{2}}\right)\left(\frac{R T}{g_{c}}\right) A_{p}^{2} x
$$

$$
\text { where: } \begin{aligned}
c_{1} & =2.12 \text { for I-Jeta } \\
A_{d} & =\text { diecharge flow area } \\
h_{T} & =\text { total mas flow rate } 1 \mathrm{~b} / \mathrm{sec} \\
x & =\text { Flow quality }=\frac{a}{M_{T}}
\end{aligned}
$$

since thare is no accelexation of the atanizer, the force the atomiger exerts on its urroundinge is:

$$
I=R_{d} A_{d}=C A_{y} \sqrt{x}
$$

where: $c=\sqrt{C_{1} R T / \bar{g}}$

(1) P. J. Winter and R. T. Bailey, "Droplet size and Bydraulic Modelo for Atomization", RDD:87:7863-01-01:01, October 11, 1988. 
It whould be emphasized that the constant, $C$, has no area depondent terms. Thi conetant is general for all I-Jet atomizera. For the conditions tested, based on Equation (3), the estimated value of the constant $c$ is 43.5 (2bf isec/dbul).

A somi-ompirjcal value for $C$ was deturmined for tho Bsw I-Jot by a laat mquares regression of the measured thrust data to an equation with the sama form as rquation (2). The result of this analyode gives the followilig values:

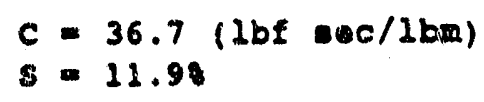

where: $s$ - the (3) etandard error of the force atimate.

Table 2 contains the masured momentum data and the I-Jet atomizer ragreseion analyai. rigure 2 howe a comparioon betweon the maeured and correlated values of the momentum force for the kK-7 and kK-12 I-Jet etamizers.

There is a 168 difference between the values of $c$ determined by the above two thode. This difference can, in part, bettributed to deficiencies in the analytical nodel in accounting for irrevexuible pressure losses through the discharge holen. There are also accumulated effects of uncertaintine in the mase flow rate and force menurements.

\section{Corralation snalrede for the Lechler Mtomizer}

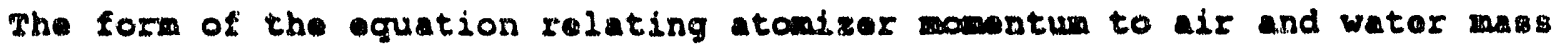
flow rates for the Lechler atomizer was developed as follow. The rodel assumen atmoupheric prassure at the oxit of the atomizer, and no-sip condition between the air and water. The manontum thoorem gives:

$$
I=P_{m} \int_{A_{d}} v^{2} d x
$$

where: $P_{n}=$ deneity of the alr/water mixture

$A_{d}$ = discharge area of the atomizer.

which, wuming a flat velocity profile, upon further raduction given:

$$
r=\frac{p_{x}^{A} d^{2}}{g_{c}}
$$




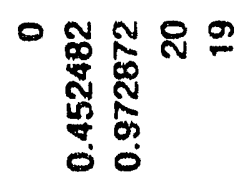

$\stackrel{9}{=}$

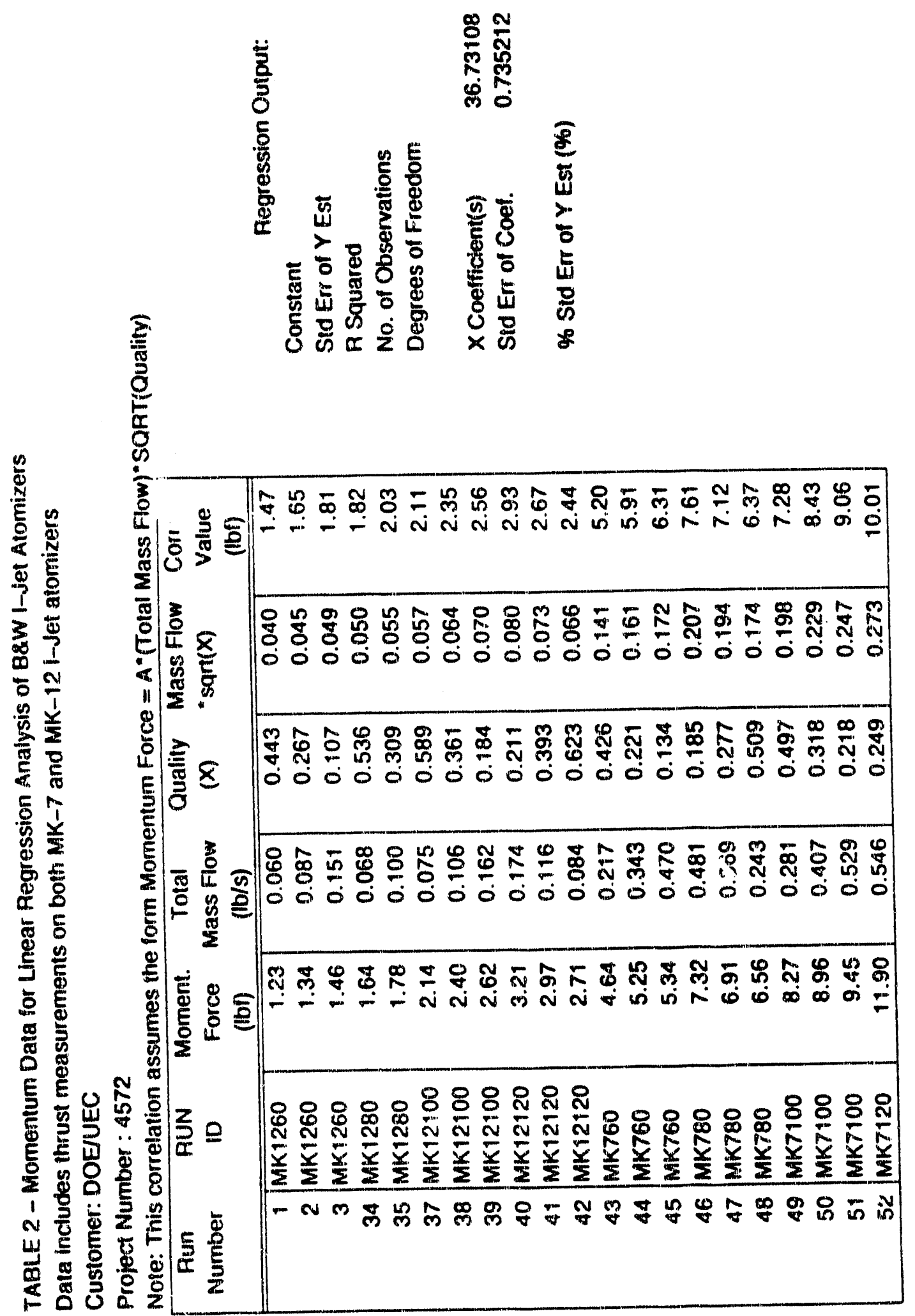




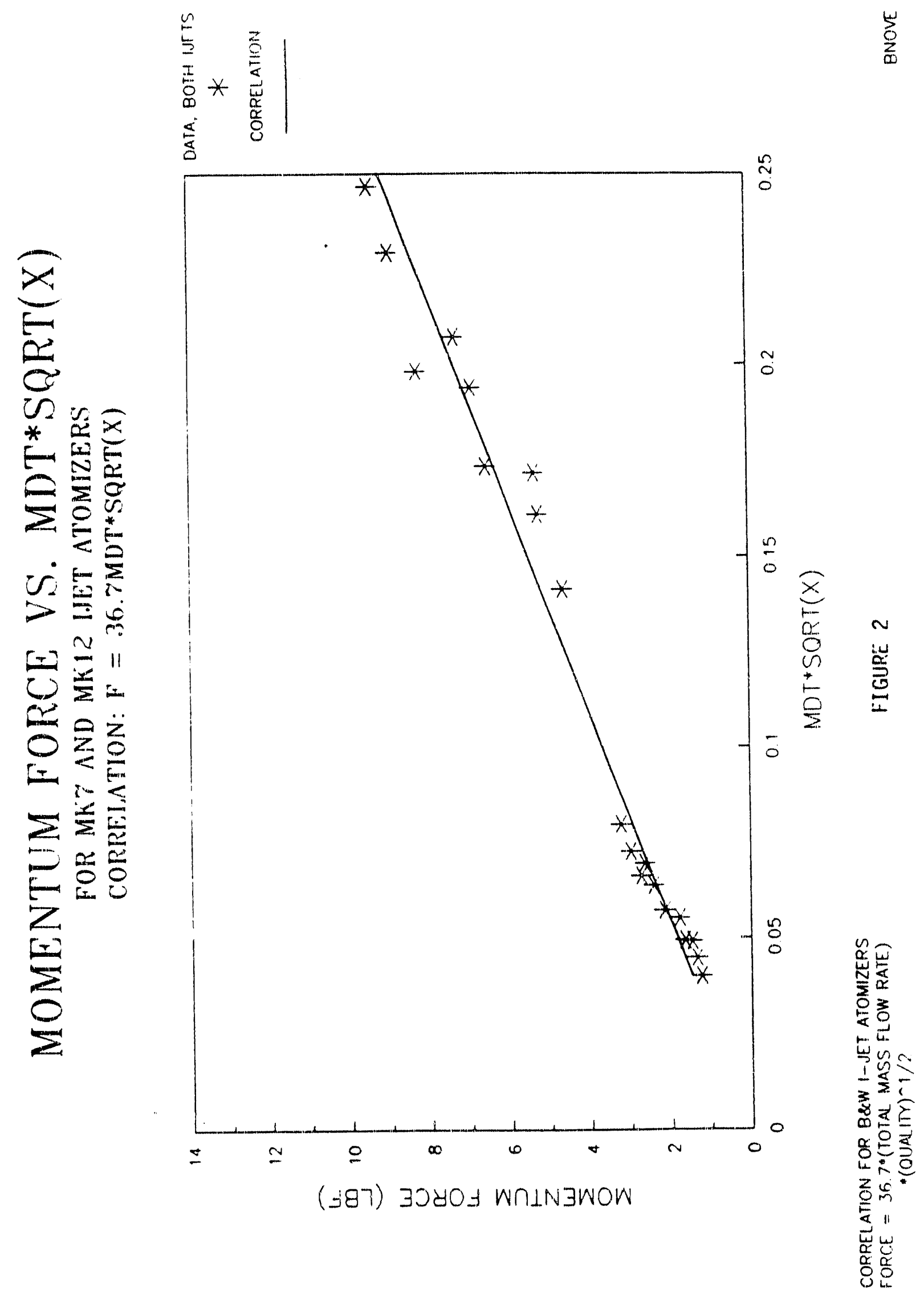


Multiplying the numerator and denominator on the gight hand side of Equation (5) by the quantity $\rho_{m} A_{d}$ and asmuxing that (2):

$$
\rho_{m} \approx \frac{\rho_{a}}{x}
$$

leadm to the following form of the momentum equation which describus the thrust $F$, produced by the Lechler atomizer:

$$
F=c \dot{s}^{2} x
$$

where: $\quad c=\frac{1}{\rho_{a} d_{d} g_{C}}$

Based on the above model for the Lechler atomizer, at the conditions tested during this program, $c=77 \mathrm{lbf} \sec ^{2} / 1 \mathrm{bm}^{2}$.

A semi-empirical value for $C$ was determined for the mpecific Lechler atomizer tosted during this program by a least squares regression of the measured thrust data to an . uation of the ame form as equation (6). The results of this regreasion analysis give:

$$
\begin{aligned}
& c=107 \\
& s=6.18
\end{aligned}
$$

where: $S=$ the (8) standard error of the force estimate.

Tuble 3 contains the monured Lechler momentum data and a sumary of the result: of the regression analyais on this data. Figure 3 hows a comparion between the measured and correlated values of the montum force for the Iechler atomizer.

Comparing the two values of the constant $C$ generatnd by the above two methods, there is a 288 difference between the correlated and calculated values of $c$ for the Lechler atomizer. Thin diffarence is explainad in part by uncertainties in the values assured for the discharge ares and the air denaity; the plug flow assumption may almo contribute to the difference in the two values.

(2) C. B. Walles, One-Dimenaional Two-Phase Flow, Copyright 1969 by MecrawBill, Ine., p. 19 . 

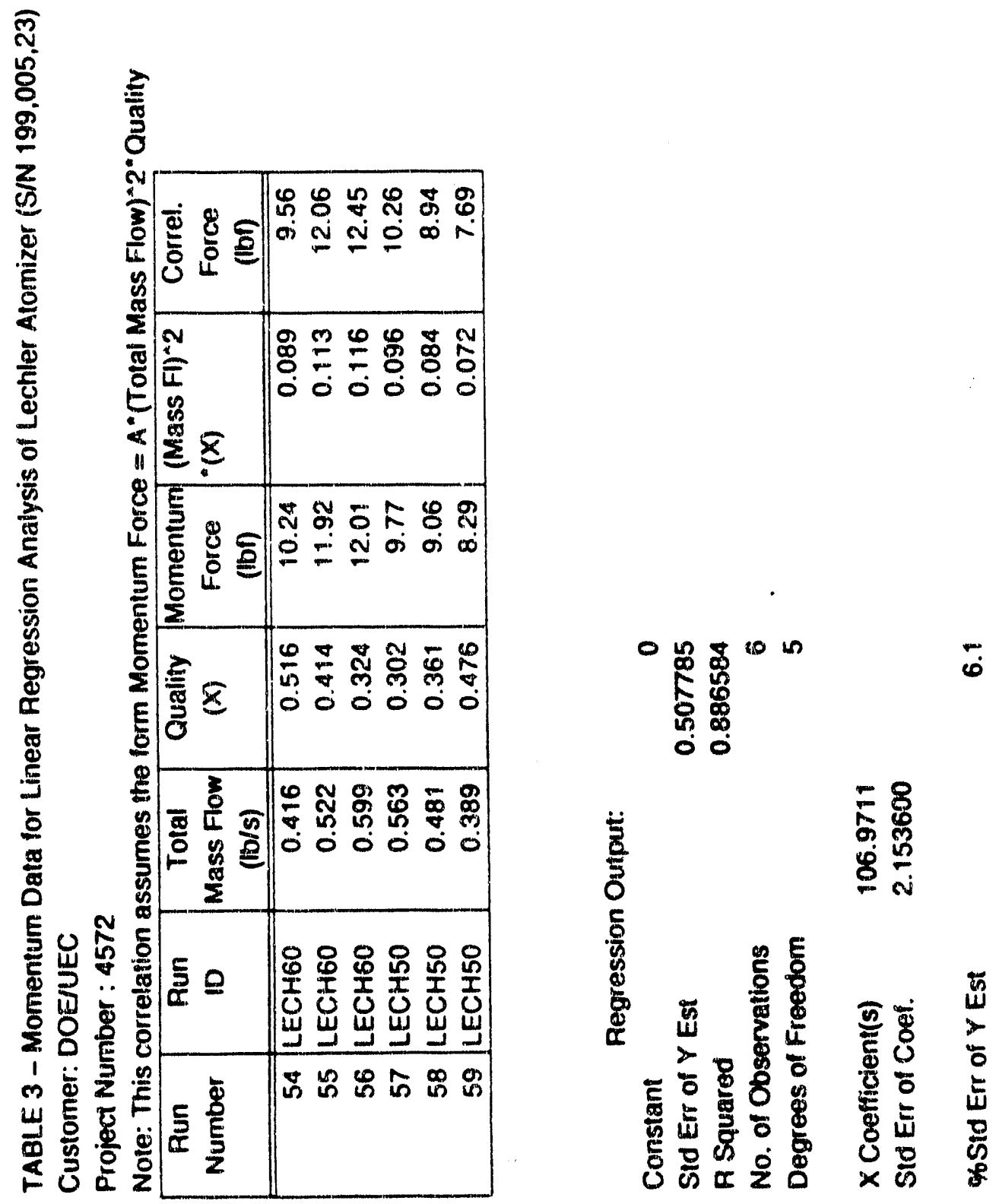


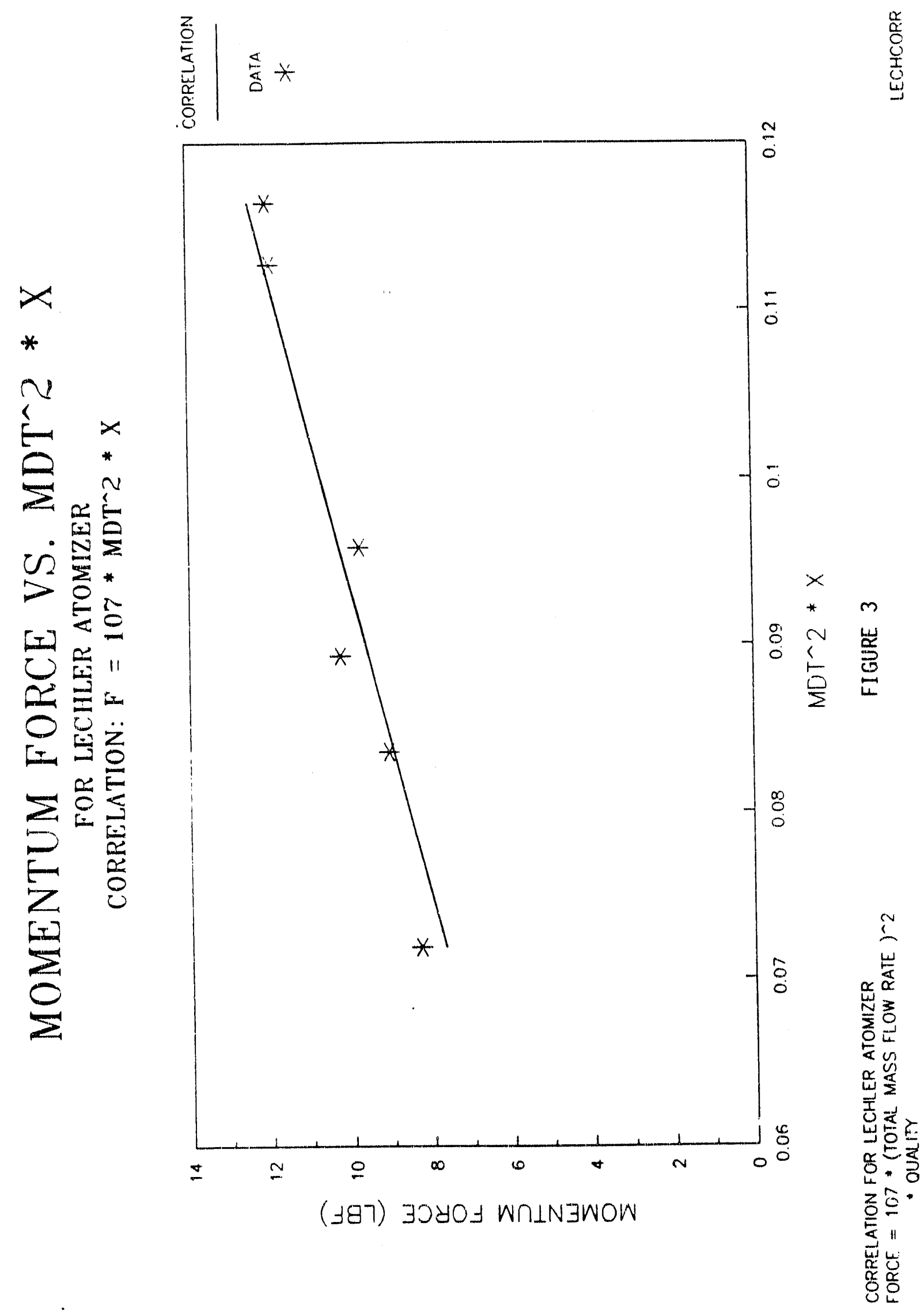


A implified form of the equation relating momentum to air and water mass flow rates for the Parker bannifin atomizex was doveloped in a manner imilar to that fox the Iachler. The Parker bannifin is an externully nixad air aseist atomizer; the ir and watar flow rates are decoupled from ench other. The total force is ansumed to be the wm of the forcos associated with the momentum flux of the air and diquid eoparately. This ansuption is appropriate for an externally mixed atomizer. An with tho Lechlor, the derivation assumes teady tate operation, with atnompheric pressure at the exit plano of the atomizer. The dexivation follow the same logic as that for the Lechlex, except that there are two parte to the force equation, one each for ir and water:

$$
F=C \dot{M}_{a}^{2}+D \dot{M}_{a}^{2}
$$

Somi-ampirical values for $C$ and $D$ were determined for the upecific parker Hannifin atomizer teated during this program by a least equares regreseion of the mesured thrust data to Equation $(8)$. The results of thic regression analyeis give:

$$
\begin{aligned}
& c=61 b \sec ^{2} / 1 \mathrm{bm}^{2} \\
& D=1821 b \mathrm{sec}^{2} / 1 \mathrm{bm}^{2} \\
& S=3.7 b
\end{aligned}
$$

where: $S$ = the (8) atandurd error of the force entimate.

Table 4 contain the moesured Parker Bannifin momentum data ond a mary of the reaults of the regression andyei on thio data. Figure shows a comparison betwfor: the measured and corrolated values of the nomentum force for the Parker Bannifin atomizer.

At the time of this tast program, it wan not posible to dovelop a version of the momentum equation for the parker Bannifin atamizer that had the degree of detail necemary to lend phyeical aignificance to the conmtant. generated by the regression analyais above. The fludd achanica at the exit plane of the atomizer are complex. The air exite the atomizer through two internally commicating air paseages, on circular and the other annular. The water exit. the atomizer through an annulus concentrically loceted botween the two ir dimchurge areas. In order to ostimate values for the air constant based on physical properties and discharge areas, the ratio of the preseure drop botween the two ir discbargo areas is required. This Information is currantly unavailable, although there is indication(3) that Parker Hannifin can provide it.

(3) Personal comanication with J. Gang, Parker gannifin Company, Cloveland, Ohio. 

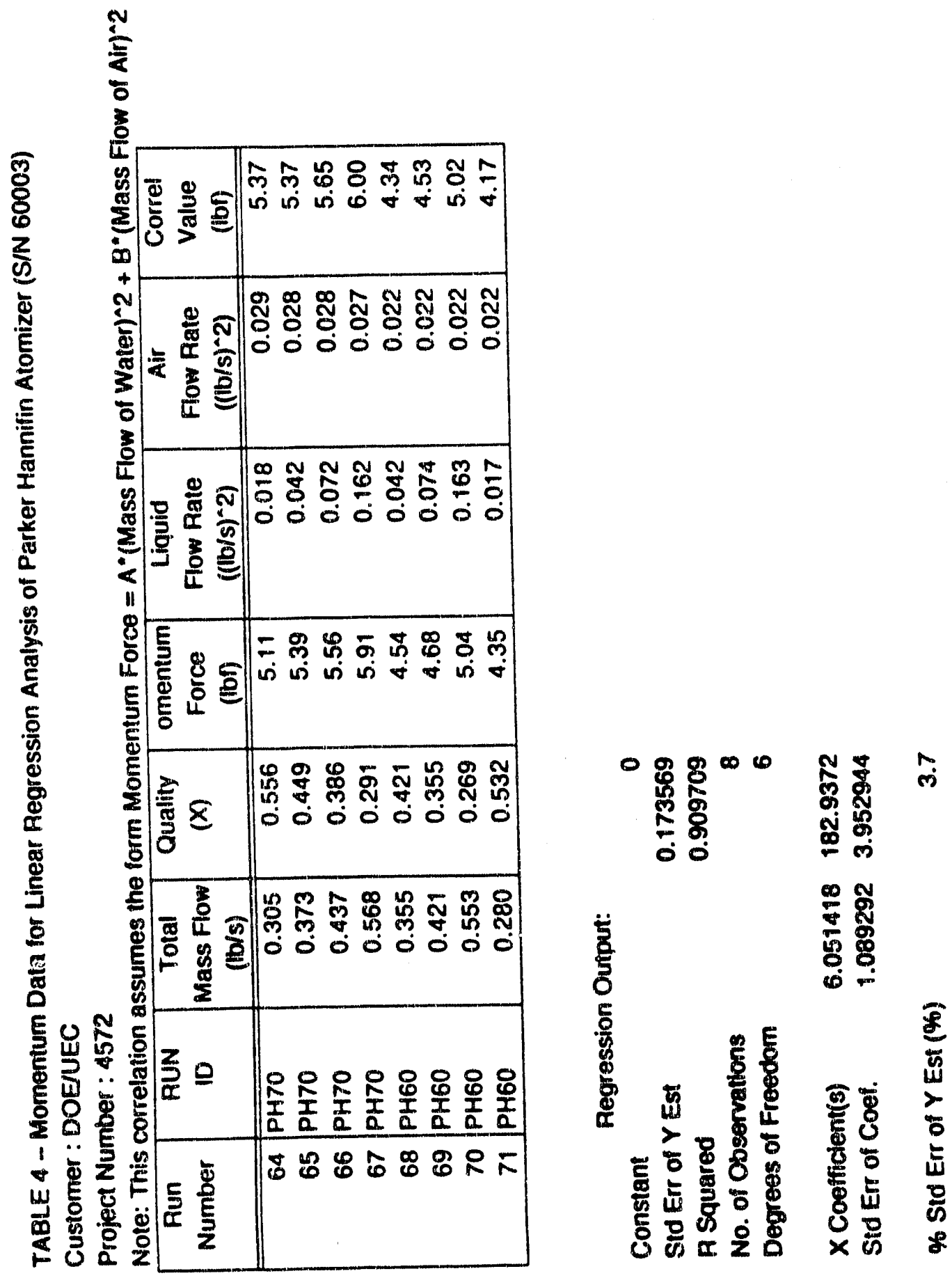


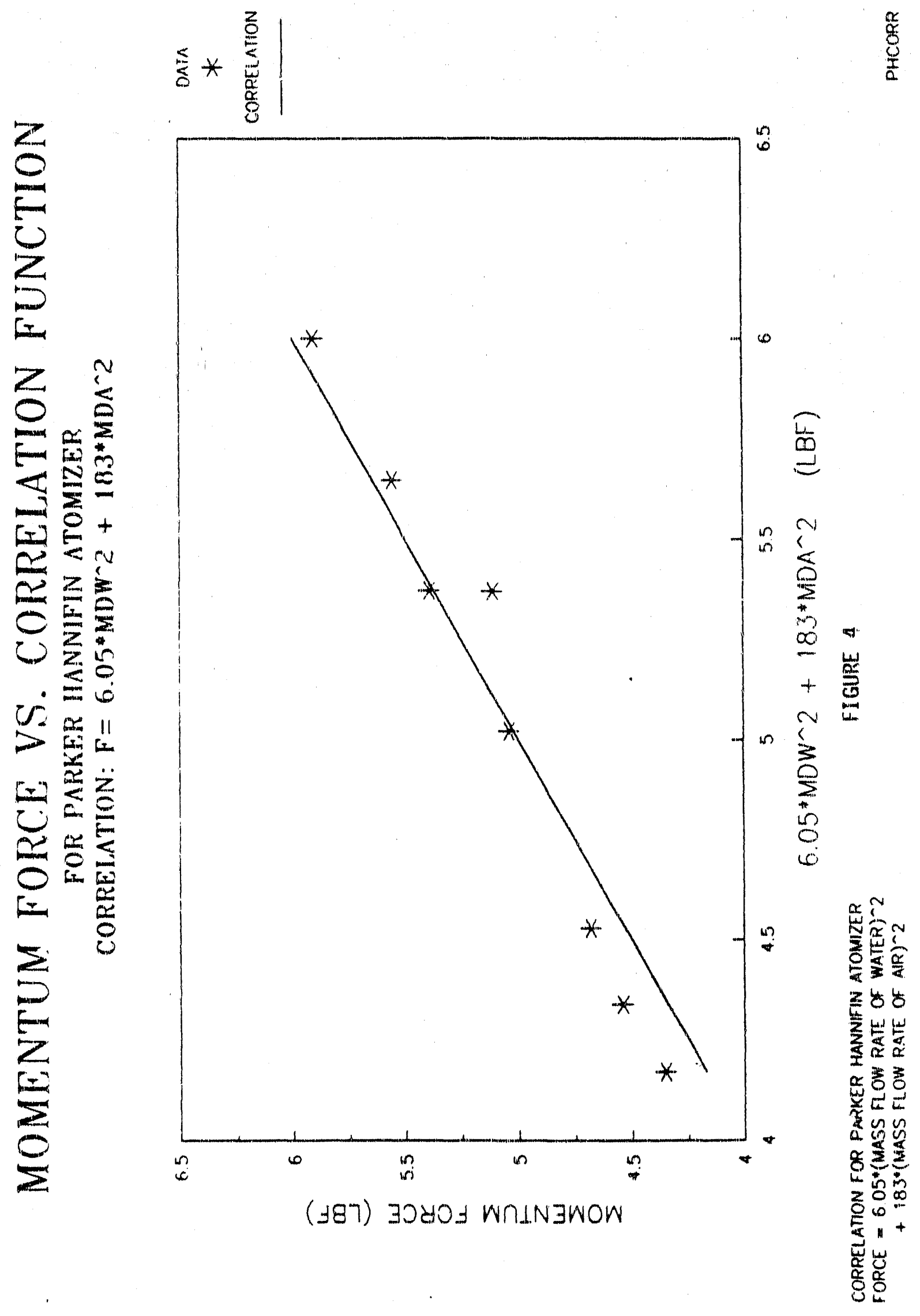


To aid in the breakup of the liquid into droplets, both the air and the liguid heve owirl induced in the atomizer internal. The owirl inparted to the fiuid is categorized by a swirl number, which is a masure of the thrusttomtorque ratio for the atomizer and the threo-udmonstonal anpect of the dimcharge fet. Parker Rannifin kas ande nonuravonte of the swixl number for various atcmizern; unfortunately, the atomizer etudied under thic program was not ineluded in those categorized. This mirl component is a necomary part of any further montum anadyais.

\section{Ptanirer reit veloelty}

In ordar to caleulate the aperficial exit velocity of given atomizer, coneidex a control volume which ineludes the atomizer and has an exit urface just past the atomizer exit plane. According to the momntum theorem, the time rate of change of monentum contained in this volume plus the net flow rate of mamentum through its surfaces nre aqual to the oum of the forces aeting on the volume. Aswuning teady tate operation, homogeneous ns-ulip flow, and the oxit surface prennure at atmosphorie, the momentum theorem gives:

$$
F=P_{m} x v^{2}
$$

Where: F - the measured momentim force prodvced by the atouizer

$P_{m}=$ the denility of the air/liguid mixture

A - 1 an exit area asociated with the epray

$v$. the exit velocity of the apray.

The total mass flow rate, Mx, for the alr/Iiquid mixture in definod as:

$$
P_{T}=P_{\text {un }}
$$

Dividing Equation (9) by Equation (10) gives:

$$
F / M_{T}=v
$$

Bince the momentum force and the total wase llow rate axe masured values, the ouperficial exit velocity can bo calculated without making any assumptions about the denaity of the aixture lavoling the atomiser, although the calculation asoume homogonoous flow exiting the atominnr. 


\section{Coneluedone}

In sury, the BtW, Lachlox, and Parker Bannifin atamilese otudied during this teat program covered a range of flow typos. Based on the type of atamizer, a Beeific einplified form of the moneatum equation was deriped that related mentum force (thruet) to the flow rates of alr and water. The constanco in the momentum aquation for each atouizen were ampiricaliy dutermined by linear least oguares regression of the data to the respective model.

Forces that ware calculated using the semi-empirical (curven (it) -guations were in good agreement with the wasured data. The ataudard orror of the entimated reaction torce was 11.98 for the I-Jet atomizers, 6.18 for the Inechler stomizer, and 3.7 for the parker Bannifin atomizer.

The correlatione generated by the linaar regraseion analyei: are atomizer apecific. To evaluate the ability to generalize to atmizere of different capacity or alightly different geometry, the conetante in the momentum oquation for the I-Jet and Lachler atomizers were ontimated based on flow areas and fluid proparties. This approach was not used on the Parker Bannifin atomizer because of an incomplete underatanding of the llow patterna at the atomizer dimcharge, and uncertainties in the flow arean and air mplita.

For the I-Jet and Lechler atomizer, the corrolated and entimated values of the conetante in the momentum aquation were in reasonably good agroement, with differencen of 168 and 288 , respetively.

The rowlts of the analysin indicate that the monentum force produced by I-Jots of any arbitrary capacity can be ostinated with reasonable accuracy. For the Lechler and Parker kannifin tomizerm, the oquatione relating atomizer momntum and air and liquid flow gat are opecific for those atomizers tested. 
AFPENDIX C

BEW'S ALLIANCE RESEARCH CENTER ATOMIZATION FACIIITY 
The Atomization Facility (Figure C-1) consists of a spray booth and an assortment of equipment and transducers that can support a wide range of atomizers. The spray booth is $8 \times 8 \times 10$ feet long with two $4 \times 8$ feet plate glass windows mounted in opposing walls. The windows provide optical access to the spray for laser diagnostics, visual observation, and still and motion picture photography. Air is continually forced through the spray booth to prevent the buildup of a "fog" of very fine droplets. The air is suppi-ed by a forced draft fan and enters the booth through the windbox. Turning vanes and a honeycomb flow straightener are used to provide a uniformly distributed flow over the spray booth cross-section. At the exit of the spray booth, the atomized droplets are removed from the sweep air by a series of demisters. The standard test equipment used at the Atomization Facility is listed in Table $\mathrm{C}-1$. The wide range of pumping capacity accommodates utility size atomizers as well as small capacity atomizers. The associated calibrated instrumentation yields accurate repeatable data at all possible test conditions.

\section{Malvesn 2600 Particle sizer}

The Malvern 2600 droplet and particle sizer system uses the diffraction pattern created by the spray to generate a droplet size distribution. Droplets, when illuminated by a beam of monochromatic light, give rise to a diffaction pattern. This pattern consists of a series of bright and dark rings superimposed on the smaller geometric image. If a lens is placed between the particles and a detector (with the detector placed at the focal point of this lens), then the undiffracted light is focused to a small spot at the center of the detector with the much larger diffraction pattern surrounding (see Figure $(-2)$. This diffraction pattern is stationary: movement of the particles does not cause a Bhifting pattern. Although a given particle diffract: light to all radii, the light energy distribution has a maximum at a radius $s$, given by:

$$
2 \pi x s / \lambda f=1.375
$$

where: $\begin{aligned} & =\text { particle radius } \\ & \\ & =\text { wavelength of the laser } \\ & =\text { focal length of the lens }\end{aligned}$ 


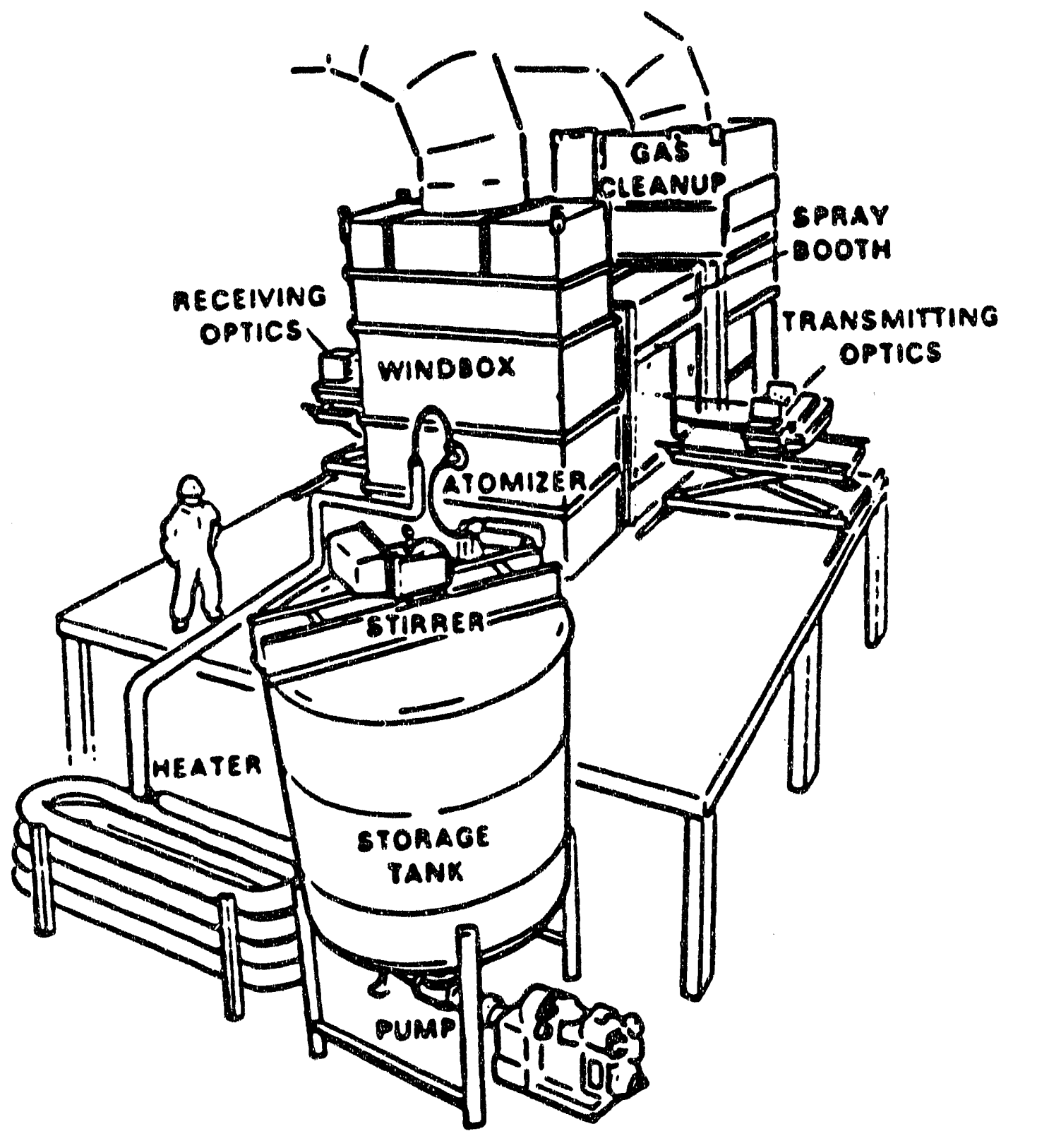

Figure C-1. SCMEMatic of atomization Facildtr 


\begin{tabular}{|c|c|c|}
\hline \multicolumn{3}{|c|}{ TABLE C-1 } \\
\hline \multicolumn{3}{|c|}{ Atomization Facility Equipment and Capabilities } \\
\hline Equipment & Manufacturers & Capacity/Range \\
\hline Air Compressor & Ingersoll/Rand & $\begin{array}{l}220 \text { psig at approx. } 200 \\
1 \mathrm{~b} / \mathrm{hr}, 150 \text { psig at } 1000 \\
1 \mathrm{~b} / \mathrm{hr}\end{array}$ \\
\hline $\begin{array}{l}\text { Progressing Cavity } \\
\text { Pump }\end{array}$ & Moyno & $\begin{array}{l}\text { Approx. } 7500 \mathrm{lb} / \mathrm{hr} \text { at up to } \\
450 \mathrm{psig}\end{array}$ \\
\hline $\begin{array}{l}\text { Mechanical positive } \\
\text { Displacement Pump }\end{array}$ & Worthington & $\begin{array}{l}8000 \mathrm{lb} / \mathrm{hr} \text { at up to } 1100 \\
\text { psig }\end{array}$ \\
\hline Forced Draft Fan & New York Blower & $\begin{array}{l}\text { Up to } 40,000 \text { sCFM through } \\
\text { the spray booth }\end{array}$ \\
\hline $\begin{array}{l}\text { Malvern Droplet } \\
\text { sizing system }\end{array}$ & Malvern & $\begin{array}{l}11.6 \text { - } 1128 \text { microns in } 15 \\
\text { size bins }\end{array}$ \\
\hline Visibility Technique & Spectron & $\begin{array}{l}3 \text { - } 3000 \text { microns in } 10: 1 \\
\text { Ianges }\end{array}$ \\
\hline Top-Size Measurement & In-House & $\begin{array}{l}\text { Volume percent greater than } \\
260 \text { microns }\end{array}$ \\
\hline Liquid Flowmeters & Micromotion & $\begin{array}{l}0 \text { - } 10,0001 \mathrm{~b} / \mathrm{hr} \text { in multiple } \\
\text { ranges }\end{array}$ \\
\hline Air Flow orifices & In-House & $\begin{array}{l}\text { Multiple sizes as required } \\
\text { by test }\end{array}$ \\
\hline Thermocouples & -- & Fluid temperatures \\
\hline Pressure Transmitters & $\begin{array}{c}\text { Bailey Controls } \\
\text { Company }\end{array}$ & $\begin{array}{l}0 \text { - } 500 \text { psig liguid } \\
0-500 \text { psig air pressure }\end{array}$ \\
\hline $\begin{array}{l}\text { Low Capacity Pumping } \\
\text { system }\end{array}$ & Moyno & $\begin{array}{l}\text { Portable pump and storage } \\
\text { tank for flows up to } 100 \\
\text { lo/hr }\end{array}$ \\
\hline
\end{tabular}




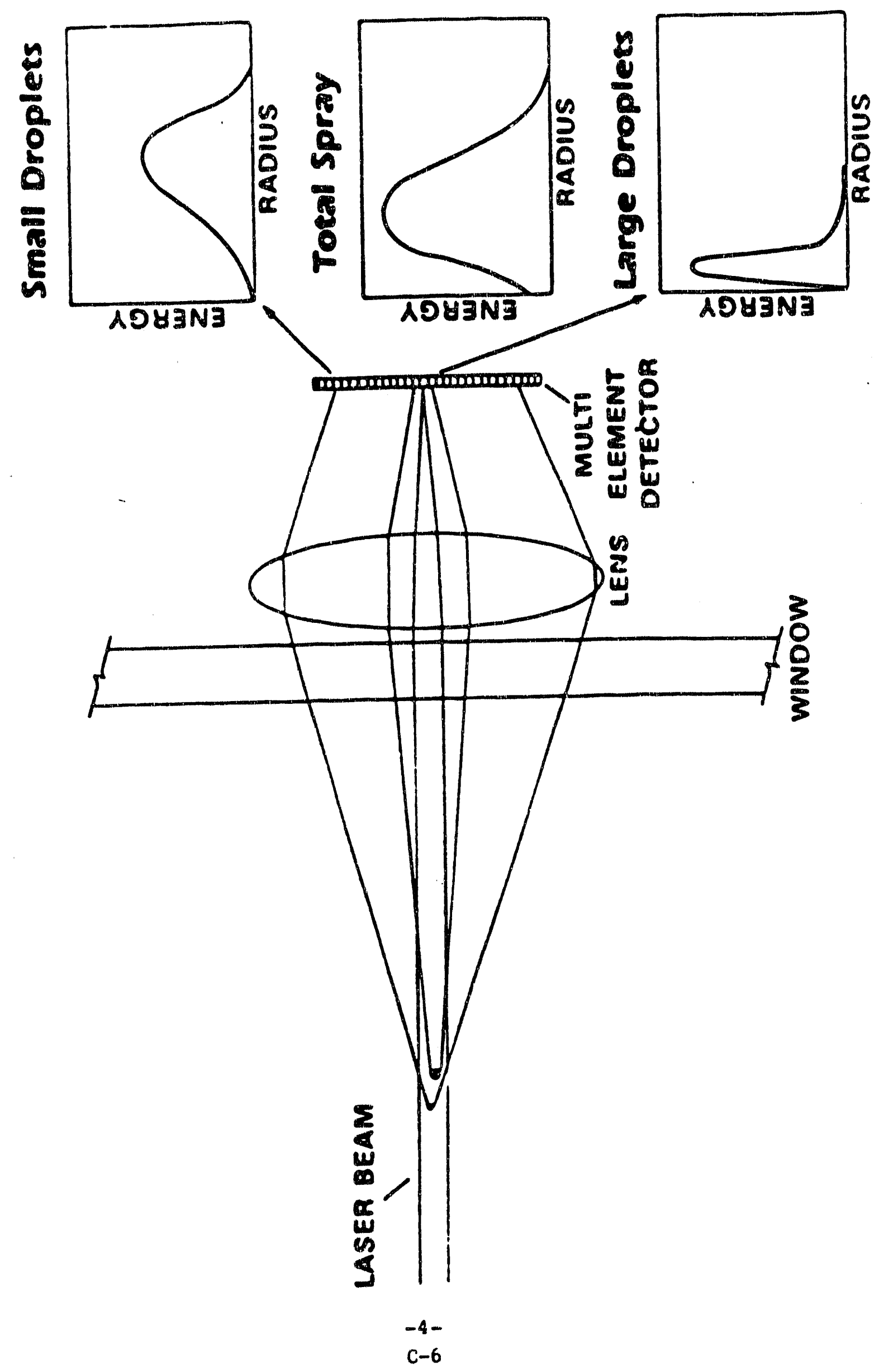

$\frac{N}{n}$

us

$\bar{U}$

$\frac{5}{2}$

8 N

$\frac{2}{3}$

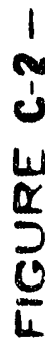


Therefore, if the detector is divided into a series of circular rings whose mean radii, $s_{i}$, correspond to equation $(c-1)$, then a set of radii, $r_{i}$, can be measured, where $r_{i}$ is the mean particle radius of the $i$ 'th size range. For each range, a uniform size distribution is assumed. Now a unique light energy distribution will yield a unique particle size distribution. With standard equipment, this distribution will cover a range of about 2 - 200 microns. Additional equipment was used to extend the size range to $11.6-1128$ microns. The detector signals are collected serially, converted to digital values, and then transmitted to a minicomputer. This process takes only a few milliseconds for each sweep of all the rings. The raw data is then stored for later recall and analysis. 

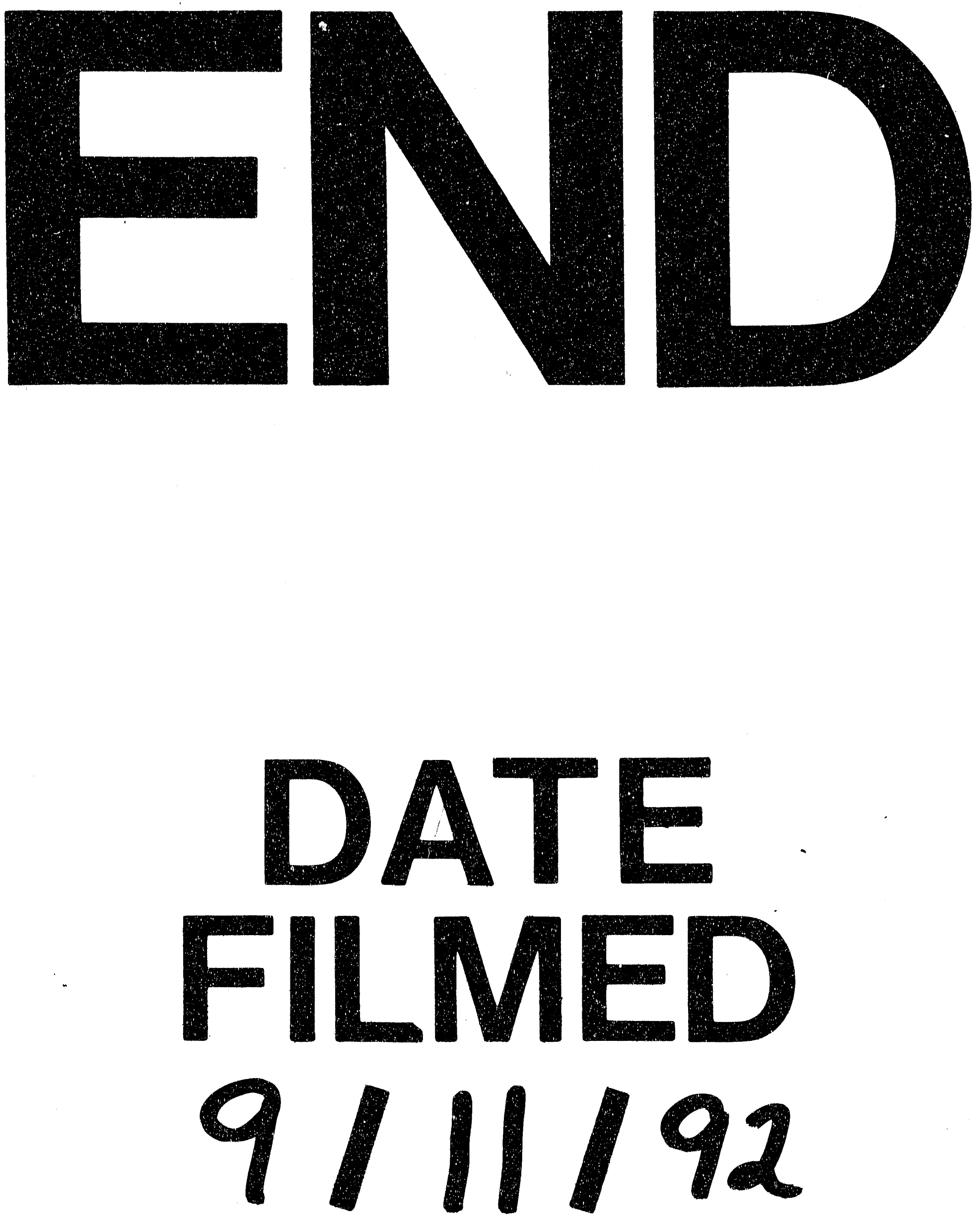
